US Army Corps

of Engineers

Waterways Experiment

Station

\title{
U.S. Army Corps of Engineers Seismic Strong-Motion Instrumentation Program
}

by Robert F. Ballard, Jr., Tina H. Grau 
The contents of this report are not to be used for advertising, publication, or promotional purposes. Citation of trade names does not constitute an official endorsement or approval of the use of such commercial products.

The findings of this report are not to be construed as an official Department of the Army position, unless so designated by other authorized documents. 


\section{U.S. Army Corps of Engineers Seismic Strong-Motion Instrumentation Program}

by Robert F. Ballard, Jr., Tina H. Grau

U.S. Army Corps of Engineers

Waterways Experiment Station 3909 Halls Ferry Road

Vicksburg, MS 39180-6199

Final report

Approved for public release; distribution is unlimited 


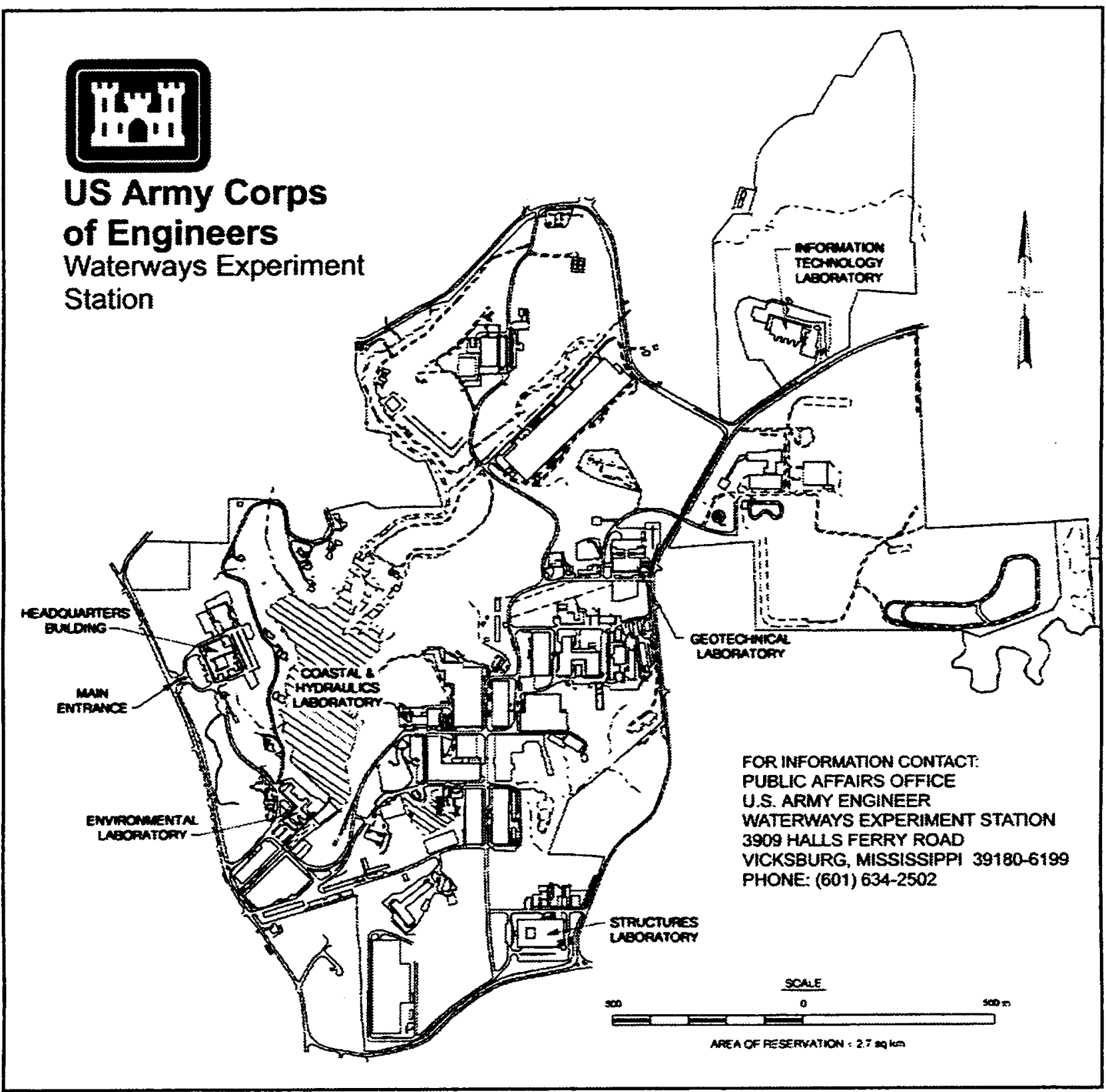

Waterways Experiment Station Cataloging-in-Publication Data

Ballard, Robert F.

U.S. Army Corps of Engineers Seismic Strong-Motion Instrumentation Program / by

Robert F. Ballard, Jr., Tina H. Grau ; prepared for U.S. Army Corps of Engineers.

115 p. : ill. ; $28 \mathrm{~cm}$.- (Technical report ; GL-98-25)

Includes bibliographic references.

1. Seismometry. 2. Accelerograms. 3. Dam safety. 4. Seismology -- Research. I.

Grau, Tina H. II. United States. Army. Corps of Engineers. III. U.S. Army Engineer

Waterways Experiment Station. IV. Geotechnical Laboratory (U.S. Army Engineer

Waterways Experiment Station) V. Title. VI. Series: Technical report (U.S. Army

Engineer Waterways Experiment Station); GL-98-25.

TA7 W34 no. GL-98-25 


\section{Contents}

Preface $\quad \ldots \ldots \ldots \ldots \ldots \ldots \ldots \ldots \ldots \ldots \ldots$

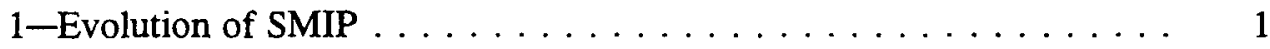

Purpose . . . . . . . . . . . . . . . . . 1

Seismic Threat Evaluation . . . . . . . . . . . . . . 2

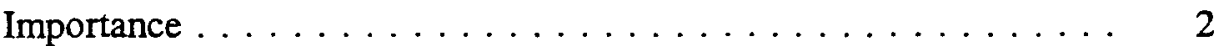

Background .................... 3

USACE Mandate for Strong-Motion Instrumentation $\ldots \ldots \ldots$

2-Locations of Strong-Motion Instruments . . . . . . . . . 7

3-Descriptions of Strong-Motion Instruments . . . . . . . . . . 13

Accelerographs . . . . . . . . . . . . . . . . . 13

Peak Acceleration Recorders $\ldots \ldots \ldots \ldots \ldots \ldots \ldots \ldots$

Seismic Alarm Device ... . . . . . . . . . . . . . . . 19

4 -Instrument Installation $\ldots \ldots \ldots \ldots \ldots \ldots \ldots . \ldots \ldots$

$5-$ Operation and Maintenance $\ldots \ldots \ldots \ldots \ldots \ldots \ldots \ldots \ldots$

6 -Earthquake Data Retrieval . . . . . . . . . . . . . . . 28

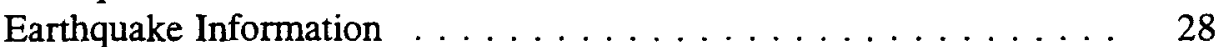

Earthquake Accelerogram Data . . . . . . . . . . 28

7 -Significant Earthquakes Recorded to Date . . . . . . . . . . 30

8 -Current Status and Future Goals . . . . . . . . . . . . . 34

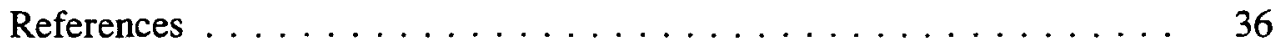

Appendix A: Pertinent SMIP Regulations $\ldots \ldots \ldots \ldots$ A1

Appendix B: WES Seismic Alarm Device Technical Specifications ... . B1

Appendix C: Seismic Alarm Device Operation Manual . . . . . . . . C C

Appendix D: USGS NEIC On-Line Information Program . . . . . . . D1

Appendix E: Tabulation of USACE Strong-Motion Data, 1971-1997 . . . E1

SF 298 


\section{List of Figures}

Figure 1. Seismic zone map of strong-motion instrumentation

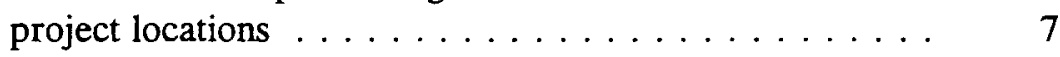

Figure 2. Model SMA-1 analog accelerograph . . . . . . . . 14

Figure 3. Model SSA-1 digital accelerograph . . . . . . . . 15

Figure 4. Model SSA-2 digital accelerograph . . . . . . . . 15

Figure 5. Etna digital strong-motion accelerograph $\ldots \ldots \ldots 16$

Figure 6. Engdahl model PAR 650L peak acceleration recorder . . 18

Figure $7 \quad$ Seismic alarm device $\ldots \ldots \ldots \ldots \ldots \ldots$

Figure 8. SMIP instrument shelter pad foundation plan $\ldots \ldots 21$

Figure 9. Plans of equipment protective enclosure . . . . . . . 21

Figure 10. Typical instrument shelter pad foundation ........ 22

Fig. 11-12. Typical instrument shelter installations . . . . . . . . 22-23

Fig. 13-15. Instrumentation laboratory functions . . . . . . . 24-25

Figure 16. SMIP van servicing J.W. Flannagan Dam, VA . . . . . 26

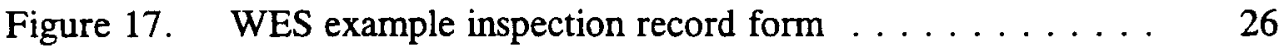

Figure 18. New Hampshire earthquake, $1982 \ldots \ldots \ldots \ldots$

Fig. 19-22. Example earthquake records from 17 January 1994

Northridge, CA earthquake . . . . . . . . . . . . 32-33

Fig. C-1. SAD control panel . . . . . . . . . . . C4

Fig. C-2. Diagram of SAD circuitry . . . . . . . . . C7

Fig. C-3. SAD circuitry diagram (solder side) $\ldots \ldots \ldots \ldots$ C8

Fig. C-4. Dimensional outline of accelerometer case . . . . . . C9

Fig. C-5. Balancing accelerometer output $\ldots \ldots \ldots \ldots$ C9

Fig. C-6. Conduit installation - equipment and conduit grounding . . C10

\section{List of Tables}

Table 1 Corps of Engineers Strong-Motion Instrumentation Program Status - March $1998 \ldots \ldots$. . . . . . . . . .

Table 2 USACE Strong-Motion Data Archived (1971-1997) . . . E2-E6 


\section{Preface}

The Strong-Motion Instrumentation Program (SMIP) described herein is operated by the U. S. Army Engineer Waterways Experiment Station (WES) by authorization of Headquarters, U. S. Army Corps of Engineers (HQUSACE). This report was written by Mr. Robert F. Ballard, Jr. (Program Manager) and Mrs. Tina H. Grau, Earthquake Engineering and Geosciences Division (EEGD), Geotechnical Laboratory (GL), WES, to document the evolution of the SMIP. This report is intended to furnish background, insight, and past experience in the program to various USACE Districts and Divisions involved in instrumenting facilities across the United States and in the Commonwealth of Puerto Rico. Further, it is an attempt to consolidate pertinent reference materials associated with the SMIP into a single document.

Mr. Ballard and Mrs. Grau were under the GL administrative supervision of Dr. Arley G. Franklin (retired), Chief, EEGD; Dr. Lillian D. Wakeley, Acting Chief, EEGD; and Dr. W. F. Marcuson III, Director. Messrs. Monroe B. "Joe" Savage and Lewis B. Smithhart, Data Acquisition Section, Operations Branch (OB), Instrumentation Systems Development Division (ISDD), Information Technology Laboratory, WES, were authors of Appendices B and C and assisted in providing descriptions of instrumentation systems and installation and maintenance procedures. Messrs. Savage and Smithhart were under the supervision of Mr. Bruce C. Barker, Chief, OB, ISDD, and Dr. C. Robert Welch, Chief, ISDD, ITL.

Dr. Robert W. Whalin was Director and COL Robin R. Cababa, EN, was Commander of WES during preparation of this report. 


\section{Evolution of SMIP}

\section{Purpose}

During the 1970s, the U.S. Army Corps of Engineers (USACE) embarked upon an undertaking which has since been termed the Strong-Motion Instrumentation Program (SMIP). The SMIP was designed to allow observation and analysis of seismic waves produced by earthquakes and explosions to examine the effect of these motions on USACE projects. Objectives of SMIP are threefold:

a. To provide insight into the safety of and to act as an inspection guide for existing USACE projects.

b. To provide a measure of project performance.

c. To act as a database for performance predictions and earthquake research.

The existence of performance data in the engineering profession is unequivocally beneficial. For instance, D'Appolonia (1990) describes the value of field performance data for geotechnical engineering. He summarizes:

"Data from long-term monitoring should be integrated into the design process [to] provide a basis for future decisions and maintain a facility in a functional state consistent with its intended purpose. A planned approach to decision making over time that draws on long-term field measurements for input, with planned analysis of the measurements and appropriate contingent actions, is sought. A monitored-decision process provides a means to gain knowledge, be innovative, and mitigate adverse relationships between parties involved in the ownership, construction, and operation of a facility." 


\section{Seismic Threat Evaluation}

As owners of critical structures, the USACE is obligated to ensure their safety to the public. The threat of earthquake induced damage is as valid and important today (as exemplified in the Northridge, CA quake of 17 January 1994) as it was with the wake-up call of the near catastrophic failure of the Lower San Fernando Dam (Los Angeles, CA) in 1971. The SMIP program was instituted to provide seismic safety monitoring of Corps structures and provide strong motion data to help advance the state-of-the-art of earthquake engineering to ensure no more surprises happen.

After a felt event, when the public asks: Is the dam safe? How will the USACE answer? How will we quantify the earthquake load and verify if it is within the expected design loads? Answers to these questions require a well conceived program of long-term strong motion monitoring.

\section{Importance}

The collection of strong motion records is important for characterizing seismicity, "the occurrence of earthquakes in space and time." Determination of seismicity is a necessary step in determining an area's seismic hazard. Seismic safety analyses of critical structures depend on the use of earthquake motion time histories or parameters derived from them (earthquake records) as input to the analysis. The needed time histories are usually scaled versions or derived from actual recorded strong motions. To accurately characterize seismicity, we therefore need to sample in both "time and space." This results in the need for SMIP networks intelligently dispersed and continually monitoring throughout the country.

Additionally, factors such as inherent geologic variability, dynamic processes of plate tectonics, and the short time frame through which strong motion data have been collected ( $\sim 100$ years) compared to the recurrence time scale of some major earthquakes $(\sim 1,000$ years), make it imperative that strong motion data collection continue. This is necessary if we are to gain a thorough understanding of earthquake related phenomena and enable accurate seismic hazard determinations.

The U. S. Army Engineer Waterways Experiment Station (WES) has been performing seismic safety analysis studies of critical structures for more than 25 years. An important step in these studies was a seismological investigation for seismic hazard determination which relies heavily on catalogued strong motion records. Examples of the use of strong motion records and their part in these studies can be obtained from many WES reports. 


\section{Background}

As described by Ballard et al. (1990), the SMIP was formalized in 1973 by Engineer Regulation (ER) 1110-2-103, Strong-Motion Instruments for Recording Earthquake Motions on Dams, (Department of the Army) which essentially required instrumentation of all USACE dams within seismic risk zones 2, 3, and 4 (after Algermissen 1969). After careful planning and deliberation with experts in the field of earthquake measurements and analysis, a revised Engineering Manual (EM) 1110-2-1908, Instrumentation of Earth and Rock Fill Dams, (Department of the Army 1976) was published for use by USACE district offices. This EM provides guidance and information concerning the selection of instruments for measuring dynamic response of earth and rock-fill dams and describes techniques for collecting and analyzing data.

In 1973, the USACE also entered into agreements with the U.S. Geological Survey (USGS) to assist in the SMIP. Specifically, the USGS was to:

a. Provide guidance in the selection of instruments.

b. Review installations for conformance with network specifications and provide suggestions for proper protection from weather and other elements.

c. Act as recipient (thus assuring adherence to specifications) for new instruments and calibrate them for installation.

d. Install and maintain those instruments at regular intervals throughout the federal fiscal year.

The USGS receives funding under the Earthquake Hazards Reduction Act to run a strong motion program. This program collects, archives, and disseminates data and performs research for the reasons listed above. It is an important distinction that they do not perform monitoring to ensure safety of particular structures and that their emphasis is geologic not structural based. The agreement and these important distinctions establish that the USGS SMIP and WES SMIP do not have duplicating but complementary missions.

In 1973 estimates of less than 200 installed instruments were provided to the USGS as the number that would ultimately make up the USACE strong-motion network. Since a large number of these installations would be east of the Rocky Mountains, the USGS viewed them as a necessary and desirable extension of an envisioned national network, which at that time had most recording stations located in the state of California.

In 1977, however, the USGS was assigned additional missions and funding without commensurate increase in personnel allotments. The WES subsequently proposed alternative plans for programs which would enable the USACE to absorb much of the work previously performed by USGS. After a very thorough investigation of alternatives which included consideration of 
contractual services, it was decided that the USGS would continue to provide installation, service and data collection for instruments in the western U.S. The WES was to phase itself into installation and maintenance of approximately one-half of the USACE instruments located in the central and eastern part of the U.S. Additionally, in a reciprocal arrangement, WES was to service certain USGS and Veterans Administration (VA) instruments. Transition occurred over a two-year period. This continuing arrangement has proven highly cost and quality effective-an exemplary demonstration of 'partnering'.

Since 1978 WES Instrumentation Services Development Division (ISDD) has assumed responsibility for in-house maintenance of more than sixty percent of the USACE instruments with USGS providing service for the remainder. Personnel of WES Earthquake Engineering and Geosciences Division (EEGD), Geotechnical Laboratory (GL), provide overall project management of SMIP and analyze recorded data.

Functionally, the SMIP has been structured so that a USACE agency can design its own program for strong-motion instrumentation with guidance from the Engineering Manual (and WES if they so desire). Upon completion of a plan for instrumenting a specific structure, the individual agency then forwards its plan to WES for approval. Once it is determined that all criteria have been taken into consideration for that particular project, WES then approves the installation.

By directive, WES is also responsible for:

a. Maintaining records of instrument servicing and location.

$b$. Reviewing instrument locations and type to assure conformance with USACE policy.

c. Processing and analyzing records obtained.

d. Furnishing copies of obtained records to the USACE district offices concerned.

$e$. Coordinating with USGS and the USACE district offices to establish schedules for inspection visits.

$f$. Billing USACE district offices for services provided.

g. Reimbursing USGS for expenses incurred.

$h$. Providing personnel for installation and maintenance of USACE instruments not serviced by USGS.

In addition to its heavy involvement with the USGS, the USACE has established a working arrangement whereby data are exchanged and coordination established with the state of California Division of Mines and Geology strongmotion network and with the U.S. Department of the Interior, Bureau of 
Reclamation (USBR). In actuality, the state of California operates the largest network of strong-motion instrumentation in the U.S., commonly referred to as CSMIP. The strong-motion instrumentation program instituted by the USBR is in its infancy but will ultimately include about 150 instruments. It is intended that close ties remain in effect between all of these agencies and the profession at large.

\section{USACE Mandate for Strong-Motion Instrumentation}

ER 1110-2-1156 (Department of Army 1992) describes dam safety policy, organization, responsibilities, and procedures. Guidance and direction for seismic design and evaluation for all civil works projects is given in ER 1110-2-1806 (Department of Army 1995). ER 1110-2-1802 (Department of Army 1979) discusses policy, objectives, and establishes procedures regarding reporting earthquake effects. Several regulations pertinent to the CE SMIP are included at Appendix A to consolidate their availability.

(NOTE: To order printed copies of these and other documents, write to the USACE Publications Depot, ATTN: CEIM-IM-PD, 2803 52nd Ave., Hyattsville, MD 20781-1102. Most official USACE engineering regulations, circulars, and manuals are provided in portable document format (PDF) from the USACE internet site at http://www.usace.army.mil/inet/usace-docs/).

According to an updated ER 1110-2-103, (Department of the Army 1981) issued by USACE, all dams in zones 2,3 and 4 of the seismic risk maps should be instrumented for strong-motion earthquake measurement. As previously mentioned, guidance on details concerning instrumentation, location, and selection is currently given in EM 1110-2-1908 (Department of Army 1995). These documents are adequate for most situations; however, numerous questions have arisen regarding instrumentation of dams in seismic risk zone 2. A popular viewpoint suggested that the low probability of obtaining meaningful data does not justify the cost of installing and maintaining instruments. In an effort to supplement the above documents (particularly for zone 2) so that sound decisions can be made regarding dams with uncertainties about the need for instrumentation, additional guidance was developed to aid in the judgment process. Considerations below are listed in order of relative importance.

a. Nature of Foundation. If foundation materials underlying the dam are composed of sands or silty sands that might be subject to liquefaction, the dam should be instrumented. If the foundation materials are rock or other materials that are not subject to liquefaction, the remaining factors below should be taken into account.

b. Type of Construction. Regardless of seismic risk zone, all hydraulic fill dams should be instrumented. Rolled earth fill or rock fill dams (being 
less susceptible to liquefaction) should be considered for instrumentation as indicated by other influencing factors.

c. Height of Dam. Most dams more than $33 \mathrm{~m}$ high should be instrumented.

d. Presence of Known Capable Faults. If the dam is located nearer than $40 \mathrm{~km}$ to a known capable fault, it should be instrumented.

e. History of Seismic Activity at the Site. If acceleration levels greater than $0.2 \mathrm{~g}$ have been recorded in the vicinity of the dam, it should be instrumented.

f. Distance from Higher Risk Zone Boundaries. If the dam is located less than $160 \mathrm{~km}$ from a higher risk zone boundary, it should be instrumented. 


\section{Locations of Strong-Motion Instruments}

As of March 1998, the USACE SMIP consisted of the following: 123 instrumented projects located in 32 states and 1 commonwealth. The locations of these projects and the seismic risk zones in which they are situated are shown in Figure 1. Descriptions of instrument locations and number of instruments as of March 1998 are shown in Table 1.

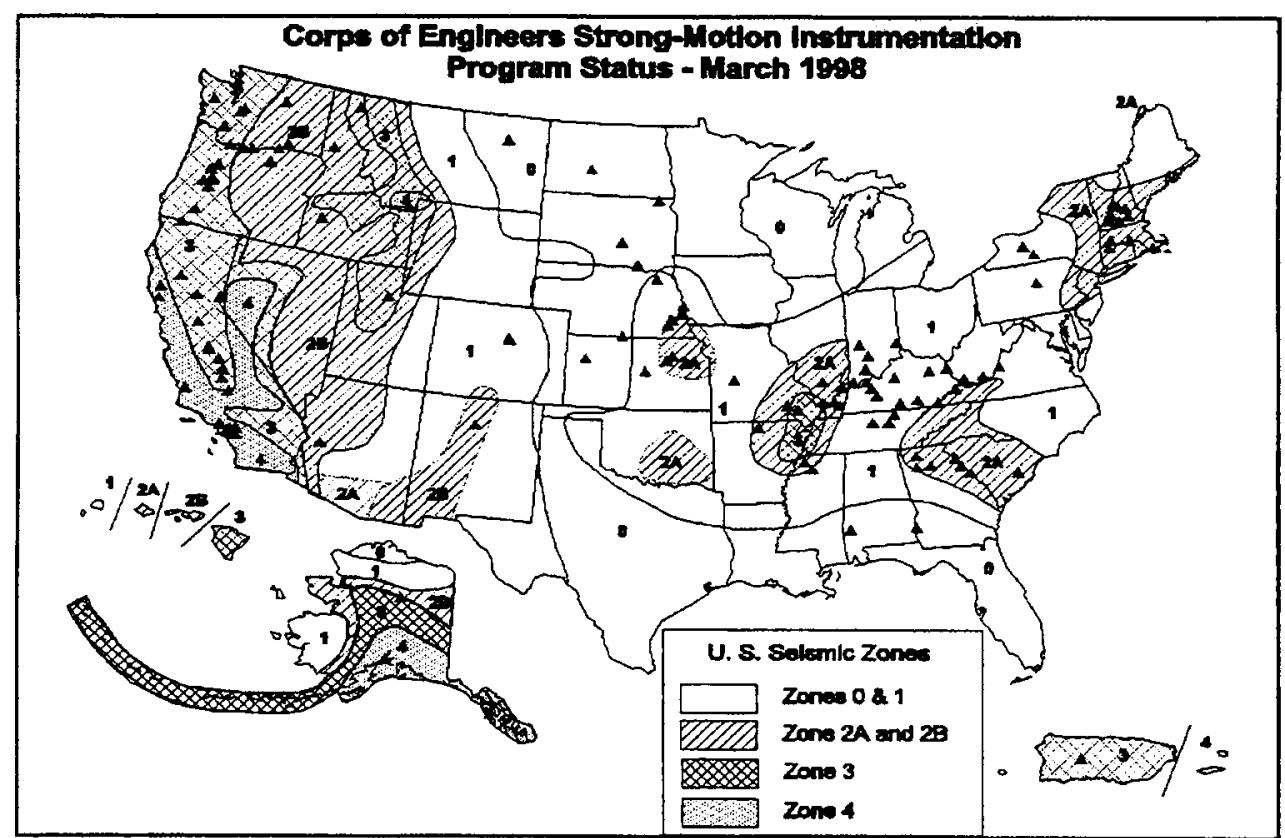

Figure 1. Seismic zone map of strong-motion instrumentation project locations 


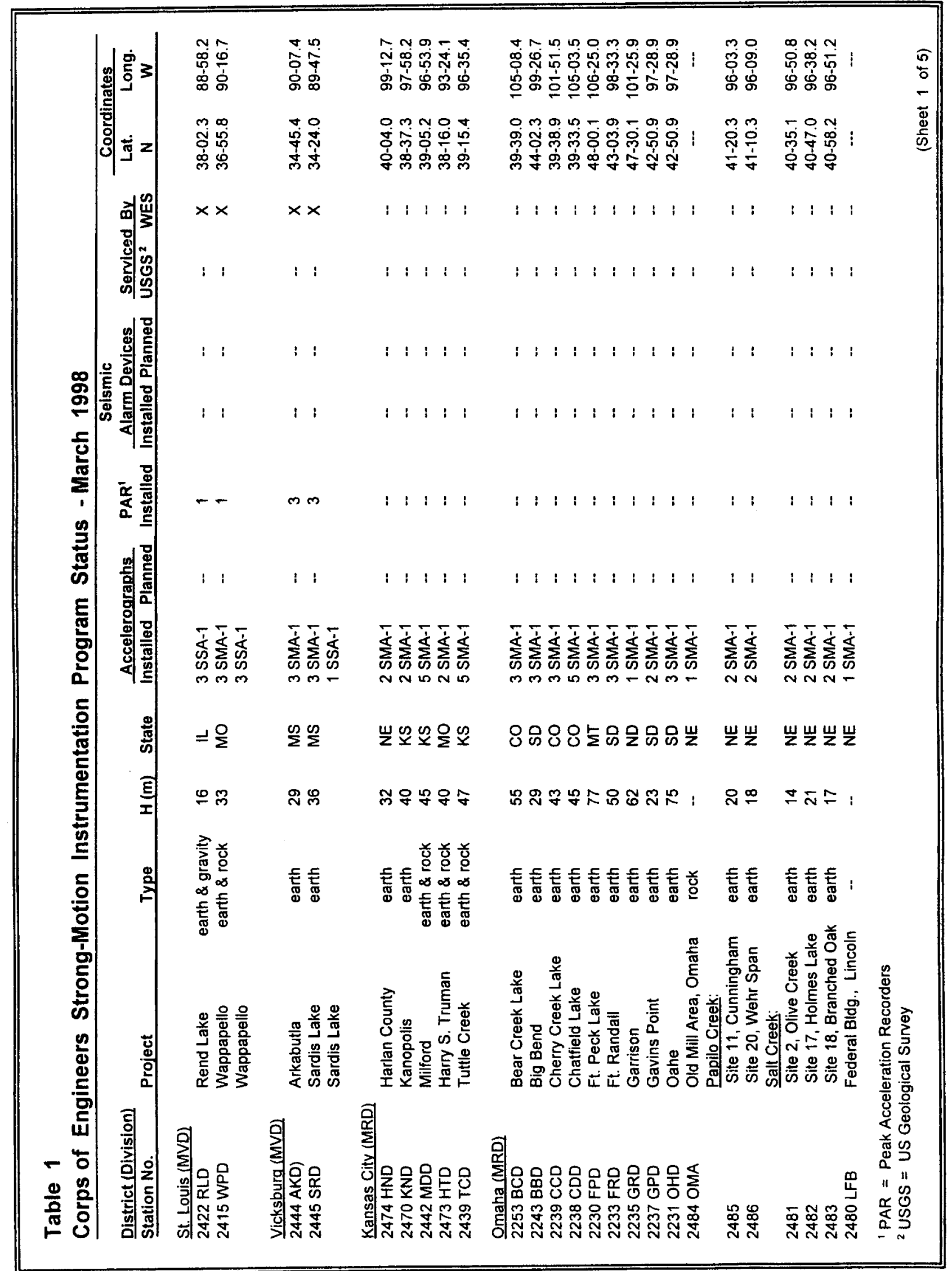




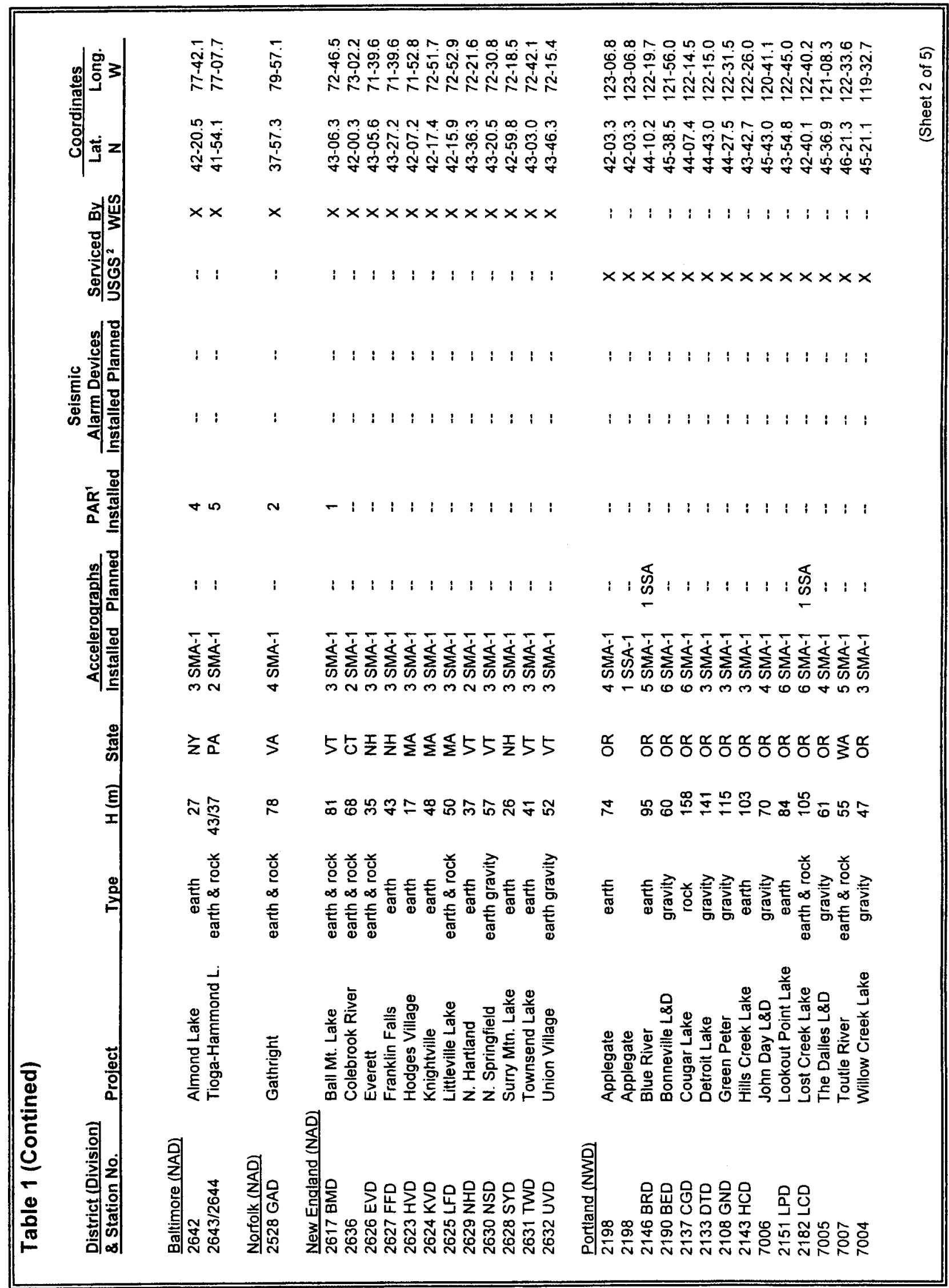

Chapter 2 Locations of Strong-Motion Instruments 


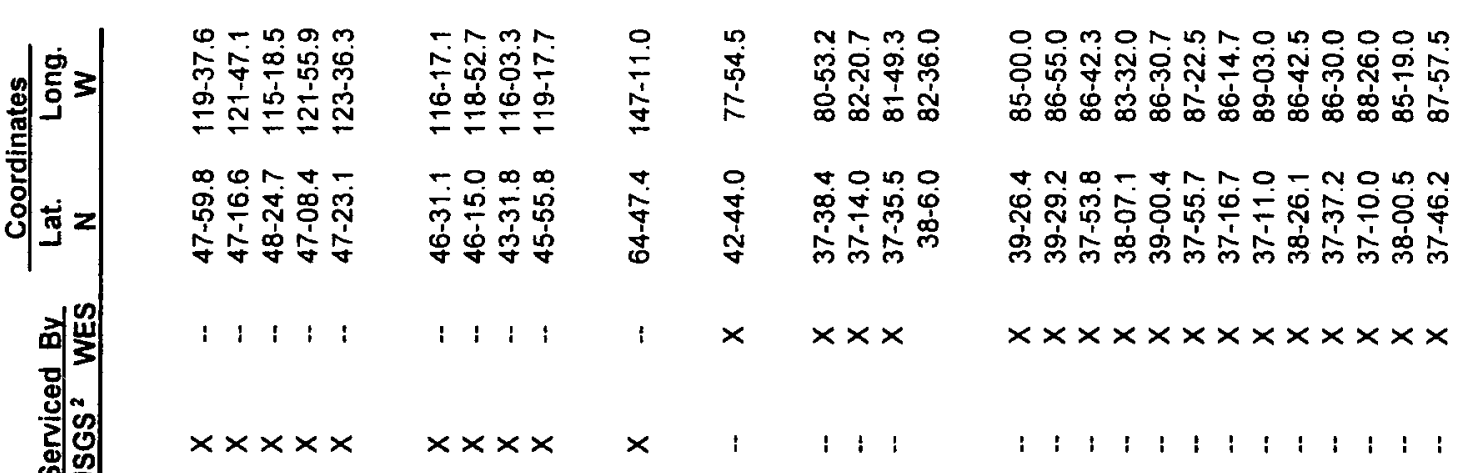

$1111: 111 \frac{2}{2}$

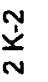

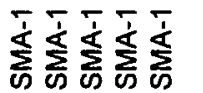

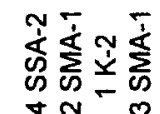

$\sum_{5}^{5}$

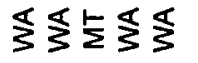

오고웅

$\checkmark$

令 引५引z

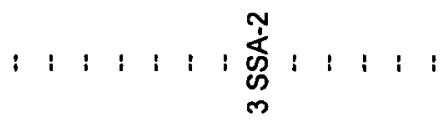
Rํํํํำ 옹ํํ웡 요 융ํㅇ

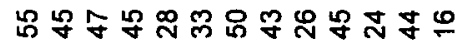

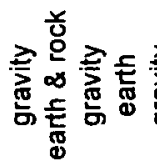

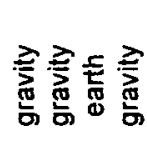

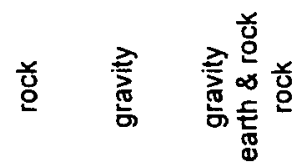

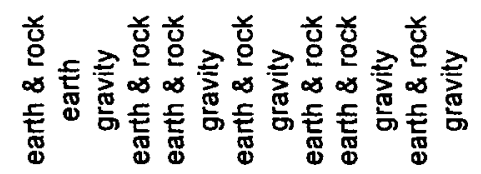

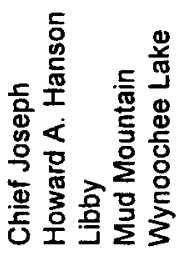
$\frac{\pi}{\frac{\pi}{d}}$

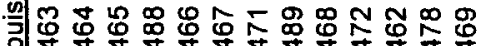




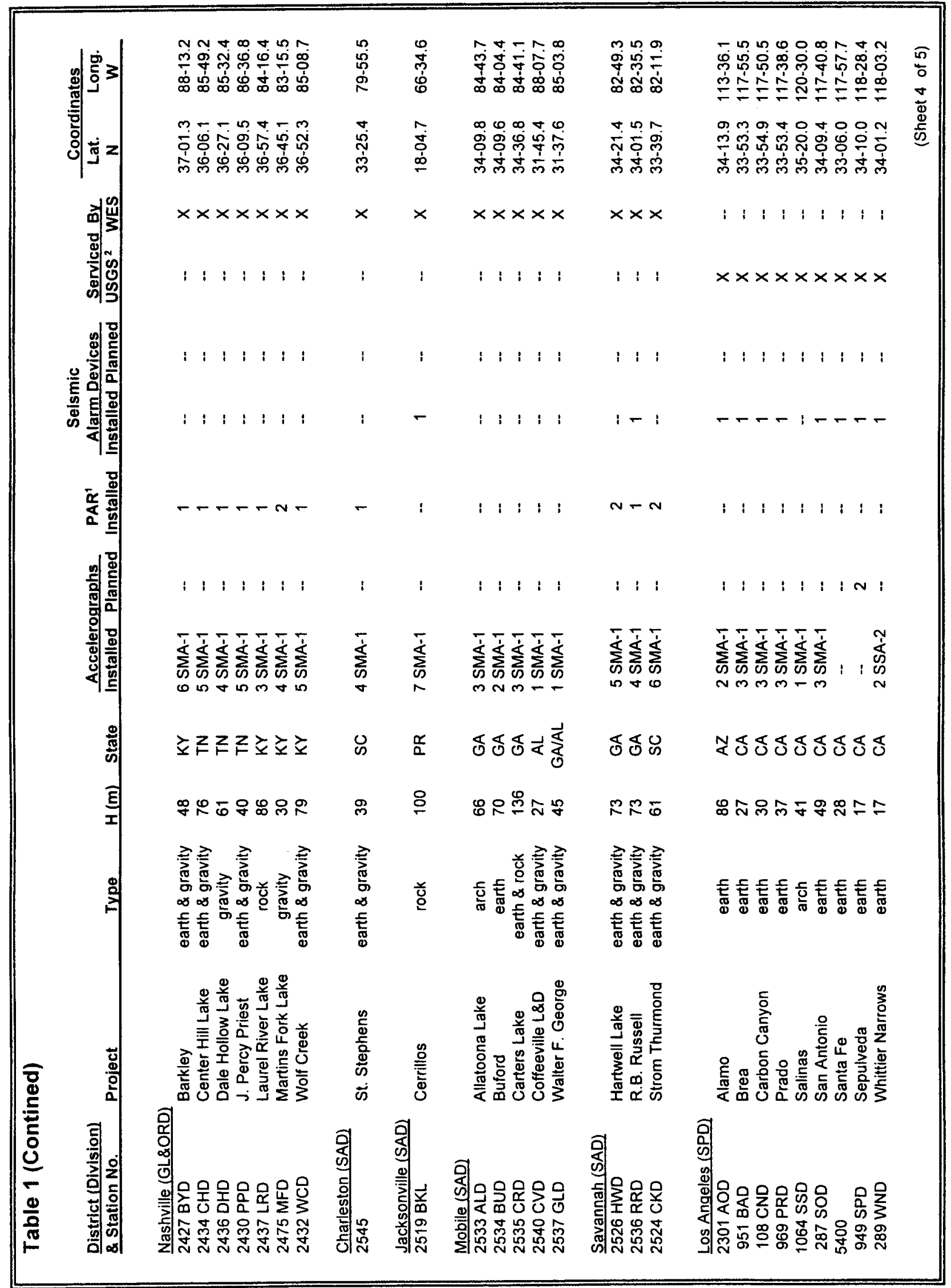

Chapter 2 Locations of Strong-Motion Instruments 


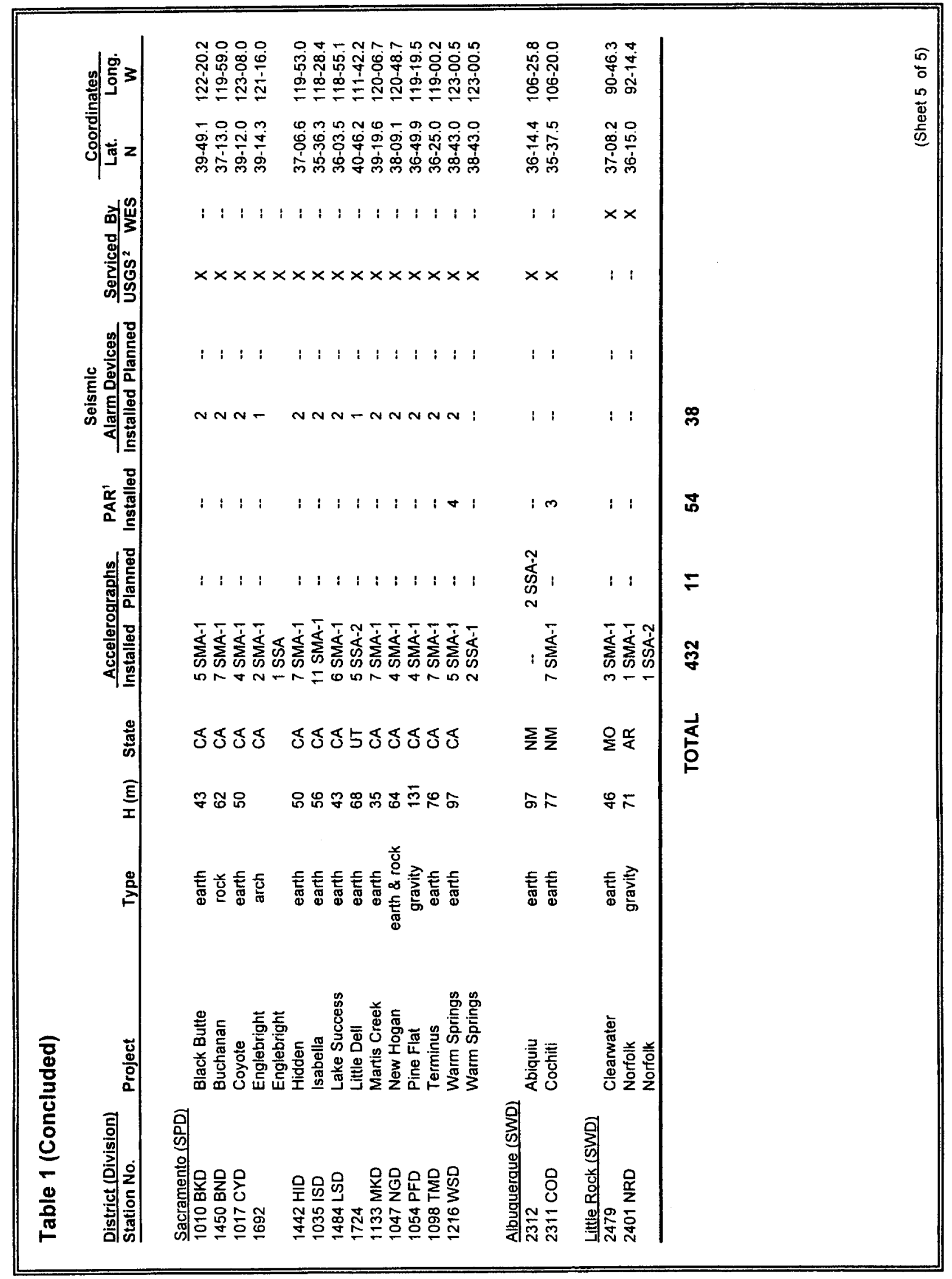




\section{Descriptions of Strong- Motion Instruments}

The instruments used for SMIP range from seismic alarm devices to digital accelerographs. In all, 432 accelerographs, 54 peak acceleration recorders, and 38 seismic alarm devices are presently (1998) used in the SMIP. Seismoscopes were eliminated from the network during Fiscal Year 92 because of questionable reliability in documenting motions at sites subjected to earthquakes.

\section{Accelerographs}

Accelerographs are the most versatile and widely used instruments by SMIP for recording strong motions. Accelerographs may be analog or digital devices which incorporate an accurate time-base receiver tuned to the National Institute of Standards and Technology (NIST) radio station WWV. Until recently, many agencies selected analog instruments because of their proven reliability. Cost is no longer a major factor since digital instruments can now compete with analog equipment and reliability equals or surpasses that of analog instruments. For new SMIP installations and upgrades of existing sites, WES strongly recommends approved digital instruments. Currently, WES uses accelerographs of the type manufactured by Kinemetrics Inc., of Pasadena, California (the analog Model SMA-1, digital Models SSA-1, SSA-2, or Etna). Figures 2, 3, 4 and 5, respectively, are photographs of these instruments. It should be noted that the SMA-1 is no longer manufactured, but working units can be traded on upgrades to digital units.

Even though outdated, the Kinemetrics Model SMA-1 (Fig. 2) is a tried and proven analog triaxial strong-motion accelerograph that photographically (optically) records strong motions on $70 \mathrm{~mm}$ film. It employs three flexure-type accelerometers (longitudinal, vertical and transverse) in a orthogonal arrangement and has a maximum recordable peak acceleration of $1.0 \mathrm{~g}$. A vertical acceleration-sensitive starter (preset at a level of $0.01 \mathrm{~g}$ for all instruments) senses the initial ground motion P-wave, and actuates the SMA-1 in less than $50 \mathrm{msec}(0.05 \mathrm{sec})$. As a general rule of thumb, a trigger level of $0.01 \mathrm{~g}$ will activate an accelerograph if an earthquake of magnitude 4.0 or larger occurs 


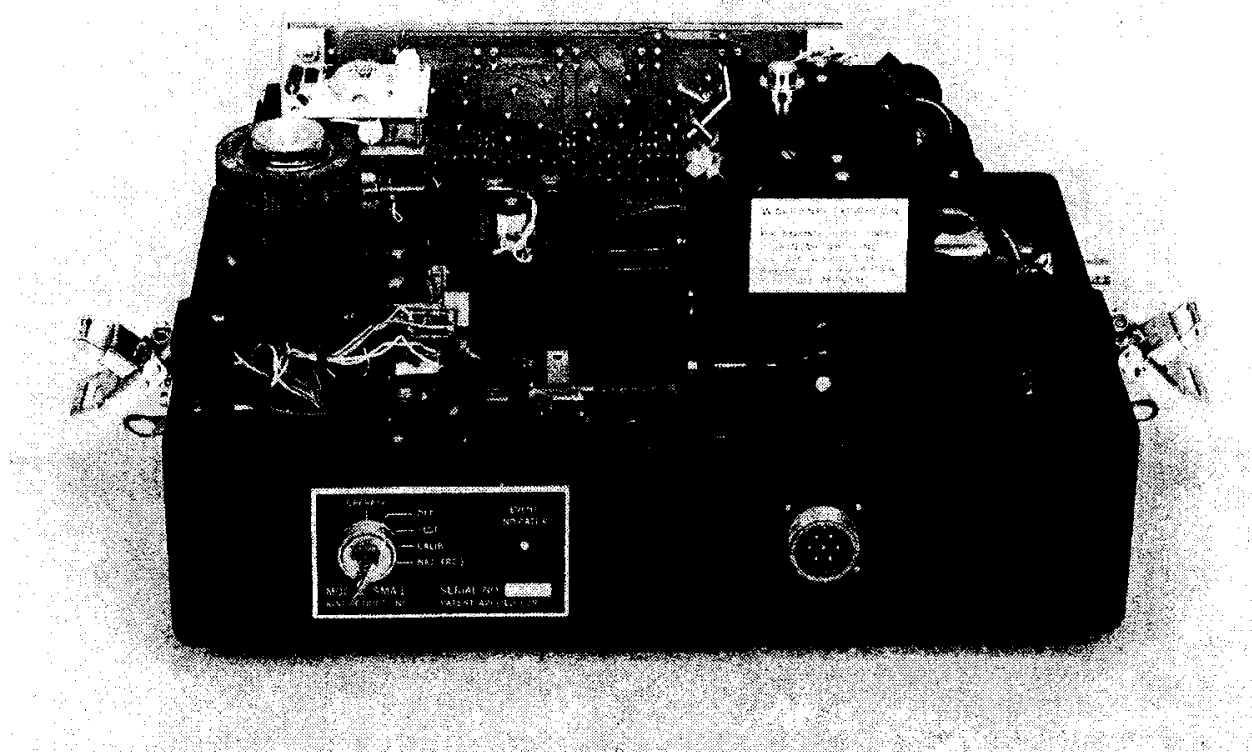

Figure 2. Model SMA-1 analog accelerograph

within approximately $80 \mathrm{~km}$ of the instrument's location. The device continues to operate for a duration of 10 seconds after the vertical starter no longer senses motion above the preset trigger level. Film is recovered during semi-annual service trips or shortly after a known strong-motion event. An attached event counter provides the number of times the instrument was activated. This count is very important to service personnel, particularly when an excessive number may be an indicator of malfunctioning. Although it is possible to develop film in the field, photographic laboratory developing is preferred. In the past, the Kinemetrics SMA-1 was the most frequently installed accelerograph for the SMIP, but is ultimately being replaced by digital models as analog instruments fail or updating is desired.

The Kinemetrics Model SSA-1 (Fig. 3) is a solid-state, digital strong-motion accelerograph that records seismic events at 200 samples per second per channel with 12-bit resolution. The SSA-1 can be configured to record up to four external channels of data from Kinemetrics FBA-11 and FBA-13 force-balance accelerometers. The typical instrument uses internally mounted triaxial force balance accelerometers with $2 \mathrm{~g}$ range. SSA-1 trigger thresholds are determined by a software-based algorithm with a bandwidth of 0.1 to $12 \mathrm{~Hz}$, preset for each of the three data channels. When signal amplitude exceeds a preset trigger threshold (normally $0.01 \mathrm{~g}$ ), the SSA-1 records and stores acceleration data in CMOS RAM. On-site data retrieval involves downloading data files to an IBM-compatible laptop personal computer. The Kinemetrics SSA-1 can be interrogated remotely via telephone modem and in 1990 was considered one of the most technically advanced accelerographs available. 


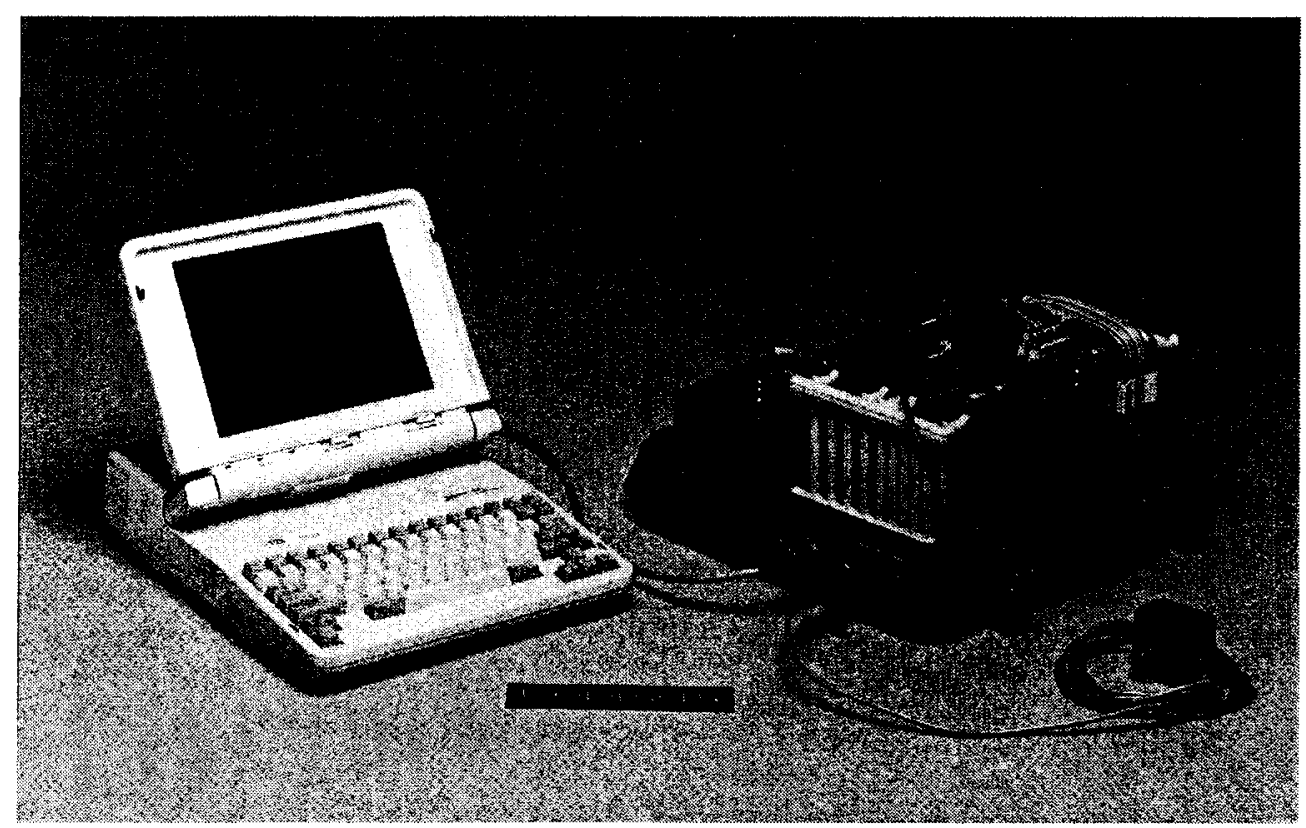

Figure 3. Model SSA-1 digital accelerograph

Addressing the market need for a more economical digital accelerograph, specifically one that could cost compete head-to-head with the analog SMA-1, Kinemetrics introduced the model SSA-2 (Fig. 4) which borrows heavily from the SSA-1. This unit retains all of the "necessary" features of the SSA-1 minus a few convenience items to appreciably reduce cost. The SSA-2 has been thoroughly evaluated by WES (and USGS) and was accepted for inclusion in the SMIP.

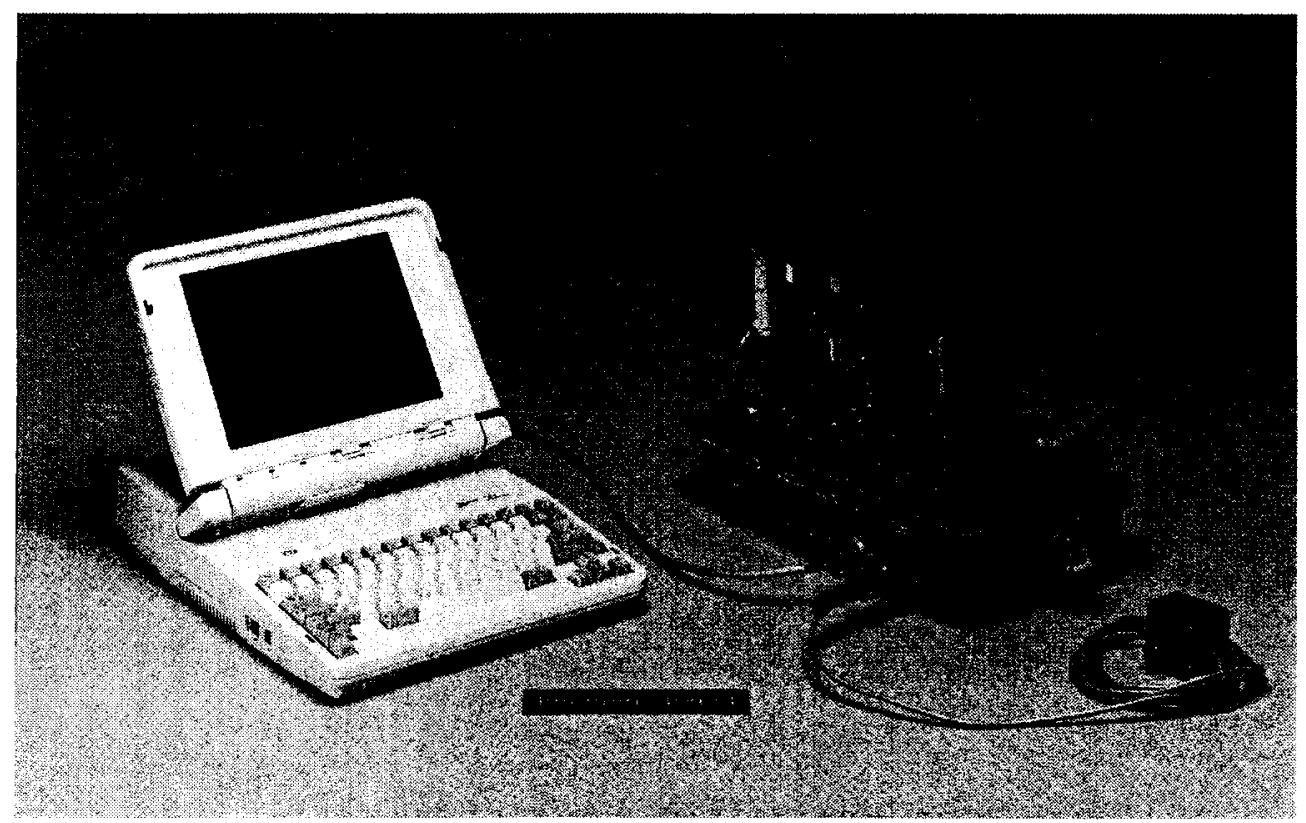

Figure 4. Model SSA-2 digital accelerograph

With the passage of time, digital technology has evolved in such an upward spiral that both the SSA-1 and SSA-2 have been replaced by Kinemetrics with its current (1998) ETNA model (Figure 5). However, both SSA-1's and -2's 
are still an active part of the SMIP program. Several ETNA units have recently been purchased for installation at Corps projects.

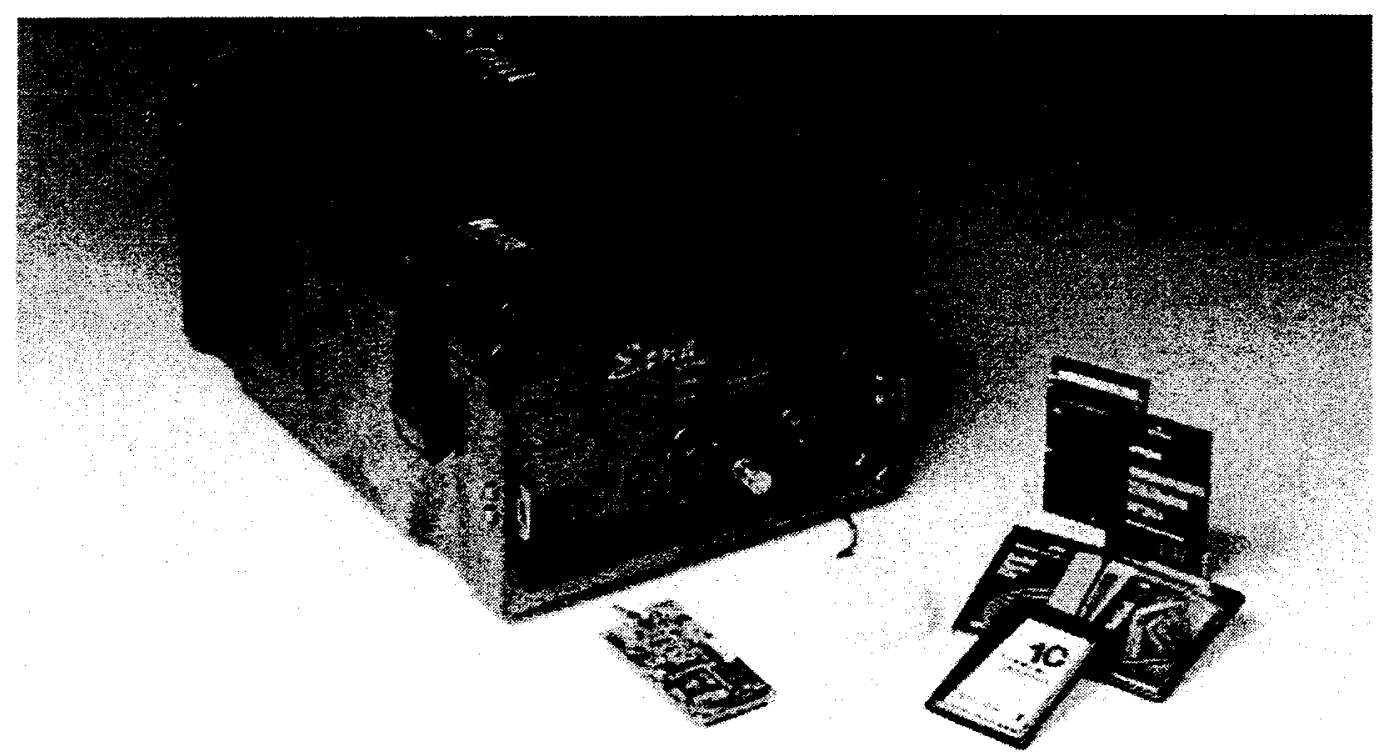

Figure 5. Etna digital strong-motion accelerograph

\section{Factors Influencing Conversion of Analog to Digital}

Of the 432 accelerographs now installed, only 47 are digital recording instruments, but as older instruments are replaced and new installations are added to the network, conversion will be made to digital. At the program's inception, only analog devices were available. Upon introduction of digital instrumentation, lack of reliability became an overriding issue. During the decade of the 1980 s, manufacturers overcame this obstacle and ultimately produced highly reliable instruments satisfactory for use in the SMIP network.

The following discussion will address the economic, scientific, and reliability factors concerning both types of instruments. One immediate advantage of digital accelerographs is having the earthquake raw data already in digital form. The analog to digital conversion is inherent in the instrument's design. There is tremendous savings in time and cost going from raw data to a finished report. The instrument's record file is retrieved directly from solid-state memory to a portable computer's memory. Then, "quick look" software resident on the computer can provide a time history plot in a few minutes. Total digital signal processing can be performed on a personal computer, and report quality plots of acceleration, velocity, and displacement (plus spectrum analysis) can be ready within 24 hours or less.

When information is recorded on analog recorders, one must carefully recover the film and chemically process it in darkroom conditions. At this point, a contact print can be made for a "quick look", but to fully analyze the record, one must optically digitize raw data and generate a digital record for future computer analysis. Since the optical digitizer WES uses is in California, film must be shipped or hand carried there to make a digital record. This 
involves several weeks' delay to prepare a complete report for the Corps Division and District. This procedure is both time-consuming and costly. Digital accelerographs are superior in virtually all respects.

Other advantages of digital accelerographs are:

a. More data are obtained because the bandwidth is DC to 50 hertz on a digital recorder instead of DC to 25 hertz on an analog recorder.

b. Higher dynamic range exists from about $40 \mathrm{~dB}$ to $66 \mathrm{~dB}$ using a 12-bit analog-to-digital converter. This means that a $2 \mathrm{~g}$ full-scale accelerometer can be used to recover data down to $0.001 \mathrm{~g}$, the advantage being that $2 \mathrm{~g}$ accelerometers are less expensive to build than $1 / 8 \mathrm{~g}$ or $1 / 4 \mathrm{~g}$ and are more durable.

c. Triggering of the instrument is more versatile. Using a digital unit, all three axes of recorded acceleration, vertical and two horizontal can be sensed. With an analog recorder, a single vertical trigger is used. The three-trigger accelerometers can be "weighted" to make the instrument equally sensitive to each axis, or it can be set to two or three times as sensitive in any one axis. Consequently, triggering can be tailored to site conditions.

d. Remote interrogation of the accelerograph is possible by use of a telephone line and modem. Complete status of the unit can be determined, i.e., number of triggers, solid-state memory used and remaining battery voltage of the main power supply and memory battery. In addition, function tests of all accelerometers may be performed and data record files of earthquake events or function tests may be transferred via modem. This is an important advantage in that it will eventually allow fewer service visits, thus appreciably reducing cost while increasing reliability.

e. Pre-event data for the earthquake event can be obtained. The digital recorder is continuously digitizing and storing data from the accelerometers. Data continuously "rolls through" the solid-state memory until the instrument is triggered. At that time, up to 15 seconds of pre-event data and the complete earthquake event is stored in a data file.

f. Post-event data can be obtained up to 60 seconds after the earthquake's acceleration is less than the trigger acceleration threshold (typically $0.01 \mathrm{~g}$ ). A typical application might be intake structures swaying at a low frequency and low acceleration level long after the main event has ceased.

g. Remote location of accelerometers from the recording instruments is easily accomplished. If an accelerometer location is too small or has limited space for the entire instrument, cabling can be installed to a remotely located tri-axial accelerometer package. Under certain 
circumstances, accelerometer packages can be placed at optimum depths in boreholes.

$h$. Better documentation is available through automatic storage of key data on the record header. Typically, information such as time and date of each event, peak acceleration of each axis, duration of the event, sensor orientation, instrumentation location (latitude, longitude, elevation), battery voltage, VAC power present, serial number, and user comments can be stored in memory.

In summary, a valid case can be made for ultimate conversion to a fully digital network. The use of digital instruments provides more reliable networks which are easier to service and produces higher quality information-rich earthquake records in a far more economical fashion.

\section{Peak Acceleration Recorders}

Peak Acceleration Recorders (PAR) provide a low-cost method for detecting a strong-motion event and often serve as a backup for accelerographs. Terra Technology of Redmond, Washington, and Engdahl Enterprises of Costa Mesa, California, both manufacture peak acceleration devices installed and maintained by the SMIP. The devices operate on different principles. The Terra Technology PRA-103 employs a spring-mass magnetic stylus on a magnetic tape and records peak acceleration of up to $2.0 \mathrm{~g}$. The tape is returned to the laboratory where it is dusted with ferric powder and analyzed. The PAR-650L from Engdahl (shown in Figure 6) records a peak acceleration level of up to $2.5 \mathrm{~g}$. A

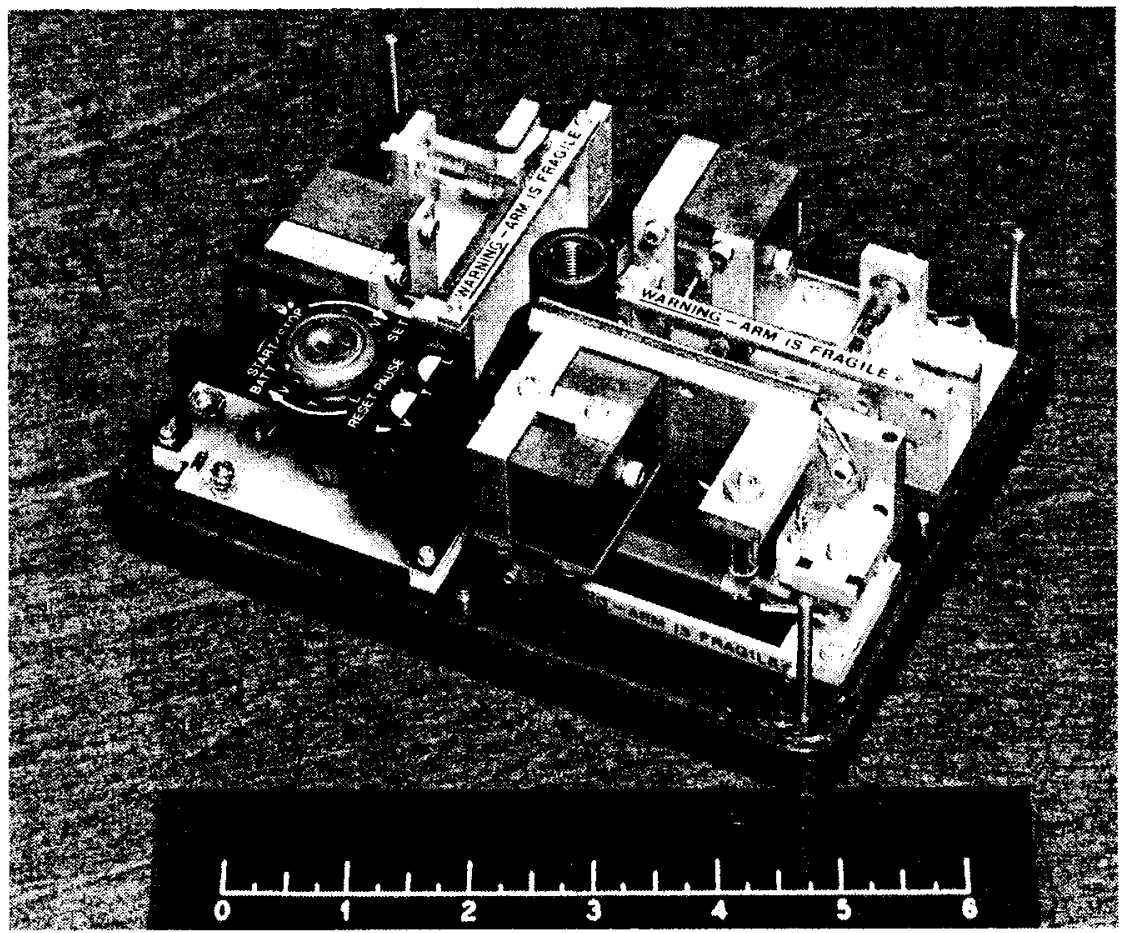

Figure 6. Engdahl model PAR 650L peak acceleration recorder (case removed) 
diamond stylus rests on a soft metal plate that is etched when strong motions are detected. The metal plates are returned to the manufacturer for resurfacing after the recorded event is analyzed. The PAR-650L has a local annunciator for preset accelerations (normally $0.1 \mathrm{~g}$ ). Approximately 75 percent of peak acceleration devices serviced by WES are the model PRA-103 produced by Terra Technology.

\section{Seismic Alarm Device}

WES designed and fabricates the Seismic Alarm Device (SAD) since it is not commercially available. Its intended purpose is to provide the responsible agency with immediate cost effective information in the aftermath of an earthquake. The device is ideal for use on unmanned facilities. The SMIP network currently incorporates 38 Seismic Alarm Devices. This alarm package (shown in Figure 7) contains a vertical accelerometer with ten individual threshold level relays. The latching relay bank stores accelerations greater than the preset threshold. A light-emitting diode (LED) indicates peak acceleration on the main control board. The standard SAD is calibrated to display peak accelerations in steps of $0.05 \mathrm{~g}$ from 0.05 to $0.50 \mathrm{~g}$. Accelerations at or greater than the threshold cause the appropriate LED to illuminate and sound an alarm indicating the instrument has triggered and should be inspected. This device has also been adapted to activate an automatic telephone dialer and remote annunciator.

Although some material is redundant, it was concluded that two documents describing the SAD should be provided to the reader in their entirety. (Each document stands alone, intended for different audiences.) Appendix B: WES Seismic Acceleration Alarm Device Technical Specification provides a detailed description of the device. The Seismic Alarm Device Operation Manual is also provided at Appendix C.

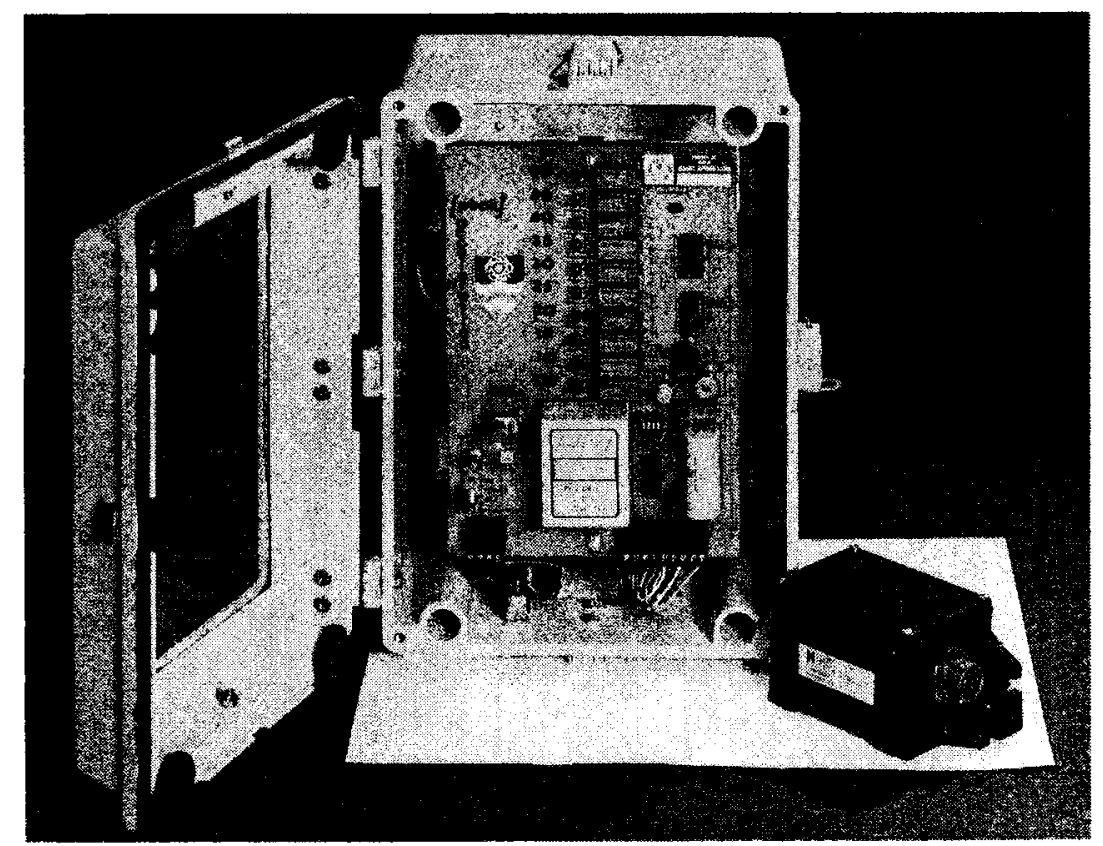

Figure 7. Seismic Alarm Device (SAD) (WES design) 


\section{Instrument Installation}

Every USACE strong-motion installation must be carefully planned in accordance with regulations so that instruments are strategically located to ensure that recorded seismic data capture all important structure responses and provide a good characterization of seismic loads. (See ER 1110-2-103, StrongMotion Instruments for Recording Earthquake Motions on Dams; ER 1110-21806, Earthquake Design and Analysis for Corps of Engineers Projects; and EM 1110-2-1908, Instrumentation of Earth and Rock-Fill Dams, Part 2, Earth Movement and Pressure Measuring Devices.) Such considerations as power, protection from weather and vandalism, and service access must also be addressed on a site-by-site basis. Generally, instruments located within existing facilities such as control structures or power houses are installed in lowtrafficked rooms such as storage areas. Those installed in open areas use a widely accepted lightweight, economical, protective structure. Plans for these structures are shown in Figures 8 and 9. Typical installations are shown in Figures 10-12. Use of the commercially available Western Power Products, Inc. Model 41-2 fiberglass shelter provides both an economical and a seismically acceptable installation.

In an effort to address questions concerning modification of earthquake records due to soil-structure interaction, an intensive study jointly sponsored by the National Science Foundation (NSF) and WES was conducted under contract and reported (Crouse and Hushmand, 1989 and Crouse et al., 1990). Forced harmonic and impulse-response vibration tests were conducted at several California accelerograph stations operated by the California Division of Mines and Geology and USGS. Results of tests on relatively short, lightweight structures showed presence of highly damped fundamental frequencies of 20 and $40 \mathrm{~Hz}$ (beyond earthquake range of interest). However, at tall ( $>6 \mathrm{ft}$ ) shelters fundamental frequencies in the $12 \mathrm{~Hz}$ region were observed (within the range of interest). While foundation impedance functions could be theoretically calculated within acceptable limits, it was readily recognized that the shorter, lighter, higher-frequency shelters were much more desirable. Hence, the current design shelter used by the USACE presents a minimally complex strong motion instrument housing. 

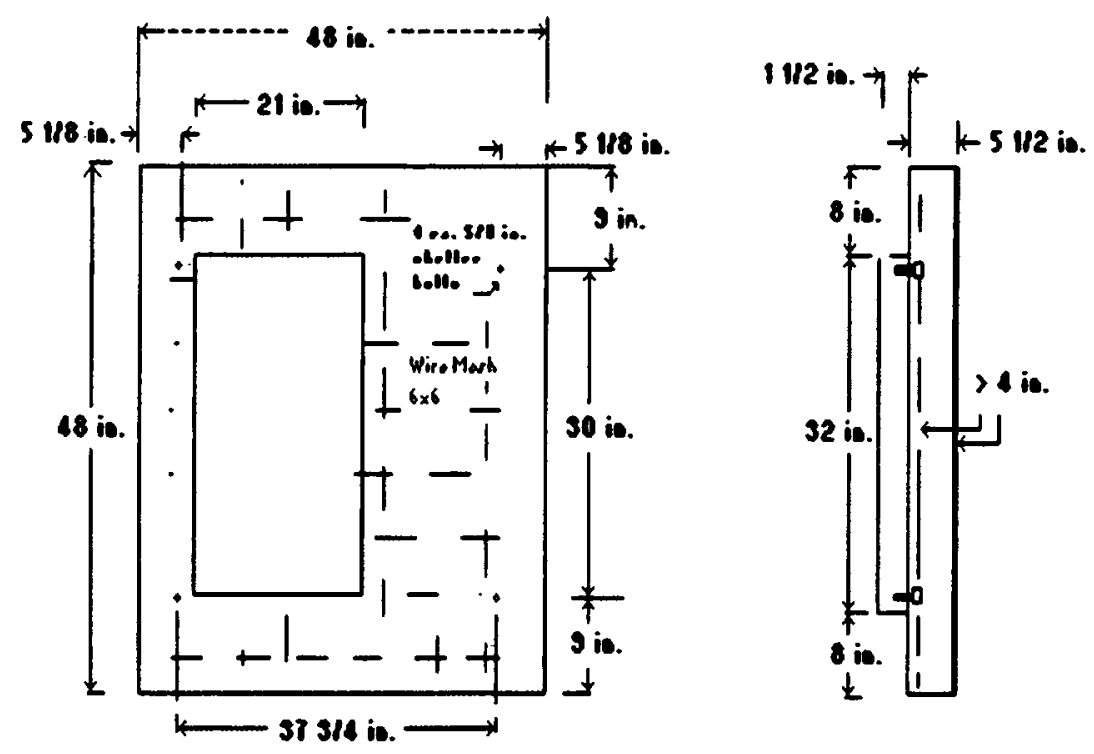

NOTE: 6 sacks of concrete mix

$3 / 4 \mathrm{in.} \mathrm{maximum} \mathrm{aggregate} \mathrm{size}$

to ea. 16 rebars, symmetrically placed

W SulP Accelerograph Shelter Pad

E Drambr. J.L Plidens

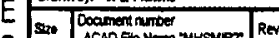
$S$ Dave: Fec.5. 1900 Pate 1012

Figure 8. SMIP instrument shelter pad foundation plan

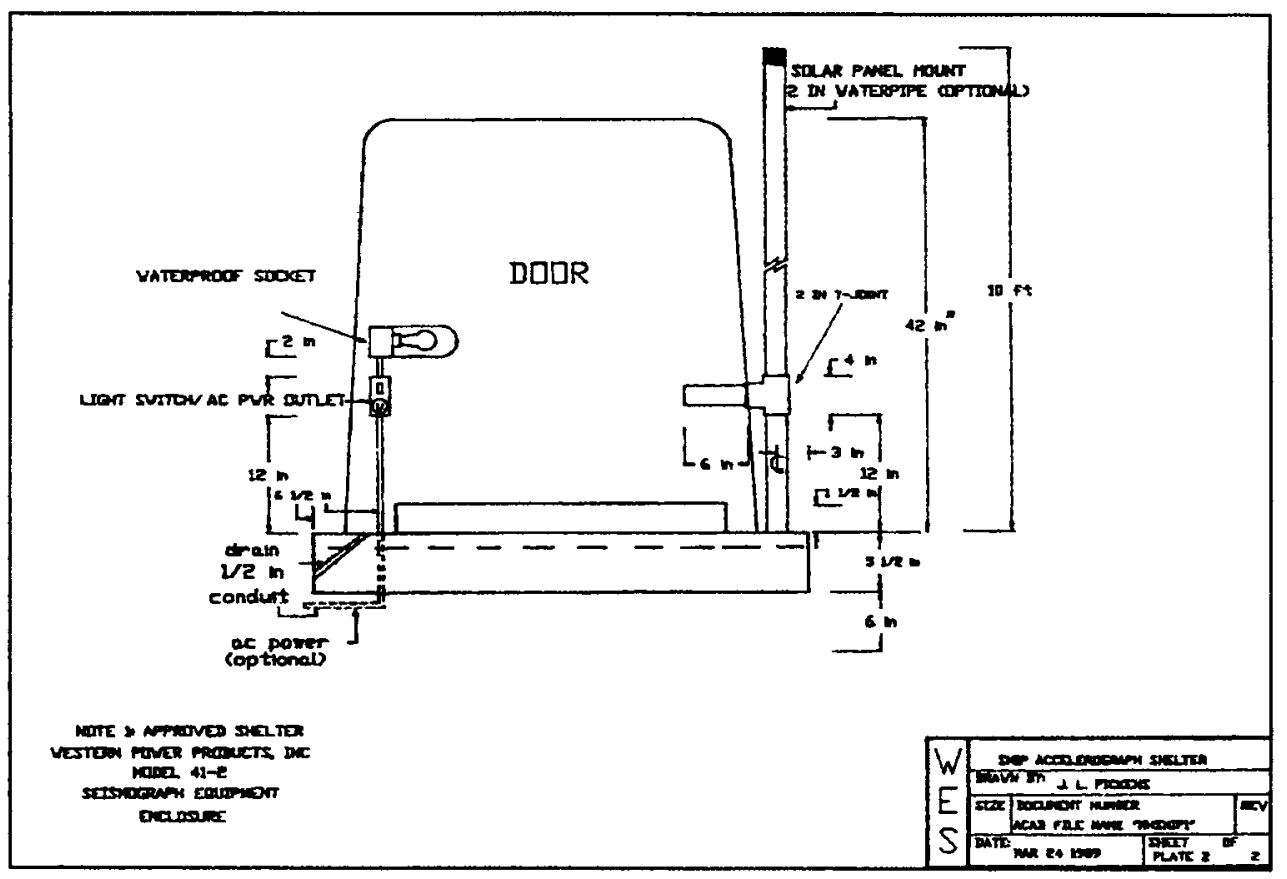

Figure 9. Plans of Western Power Products, Inc. model 41-2 equipment protective enclosure 


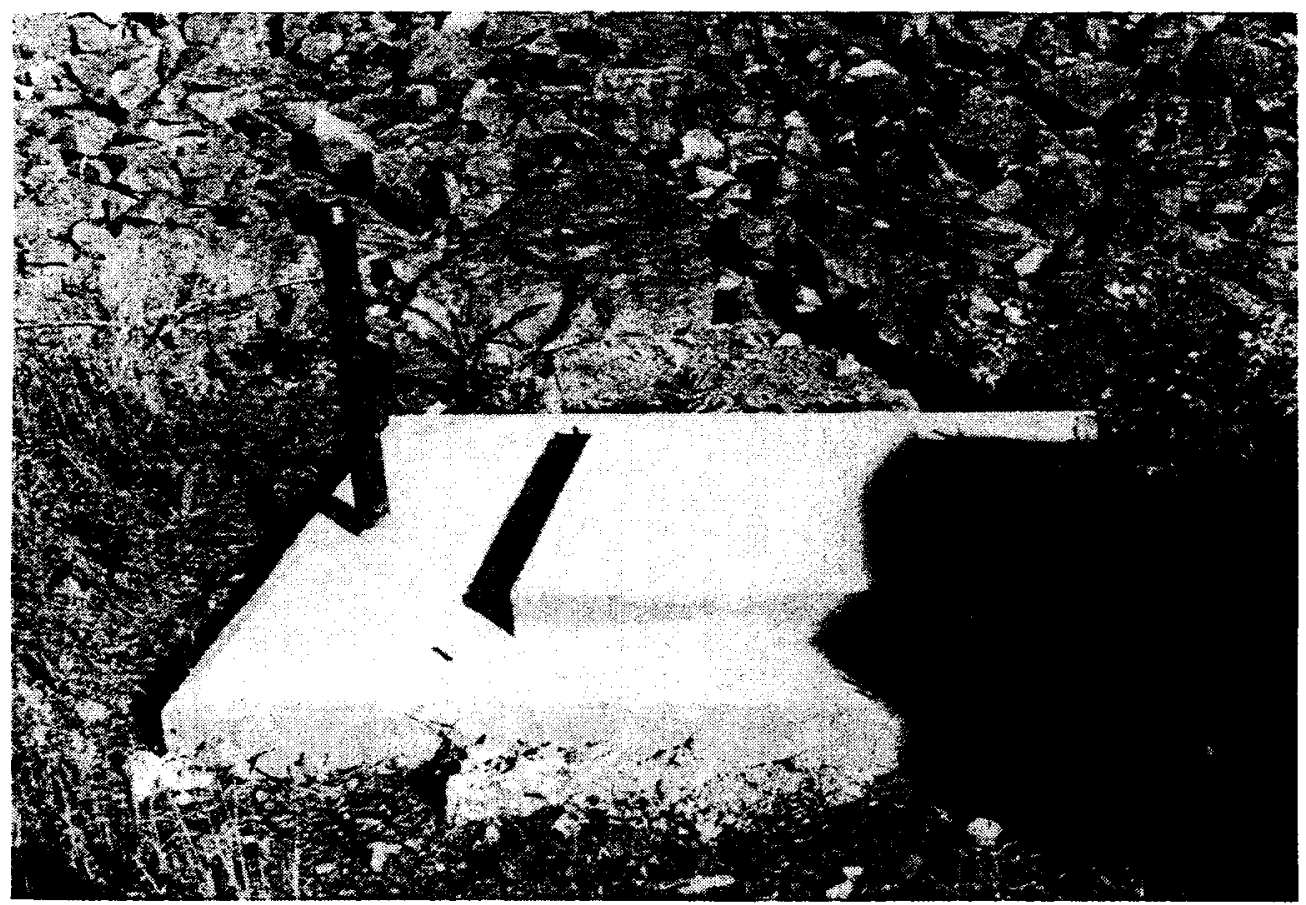

Figure 10. Typical instrument shelter pad foundation

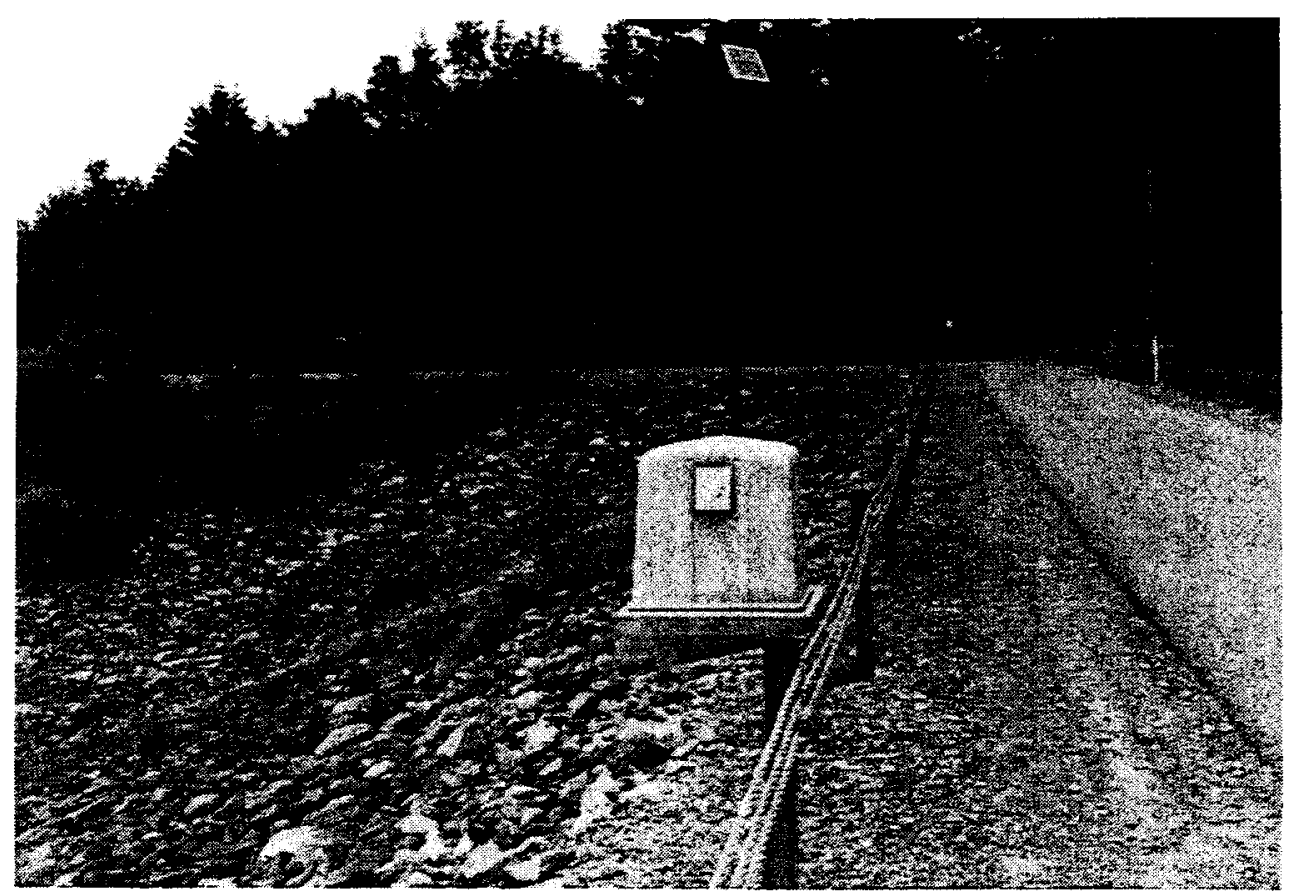

Figure 11. Typical strong-motion instrument installation at crest of Almond Dam, NY. Note solar cell power source 


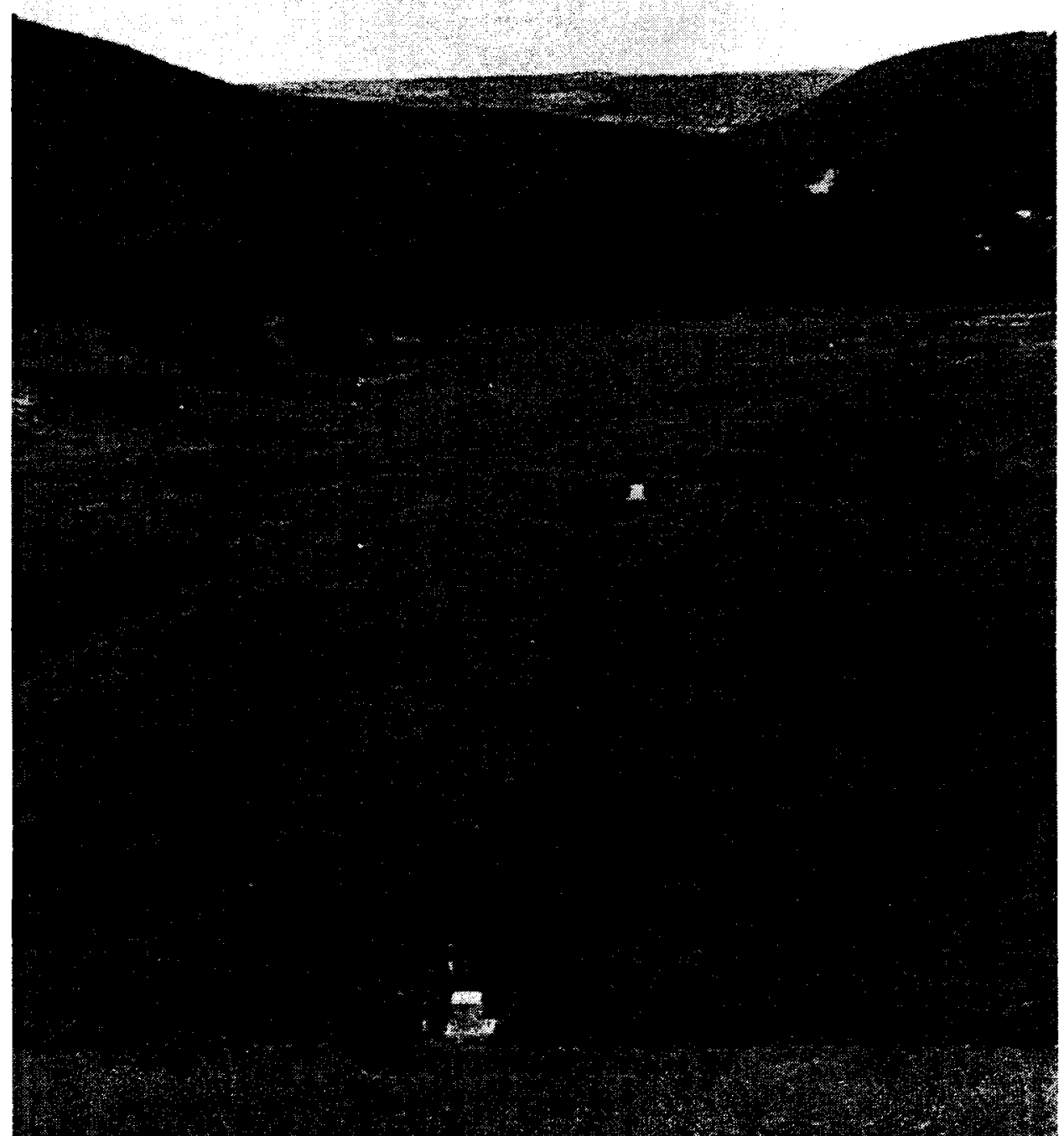

Figure 12. Typical strong-motion instrument installations (Almond Dam, NY, toe and free field stations) 


\section{Operation and Maintenance}

ISDD personnel (an electronics engineer and two electronics technicians) prepare and service SMIP instruments under the jurisdiction of WES. Laboratory functions are shown in Figures 13-15. Typically one electronics technician is involved in servicing that includes four routes looping through all project sites twice a year. Plenty of spare parts are at hand to make the service teams autonomous. A detailed inspection record for each device is completed on location and accompanies recorded data to WES for interpretation and cataloguing in a computer database. Figure 17 is an example inspection record form.

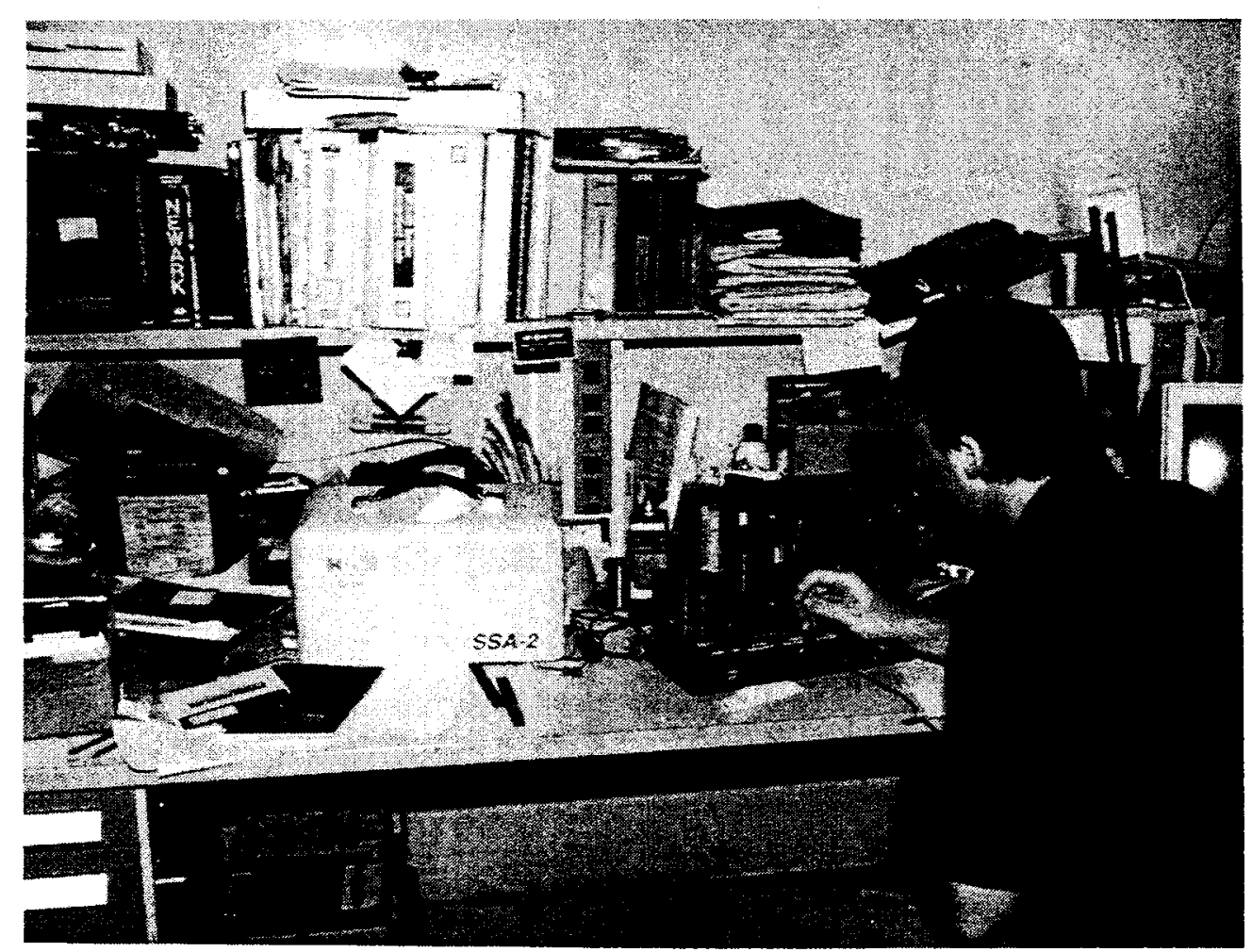

Figure 13. WES Instrumentation Services Division personnel checkout/repair of strong-motion instruments 


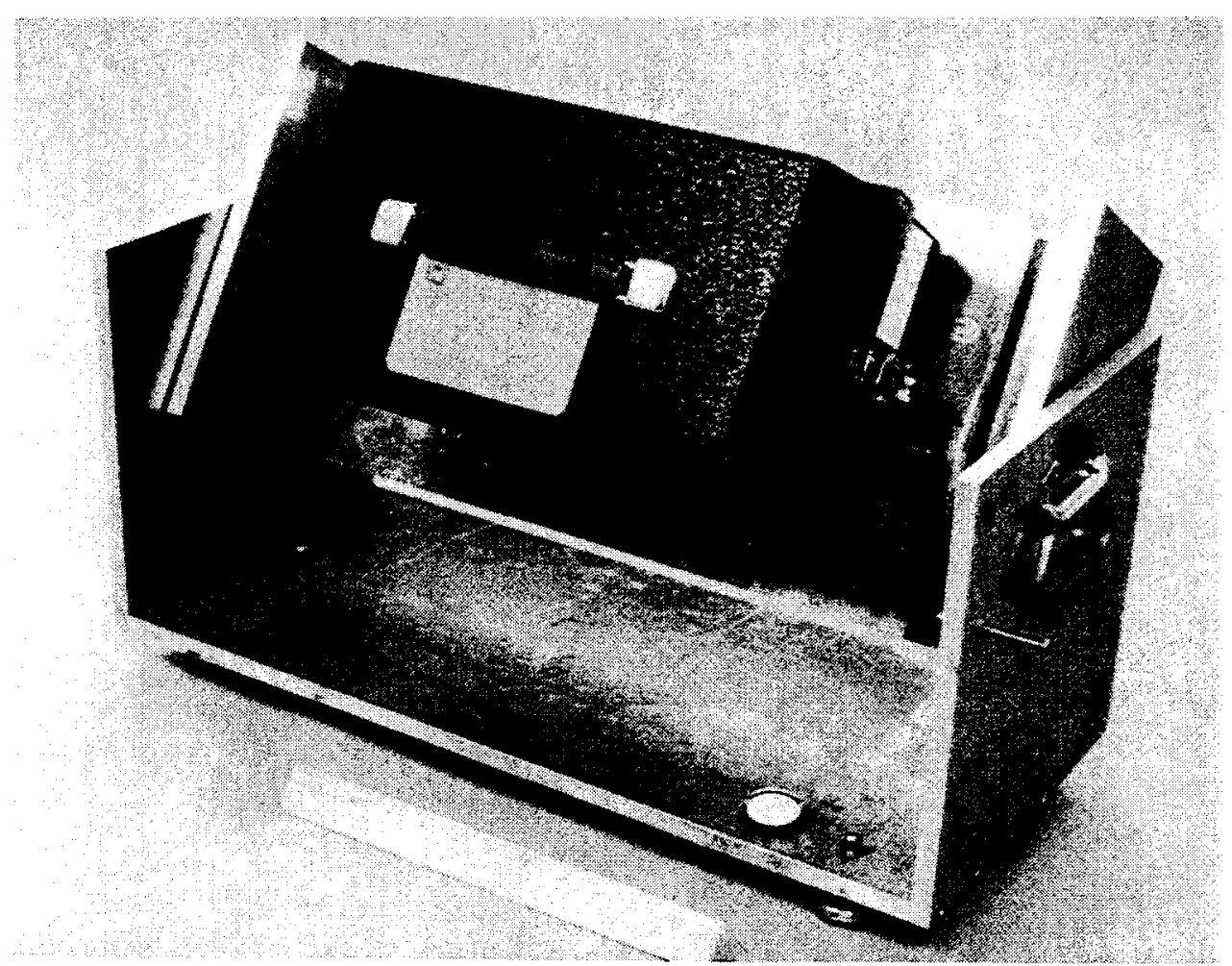

Figure 14. Laboratory tilt table calibration test. All accelerographs are subjected to periodic calibration. The tilt table is portable enough to be used in field servicing

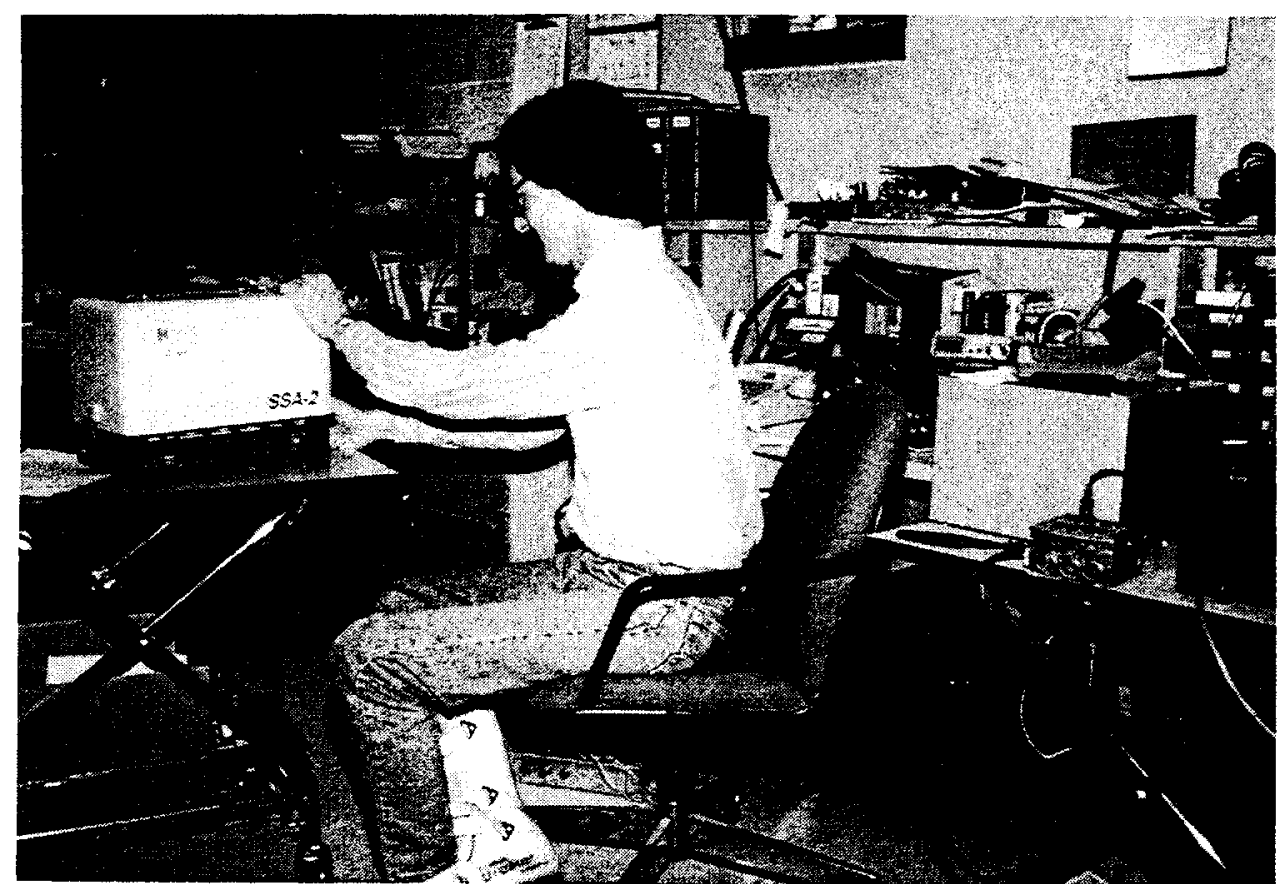

Figure 15. WES Instrumentation Services Division preinstallation Laboratory checkout of strong-motion accelerograph 


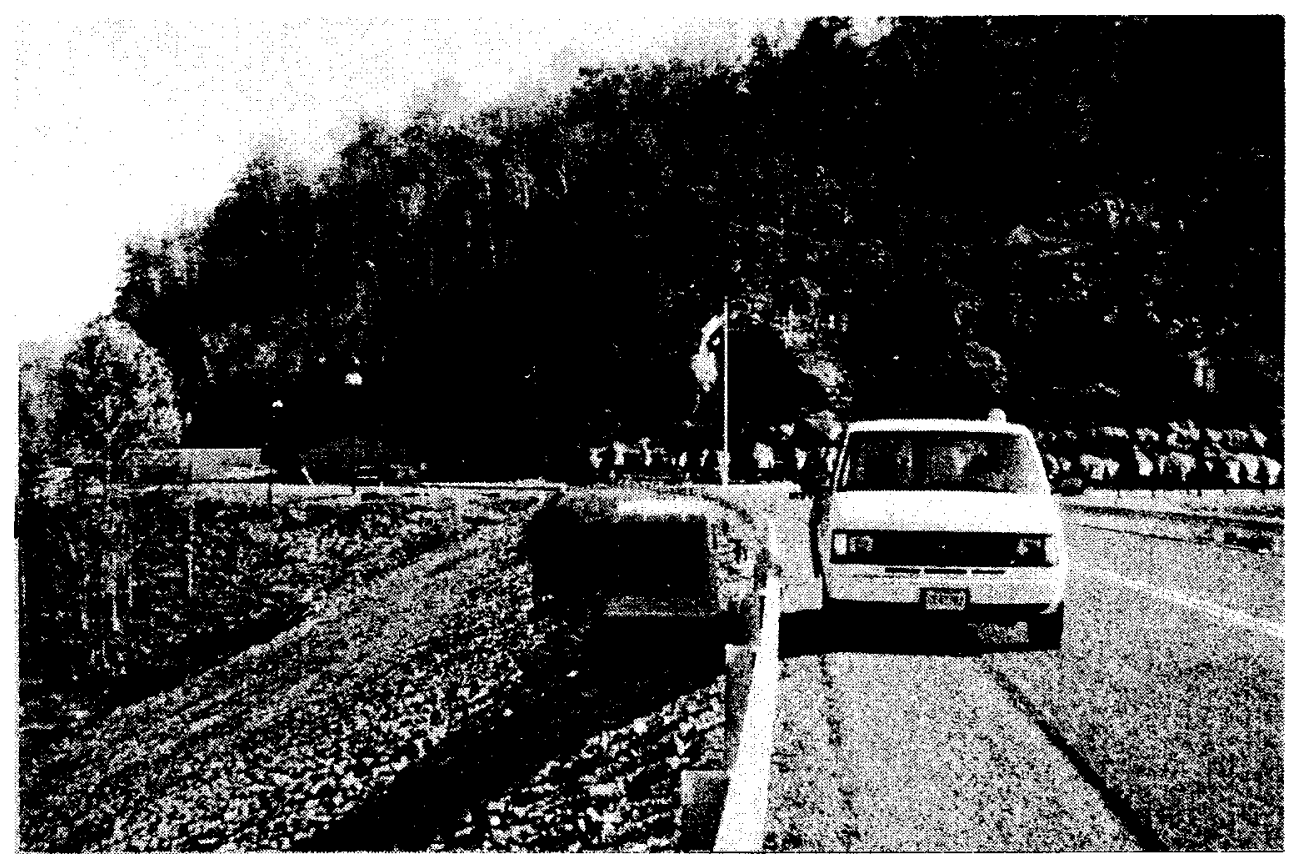

Figure 16. WES SMIP dedicated van servicing crest instrument at J.W.

Flannagan Dam, VA (Huntington District)

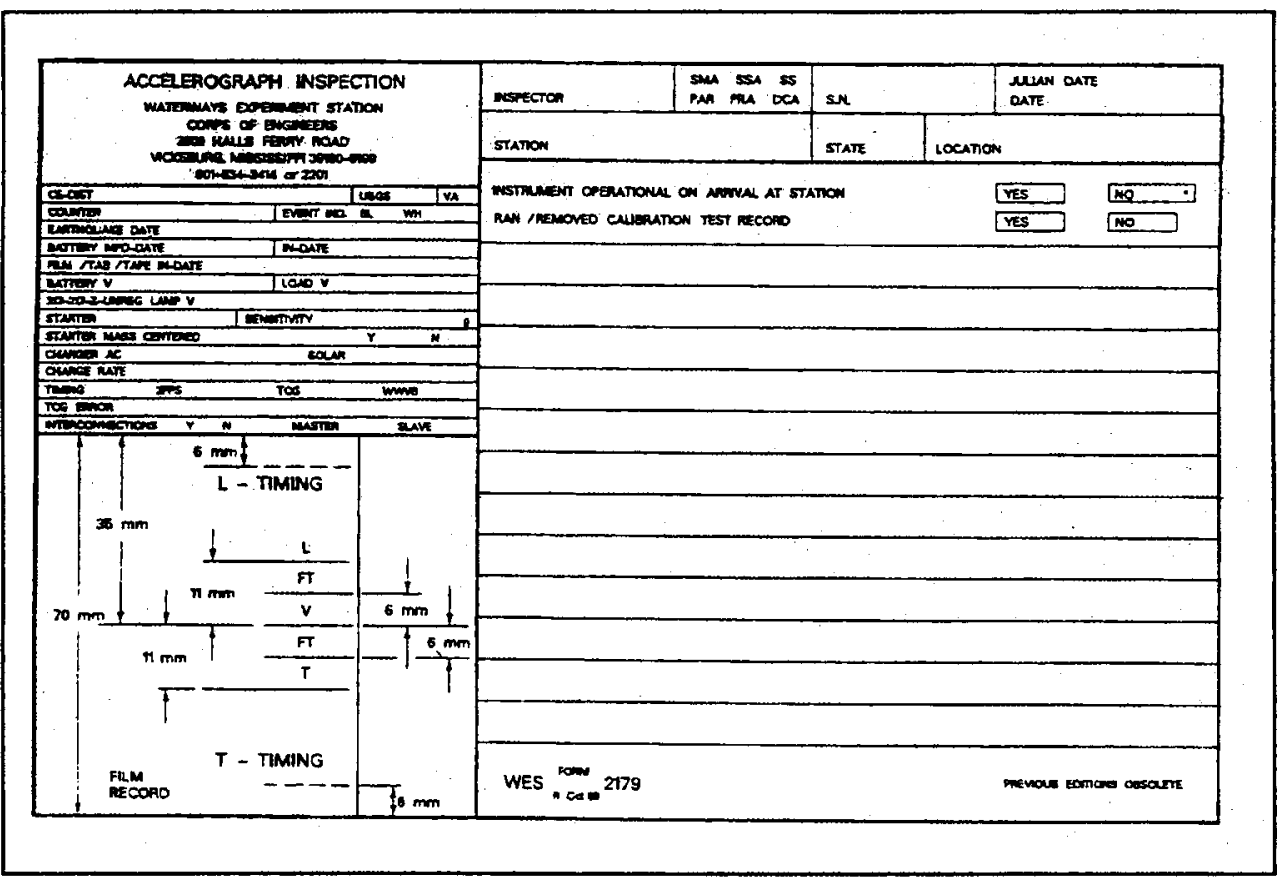

Figure 17. WES example inspection record form

Once accelerometer recordings of an earthquake are delivered to WES, they are processed and baseline and instrument corrections are made. Kinemetrics developed (PC-compatible) software is used to process data received at WES. For analog records, the traces are first optically digitized at a rate of 600 points per second of record. Computer algorithms written by USGS are used to 
integrate the variation of acceleration with time to obtain velocity and displacement records. Further processing includes plots of response spectra. Once all data reduction is completed, a WES seismologist analyzes results to determine natural periods and various amplification factors. Reports are published for larger events under sponsorship of the respective USACE district office (e.g., Chang 1985).

To minimize operating costs while increasing reliability and overall effectiveness of the SMIP, it is necessary to modify and/or upgrade various instruments as maintenance records and technological advances dictate. Charges for services are adjusted annually on the basis of actual cost. Currently, individual letters including costs and newsworthy items are submitted to participating Corps agencies on an annual basis. This action essentially has served to replace a biannual Engineering Circular thus saving appreciable cost. 


\section{Earthquake Data Retrieval}

Earthquake data can be event parameters such as location, time, magnitude, or more detailed data such as accelerograms and parameters derived from these records for individual recording stations.

\section{Earthquake Information}

The National Earthquake Information Center (NEIC), located in Golden, Colorado, dispenses factual information about an earthquake within minutes of its occurrence. Such factors as location, magnitude, damage, casualties, and history of previous seismic events are sent to interested parties throughout the world. Access to the NEIC database is available to anyone via computer and telephone modem. The system is called "Quick Epicenter Determinations" (QED) and there is no charge for logging onto the NEIC system. More detailed information and examples of data available from NEIC are shown at Appendix E.

\section{Earthquake Accelerogram Data}

WES is linked to NEIC via electronic-mail. Several WES personnel monitor earthquake information on a daily basis. If an earthquake exceeds magnitude 4.5 and its epicenter is located within $80 \mathrm{~km}$ of an instrumented USACE structure, WES contacts the responsible USACE district office to determine whether or not instruments have triggered. If personnel on the site confirm instrument activation, special arrangements are made to service the instrument(s) and retrieve records.

Digitized raw (uncorrected) earthquake records are processed using USGS AGRAM/BAP accelerogram computer processing software and output in USGS Strong Motion CD-ROM (SMC) format. This processing includes filtering (noise removal), baseline correction, removal of instrument response, data formatting, and calculation of response spectrum. Records are then logged into the USGS NSMIP database catalog and archived. The WES strong motion database provides on-line Internet access to unprocessed data from the 1994 
Northridge, CA earthquake ( http://geoscience.wes.army.mil/smip.html), and can be reached by anonymous $\mathrm{ftp}$. Other internet sources for this type data are the USGS NSMIP strong motion digital data series database

(http://agram.wr.usgs.gov), NOAA National Geophysical Data Center earthquake database, Boulder, CO (http://julius.ngdc.noaa.gov), National Center for Earthquake Engineering Research's (NCEER) strong motion database located at Lamont-Doherty Earth Observatory (http://www.ldgo.columbia.edu/nceer/nceer.html), and the California Department of Conservation, Department of Mines and Geology's strong motion data center (http://www.consrv.ca.gov/dmg/csmip/index.htm). 


\section{Significant Earthquakes Recorded to Date}

Since inception of the SMIP, a number of significant earthquake records have been acquired. Appendix $\mathrm{E}$ is a tabulation of USACE strong-motion data archived between 1971 and 1997.

One of the most important recent events was an earthquake that occurred near Franklin Falls, New Hampshire, on 18 January 1982. This event was rated at 4.8 on the Richter Scale and triggered some 13 instruments in the New England area. These data (see Figure 18 for a typical record) are the most significant strong motions recorded in the New England area in over 40 years. Detailed analyses indicated that preconceived notions about attenuation factors, frequencies, and amplitudes should be revised for the New England area. (Chang, 1982, 1987)

Other high quality records have been obtained at Coyote Dam, California, in March 1978, Mt. Borah, Idaho, in October 1983 (Chang 1985), and Whittier Narrows, California, in October 1987 and in February 1988. The Mt. Borah earthquake $\left(M_{S}=7.3\right.$; USGS, 1983) was recorded at Dworshak Dam $(330 \mathrm{~km}$ from epicenter), Lucky Peak Dam (179 km from epicenter), and at Ririe Dam (180 km from epicenter) which was constructed and instrumented by USACE but is presently owned and operated by the USBR. The 1987 Whittier Narrows earthquake was recorded at Brea, Carbon Canyon, Prado, San Antonio, Sepulveda, and Whittier Narrows Dams. No SMIP instruments were triggered during the October 1989 Loma Prieta, California, earthquake $\left(M_{s}=7.1\right)$. The nearest USACE project (New Hogan Dam, California) was located more than $130 \mathrm{~km}$ from the epicenter. More recently, the magnitude $5.8 \mathrm{M}_{\mathrm{L}}$ "Sierra Madre" earthquake of 28 June 1991 in the Los Angeles area was recorded by USACE instruments at seven sites. On 22 April 1992, the magnitude $6.1 \mathrm{M}_{\mathrm{w}}$ Joshua Tree earthquake epicentered near Desert Hot Springs, CA, was recorded by six USACE instruments. Most noteworthy, however, were numerous records obtained as a result of the 17 January 1994 Northridge, California $M_{s}=6.6$ earthquake. Example records are shown in Figures 19-21. Numerous other less significant earthquakes were also recorded. 
It is interesting to note that the data displayed in Figures 19 and 20 were digitally recorded, whereas Figures 21 and 22 show analog recordings. It is readily apparent that the digital records, which can be scaled upon retrieval, show greater clarity and detail for "quick look" analysis. Analog records must be digitized or optically magnified for more than a cursory analysis.

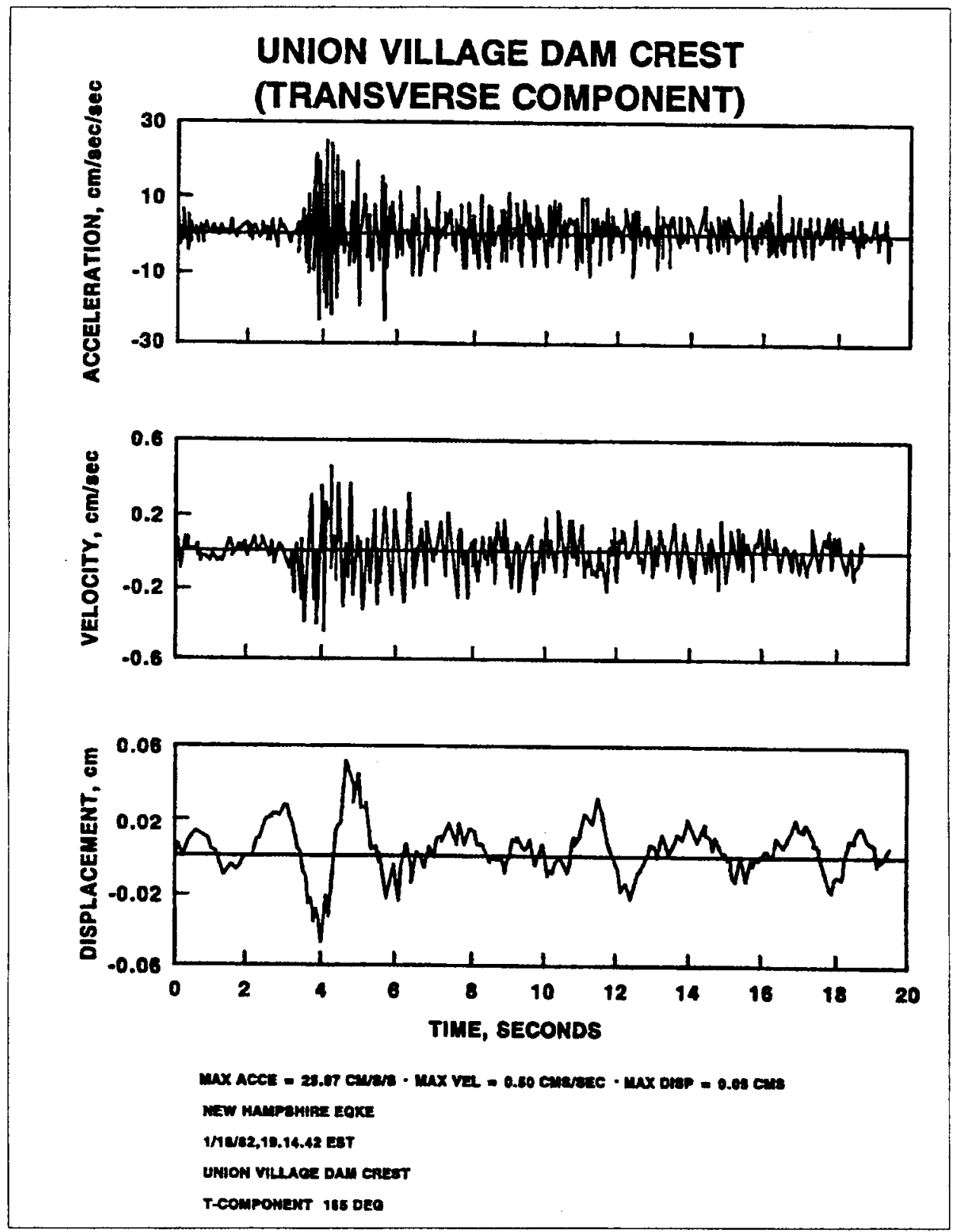

Figure 18. New Hampshire earthquake of 1982. Transverse component, Union Village Dam crest 


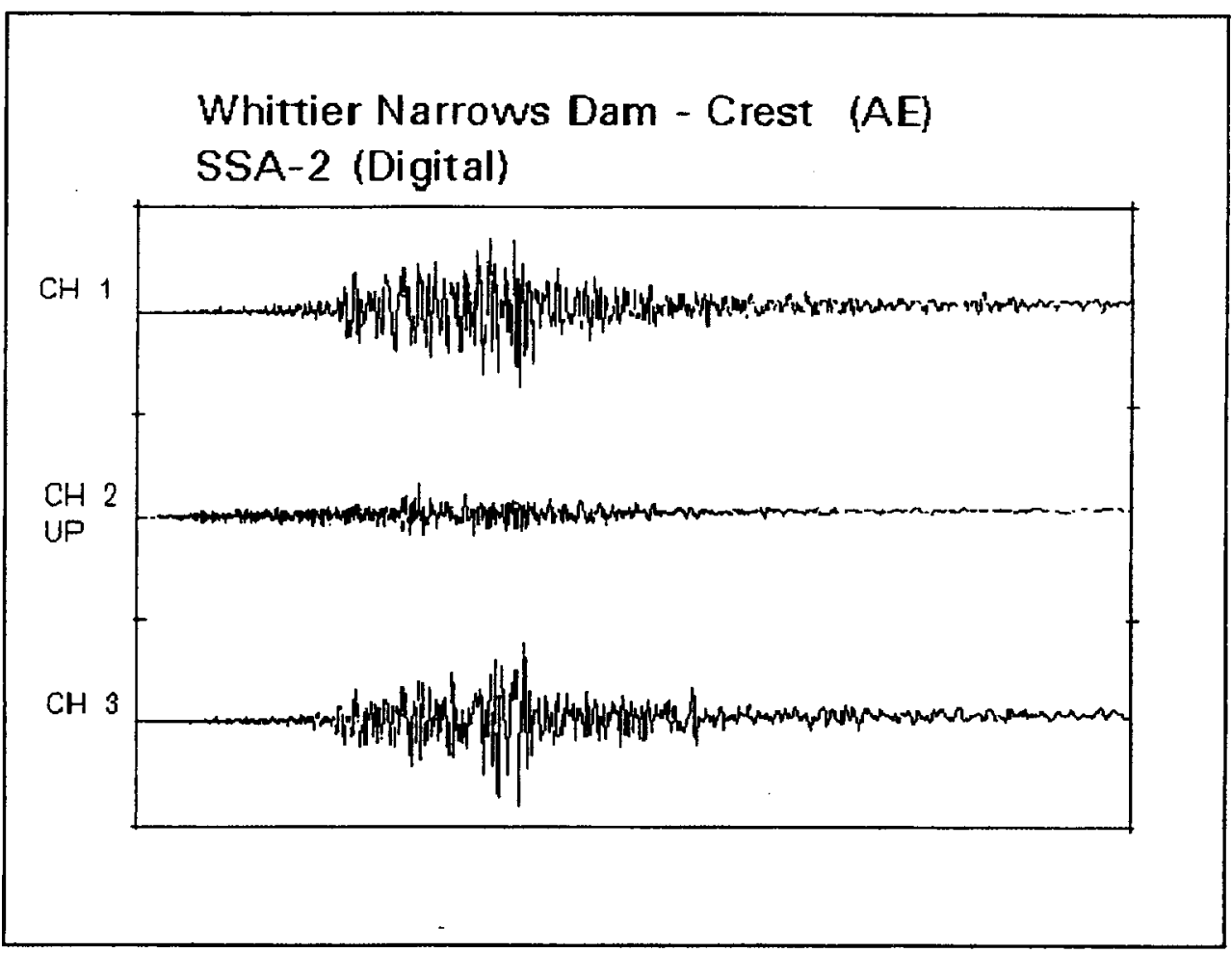

Figure 19. Example record of 17 January 1994 Northridge, $C A M_{s}=6.6$ earthquake (No. 1) (Porcella, et al, 1994)

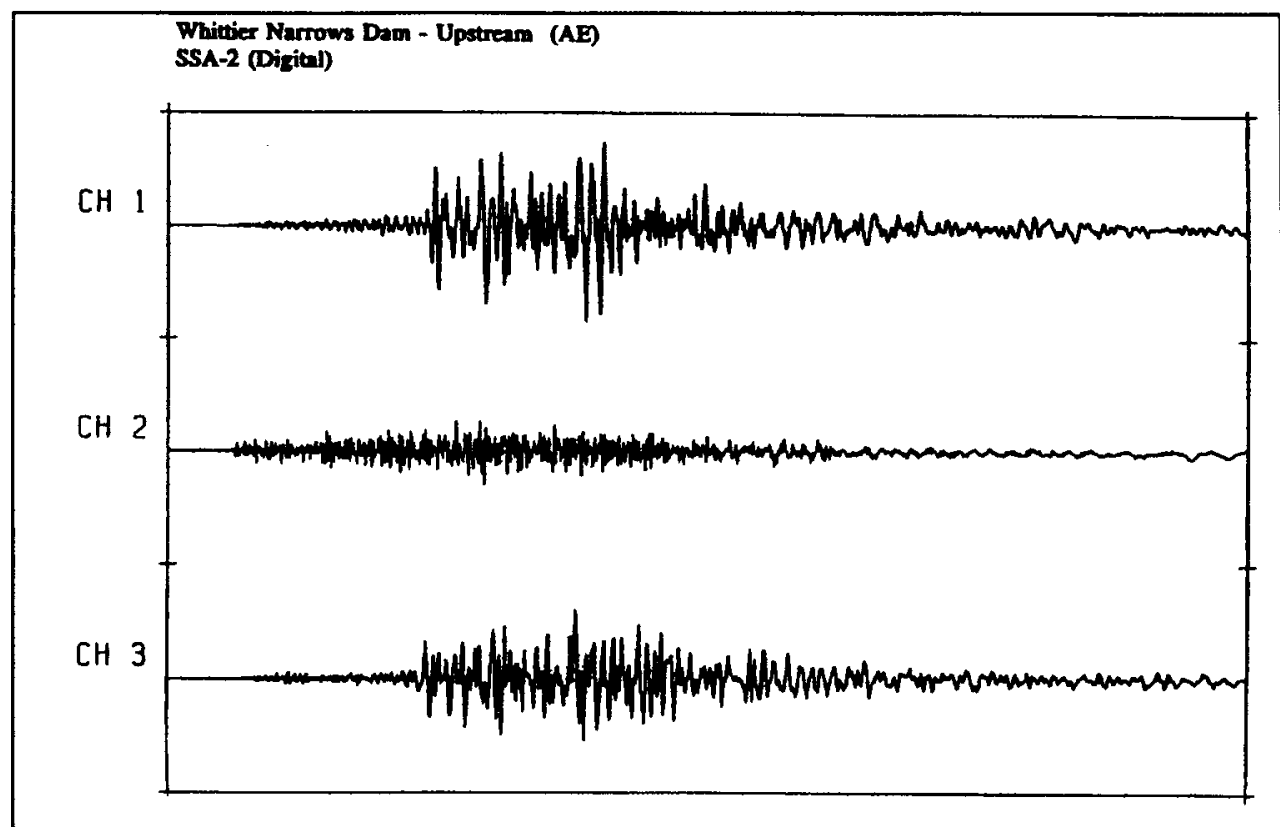

Figure 20. Example record of 17 January 1994 Northridge, $C A M_{s}=6.6$ earthquake (No. 2) 
Prado Dam - Downstream (AE)

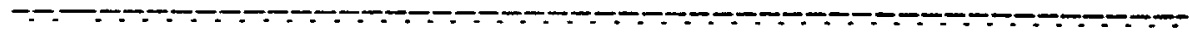

(1)

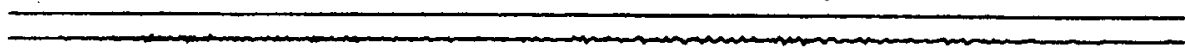

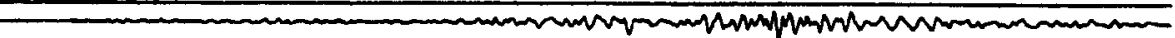

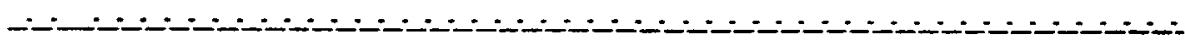

Figure 21. Example record of 17 January 1994 Northridge, $C A M_{s}=6.6$ earthquake (No. 3)

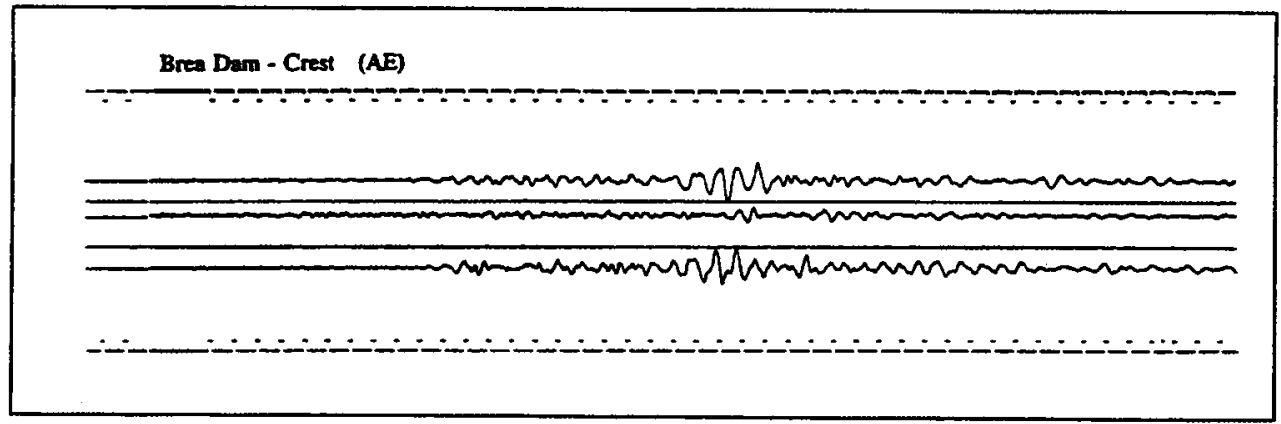

Figure 22. Example record of 17 January 1994 Northridge, $C A M_{s}=6.6$ earthquake (No. 4) 


\section{Current Status and Future Goals}

In the beginning, the SMIP was designed to provide insight into the safety of, and to act as an inspection guide for existing and future structures. It was devised to provide a measure of project performance and design performance comparisons, and to act as a database for performance predictions and earthquake research. These goals are being achieved. Because of the relatively short recorded history of seismic events in the United States, seismic risk maps are continually updated but still can only give an approximation of the longterm hazard.

As additional information is gained and technological advances made, both in terms of instrumentation and analytical seismic analysis techniques, more reliable assessments of USACE projects will be made. As confidence is gained, many of the very conservative assumptions now being used to assess structure stability will undoubtedly be revised to more realistically address the problem. Thus, many structures considered borderline by today's standards can be conclusively assessed as safe by future standards thereby eliminating or drastically modifying expensive remedial actions. These measures will invariably result in reduced costs.

A second goal, minimizing on-site inspections after earthquakes, has already proven feasible in areas of high earthquake activity through the development and installation of seismic alarm devices on USACE projects. Following an event, site personnel can readily determine if any of the preset threshold levels were reached. After enough data are obtained through the SMIP, an acceptable threshold level of acceleration can be safely established for individual structures. Inspections would be required only if that threshold level is exceededthereby saving numerous operational man-hours. An automatic telephone dialer, highly desirable for unmanned structures, can be incorporated to relay information to district or division offices.

In the normal course of technological improvements in instrumentation, it is expected that digital accelerographs will ultimately replace analog instruments and could even be used as "seismic alarm" devices. Performance and reliability evaluation of digital devices is an ongoing goal of the SMIP. As performance 
evaluations show continued positive signs of reliability, recommendations will be made to incorporate specific models which meet SMIP criteria. A prime objective of the strong-motion instrumentation program is to automate data acquisition and instrument status, via computer modem or FM radio telemetry remote capability, for better response and control of the network. The first working example of this concept was installation of a stand-alone digital accelerograph at Olmsted Dam (Louisville District). This instrument was installed during January 1995 and can be queried by modem. Additional instruments have since been installed at Yatesville Dam (Huntington District). These remotely located accelerographs are pioneering the use of solar-powered cellular telephones for modem operation.

As the transition to digital instruments continues, incentives are being offered to Corps agencies to promote the upgrade. WES and USGS have agreed to reduce digital service visits to a biennial mode. Digital instruments utilizing modems and telephone lines will be queried from WES on a monthly basis. If a malfunction is noted, on-site personnel will be informed and guided through checkout procedures. If a "fix" cannot be achieved, that instrument will be repaired by WES or USGS personnel during the next scheduled service visit. A dramatic service cost reduction (by as much as a factor or three) is anticipated using this procedure. The biennial on-site visit will be necessary for normal maintenance and battery replacement. 


\section{References}

Algermissen, S. T. (1969). "Seismic risk studies in the United States." Proceedings, 4th World Conference on Earthquake Engineering, Santiago, Chile.

Ballard, R. F., Jr., Comes, G. D., and Sykora, D. W. (1990). "Overview of the U.S. Army Corps of Engineers Seismic Strong-Motion Instrumentation Program (SMIP)," Proceedings Symposium on Engineering Geology and Geotechnical Engineering, Pocatello, Idaho.

Chang, F. K. (1983). "Analysis of strong-motion data from the New Hampshire Earthquake of 18 January 1982," Report NUREG/CR-3327, U.S. Nuclear Regulatory Commission, Washington, D.C.

Chang, F. K. (1985). "Analysis of strong-motion data from the Mount Borah, Idaho, Earthquake of 28 October 1983," Miscellaneous Paper GL-85-12, U.S. Army Engineer, Waterways Experiment Station, Vicksburg, MS.

Chang, F. K. (1987). "Response spectral analysis of Franklin Falls Dam, New Hampshire," Miscellaneous Paper GL-87-1, U.S. Army Engineer Waterways Experiment Station.

Crouse, C. B., and Hushmand, B. (1989). "Soil-structure interaction at CDMG and USGS accelerograph stations," Bulletin of the Seismological Society of America, Vol 79, No. 1, pp 1-14.

Crouse, C. B., Hushmand, B., Luco, J. E., and Wong, H. L. (1990).

"Foundation impedance functions: theory versus experiment," Journal of Geotechnical Engineering, ASCE, Vol 116, No. 3, pp 432-449.

D'Appolonia, E. (1990). "Monitored decisions," Journal of Geotechnical Engineering, ASCE, Vol 116, No. 1, pp 4-34.

Department of the Army. (1976 Nov). "Instrumentation of earth and rock-fill dams," Part 2 of 2, EM 1110-2-1908, USACE, Washington, DC. 
. (1979 Jul). "Engineering and design: reporting earthquake effects," ER 1110-2-1802, Office of the Chief of Engineers, Washington, DC.

. (1981 Dec). "Engineering and design: strong-motion instruments for recording earthquake motions on dams," ER 1110-2-103, USACE, Washington, DC.

. (1992 Jul). "Engineering and design: dam safety - organization, responsibilities, and activities," ER 1110-2-1156, USACE, Washington, DC.

- (1995 Jun). "Engineering and design: instrumentation of embankment dams and levees," EM 1110-2-1908, USACE, Washington, DC.

(1995 Jul). "Engineering and design: earthquake design and evaluation for civil works projects," ER 1110-2-1806, USACE, Washington, DC.

Porcella, R. L., Etheredge, E. C., Maley, R. P., and Acosta, A. V. (1994 Feb). "Accelerograms recorded at USGS national strong-motion network stations during the Ms $=6.6$ Northridge, California Earthquake of January 17, 1994," Department of the Interior U. S. Geological Survey Open file Report 94-141.

U.S. Geological Survey. (1983). "Preliminary determination of epicenters, monthly listing," No. 43-83, National Earthquake Information Service, Golden, Co. 


\section{Appendix A Pertinent Strong-Motion Instrumentation Program Regulations}




\section{Engineering and Design EARTHQUAKE DESIGN AND EVALUATION FOR CIVIL WORKS PROJECTS}

\section{Purpose}

This regulation provides guidance and direction for the seismic design and evaluation for all civil works projects.

\section{Applicability}

This regulation is applicable to all HQUSACE elements and USACE commands having responsibilities for the planning, design, and construction of civil works projects.

\section{References}

References are listed in Appendix A.

\section{Policy}

The seismic design for new projects and the seismic evaluation or reevaluation for existing projects should be accomplished in accordance with this regulation. This regulation applies to all projects which have the potential to malfunction or fail during major seismic events and cause hazardous conditions related to loss of human life, appreciable property damage, disruption of lifeline services, or unacceptable environmental consequences. The effort required to perform these seismic studies can vary greatly. The scope of each seismic study should be aimed at assessing the ground motions, site characterization, structural response, functional consequences, and potential hazards in a consistent, well-integrated, and cost-effective effort that will provide a high degree

This regulation supersedes ER 1110-1-1806, dated 16 May 1983. of confidence in the final conclusions. Survival of operating equipment and utility lines is as essential as survival of the structural and geotechnical features of the project. When justifying circumstances exist, requests for departures from this policy should be submitted by the District Commander through the Division Commander to HQUSACE (CECW-E).

\section{General Provisions}

a. Project hazard potential. The classification in Appendix B is related to the consequences of project failure. Critical features are the engineering structures, natural site conditions, or operating equipment and utilities at high hazard projects whose failure during or immediately following an earthquake could result in loss of life. Such a catastrophic loss of life could result directly from failure or indirectly from flooding damage to a lifeline facility, or could pose an irreversible threat to human life due to release or inundation of hazardous, toxic, or radioactive materials. Project hazard potential should consider the population at risk, the downstream flood wave depth and velocity, and the probability of fatality of individuals within the affected population. All other features are not critical features.

b. esign. Seismic design for new projects shall include assessments of the potential earthquake motions and project features to ensure acceptable performance during and after design events. The level of design required to help ensure such performance is dependent upon whether or not seismic loadings control design, the complexity of the project, and the consequences of losing project service or control of the pool. The analysis should be performed in phases in order of increasing complexity. Continuity of the design process is important throughout each stage. The plan of study for each stage of design should be consistent with this regulation and with ER 1110-2-1150. An initial assessment of 
project hazards associated with the earthquake shall be included in the reconnaissance stage of study. The magnitude of seismic motions and an initial evaluation of key project features shall be included in the feasibility stage in design of sufficient detail to determine whether seismic loads control the design. Detailed seismic analysis should be completed during the design memorandum stage. Final detailing should be in the plans and specifications. In-progress review meetings should be accomplished early in the study and at key points within each phase.

c. Evaluation. Evaluation of existing project features differs from the design of new features. The evaluation of existing project features should be initiated for circumstances outlined in paragraph $5 d$. The evaluation begins with a careful review of the project foundation conditions and construction materials, and an understanding of design and construction practices at the time the project was built. Available information such as geological maps, boring logs, acceleration contour maps, standard response spectra, and as-built project records should be used to screen from further consideration project features that have adequate seismic designs, or for which seismic loads do not control the design. Detailed site explorations, site-specific ground motion studies, and structural analyses should be undertaken only for projects in zones 3 and 4 , or for zone $2 \mathrm{~A}$ and $2 \mathrm{~B}$ projects when seismic loads control the design. All potential modes of failure must be carefully evaluated using field investigations, testing, and appropriate analyses.

d. Basis. Existing project features, designed and constructed to older standards, may not provide adequate seismic protection, or a ductile response to earthquake ground motions for reinforced concrete structures. Evaluation or reevaluation of existing projects should be undertaken for one or more of the following reasons:

(1) Performance is inconsistent with the design intent during a major earthquake.

(2) An alteration of the project functions is made which could cause more stringent loading conditions (higher pools, more frequent high pools, or longer duration) during major earthquakes.

(3) An advance in the state of the art occurs which demonstrates that previous evaluations are inadequate or incomplete and potentially hazardous.
(4) Project modifications are made to improve operational conditions which adversely impact or reduce the seismic resistance of particular project features.

(5) Periodic inspection is required. Reevaluations should be conducted every third periodic inspection or every 15 years, whichever comes first.

e. Remediation. Bringing existing project features up to current seismic design standards is generally expensive. Expert judgment as well as appropriate linear elastic and nonlinear analytical studies may be required to clearly demonstrate the need for remediation. In instances where the capacity of the project feature is less than the earthquake demand, a risk assessment should be performed. The risk assessment should include a probabilistic seismic hazard analysis, as defined in paragraph $5 h(2)(b)$, to quantify the threshold event corresponding to failure. This information is needed to evaluate the urgency of remediation, and to justify funding for additional investigations and retrofit design. Downstream, nonstructural measures to reduce the project hazard should be considered as an alternative to seismic remediation.

f. Project team concept. Earthquake design or evaluation of civil works projects requires close collaboration of an interdisciplinary team that includes specialists in seismology, geology, material, and geotechnical and structural engineering. The team is responsible for establishing the earthquake engineering requirements for the project, planning and executing the seismological and engineering investigations, and evaluating results. A senior structural or geotechnical engineer should be responsible for leading the seismic design or evaluation studies related to the principal structural or geotechnical features, respectively, of the project. Technical experts should be included on the team to provide guidance on seismic policy, advice on the overall earthquake engineering requirements, and evaluation of results for the project, or to provide advice on specific aspects of the seismological and engineering investigations. This team should establish the scope of the entire seismic study early in the design or evaluation process to ensure that resources are being used efficiently and that the seismotectonic, geologic, site, and structural investigations are compatible and complete.

g. Consulting technical experts. Seismic design or evaluation of civil works projects is a rapidly evolving and highly complex field of earthquake engineering 
which requires special expertise and substantial judgment to be effective. In many instances, the project team should augment the inhouse staff with technical experts to ensure independent review of the methodology and results, to add credibility to the results, and to ensure public acceptance of the conclusions. Such experts should be drawn from the fields of geology, seismology, and structural and geotechnical earthquake engineering. These experts may be from within the U.S. Army Corps of Engineers, other government agencies, universities, or the private sector. Technical experts should be included in the early team planning sessions to assist in identifying the scope of earthquake problems, selecting approaches and criteria, reviewing results, and selecting interim and final seismic parameters. The experts shall participate with the team in meetings and provide memoranda of concurrence and summary advice which shall be a part of the formal record of design or evaluation.

h. Standard and site-specific studies. Seismic studies should include the seismotectonic, geologic, site, geotechnical, and structural investigations required to select the design ground motions, and to determine the foundation and structural response for the earthquake events applicable at the project site. Further guidance on the design and analysis requirements are provided in Appendices B-F.

(1) Standard seismic studies are based on existing generic seismological studies, available site data and information, and simplified methods of evaluation developed for similar projects or structures. Generally, standard studies use preliminary values of the ground motions obtained from published seismic zone maps, a preliminary structural analysis, and a simplified assessment of soil liquefaction and deformation to determine if seismic loadings control the design, and to set the scope of any proposed site-specific studies. Standard methods and data in the referenced guidance are useful for preliminary and screening investigations in all seismic zones, and may be satisfactory for final design or evaluation in seismic zones 1 or $2 \mathrm{~A}$.

(2) Site-specific studies involve the use of actual site and structural conditions in evaluating the project hazards and the response of project features to seismic loading. Detailed field exploration and testing programs should be carefully planned and executed. Geologic studies should describe the seismotectonic province, characterize the site, and investigate all faults that can affect the site. Seismologic investigations should describe the earthquake history, earthquake recurrence relationship, and the strong motion records to be used in design or evaluation. Special emphasis should be placed on identifying all geological, seismological, and geotechnical parameters necessary to encompass the design and response of foundations and structures. Structural investigations should accurately account for all relevant factors which affect the seismic hazard at the specific site and the actual dynamic behavior of the structure, including damping and ductility of the structural systems. Geotechnical investigations should determine the types and spatial distribution of foundation and embankment maturate and the engineering properties of soil and rock. Propagation of the ground motion through the foundation and embankment, liquefaction potential of foundation and embankment soils, stability of natural and artificial slopes, and estimates of deformations should also be determined. The final results of sitespecific studies are used as a basis for making design or evaluation decisions and for designing any remedial measures. Site-specific studies should be conducted for all zone 3 and 4 projects, and for zone $2 \mathrm{~A}$ and $2 \mathrm{~B}$ projects for which earthquake loadings control the design. There are two general approaches for conducting sitespecific seismic hazard analyses, which are described below:

(a) Deterministic seismic hazard analysis (DSHA). The DSHA approach uses the known seismic sources sufficiently near the site and available historical seismic and geological data to generate discrete, single-valued events or models of ground motion at the site. Typically one or more earthquakes are specified by magnitude and location with respect to the site. Usually the earthquakes are assumed to occur on the portion of the source closest to the site. The site ground motions are estimated deterministically, given the magnitude, sourceto-site distance, and site condition.

(b) Probabilistic seismic hazard analysis (PSHA). The PSHA approach uses the elements of the DSHA and adds an assessment of the likelihood that ground motions will occur during the specified time period. The probability or frequency of occurrence of different magnitude earthquakes on each significant seismic source and inherent uncertainties are directly accounted for in the analysis. The results of a PSHA are used to select the site ground motions based on the probability of exceedance of a given magnitude during the service life of the structure or for a given return period. 


\section{Design Earthquakes and Ground Motions}

a. Maximum credible earthquake (MCE). This earthquake is defined as the greatest earthquake that can reasonably be expected to be generated by a specific source on the basis of seismological and geological evidence. Since a project site may be affected by earthquakes generated by various sources, each with its own fault mechanism, maximum earthquake magnitude, and distance from the site, multiple MCE's may be defined for the site, each with characteristic ground motion parameters and spectral shape. The MCE is determined by a DSHA.

b. Maximum design earthquake ( $M E$ ). The MDE is the maximum level of ground motion for which a structure is designed or evaluated. The associated performance requirement is that the project perform without catastrophic failure, such as uncontrolled release of a reservoir, although severe damage or economic loss may be tolerated. For critical features, the MDE is the same as the MCE. For all other features, the MDE shall be selected as a lesser earthquake than the MCE which provides economical designs meeting appropriate safety standards. The MDE can be characterized as a deterministic or probabilistic event.

c. Operating basis earthquake (OBE). The OBE is an earthquake that can reasonably be expected to occur within the service life of the project, that is, with a 50-percent probability of exceedence during the service life. (This corresponds to a return period of 144 years for a project with a service life of 100 years.) The associated performance requirement is that the project function with little or no damage, and without interruption of function. The purpose of the OBE is to protect against economic losses from damage or loss of service, and therefore alternative choices of return period for the OBE may be based on economic considerations. The OBE is determined by a PSHA.

\section{d. Estimating $O B E$ and $M E$ ground motions.}

Estimates are usually made in two phases. The first estimates are used as a starting point for the study and are obtained from the National Earthquake Hazard Reduction Program (NEHRP) spectral acceleration maps (Appendix D). Site-specific studies in accordance with paragraph $5 h(2)$ are often required for selecting the final estimates of OBE and MDE ground motions. Both DSHA and PSHA approaches are appropriate. Combining the results of deterministic and probabilistic analyses is often an effective approach for selecting MDE ground motions. Typical results of a probabilistic analysis are a hazard curve and an equal hazard spectrum which relate the level of ground motion to an annual frequency of exceedance or return period. This information can be used to complement the deterministic analysis by removing from consideration seismic sources that appear unreasonable because of low frequencies of occurrence, by justifying mean or mean-plus-standard deviation estimates of deterministic ground motion, or by ensuring consistency of MDE ground motions with some performance goal.

\section{Site Characterization}

a. Site studies. The two primary concerns in the site characterization for a project are: the effects of the ground motion on the site, such as loss of strength in foundation materials and instability of natural slopes; and the effects of soil strata and topographic conditions (basin effects, or ray path focus) on the propagation of the specified ground motion from rock outcrop to a particular project feature. The objective of a site characterization study is to obtain all of the data on the site conditions that are essential to design or to operate a project safely. Relevant site conditions normally include topographic and hydrologic conditions; the nature and extent of the material present in the foundation, embankment, natural slopes, and structures at the site; and the physical and dynamic engineering properties (such as modulus, damping, and density) of these materials. The site characterization should be of a progressive nature starting with the information from available sources on the geology, seismicity, and project features at the site. This should include a description of the site geology, seismicity such as known faulting in the region, seismic history, and prior relevant seismic evaluations in the vicinity, and any known data related to specific project features at the site or proposed for the site.

b. New projects. For new projects, field exploration and material testing programs should be developed to identify the stratigraphy and the physical and engineering properties of the foundation materials for the project features. Prior field investigations in the area of the project may also be used to provide additional information.

c. Existing projects. For evaluation or re-evaluation of existing projects, new field investigations may be required where available data are insufficient to resolve all significant safety issues. The project team should 
integrate this information into the decisionmaking process for designs or resolution of safety issues.

\section{Concrete and Steel Structures and Substructures}

a. Role of structural engineers. Appropriate methods for seismic studies vary greatly with the type of structure or substructure. Structural engineers should be involved in the selection of ground motions from the earliest stages of study. Their understanding as to how the ground motions will be used in the structural analysis as it proceeds through progressively more sophisticated stages is needed to reach definitive conclusions and make sound decisions. The structural engineer needs to establish how response spectra from standard and site-specific studies and time-histories from sitespecific studies will be used in the progressive stages of the structural investigations. This progression is related to the level of accuracy or sophistication of the model needed, and to all the uncertainties which must be dealt with correctly and consistently so that the final result will be reliable and safe but not overly conservative and unnecessarily expensive.

b. esign standards. Minimum standards for the seismic design or evaluation of buildings and bridges are available in national, regional, or local building codes, in Tri-Service technical manuals, and in Federal and state design specifications for highway systems. New building designs and upgrades to existing buildings shall be in accordance with the provisions of Tri-Service manuals TM 5-809-10 and TM 5-809-10-1. Existing buildings conforming to the seismic requirements of the Uniform Building Code, the National Building Code, or the Standard Building Code, including their 1992 supplements and additions, need not follow the seismic design provisions of TM 5-809-10. Bridges on projects which are open to public access shall be designed or evaluated in accordance with the American Association of State Highway Transportation Officials and state design standards.

c. Code requirements. Seismic code requirements for concrete and steel hydraulic structures (CSHS) have not been developed as fully as those for buildings and bridges. Design guidance for CSHS shall be in accordance with the references in Appendix A.

d. Load combinations. Design loading combinations for CSHS shall be in accordance with the referenced guidance for specific structures. In general,
CSHS shall have adequate stability, strength, and serviceability to resist an OBE and MDE. The structural and operating requirements are different for these two levels of earthquakes, and either level may control the design or evaluation. The structure should essentially respond elastically to the $O B E$ event with no disruption to service. The structure may be allowed to respond inelastically to the MDE event, which may result in significant structural damage and limited disruption of services, but the structure should not collapse or endanger lives. Economic considerations will be a factor in determining the acceptable level of damage. For critical structures, the MDE is equal to the MCE. In general, the OBE is an unusual loading condition, and the MDE is an extreme loading condition.

e. Analysis methods. Techniques used to evaluate the structural response to earthquake ground motions include seismic coefficient methods, response spectrum methods, and time-history methods. Details of these methods of analysis may be found in the references in Appendix A. Simplified response spectrum analysis procedures are available for analysis of some types of CSHS, for example concrete gravity dams and intake towers (Chopra 1987, Chopra and Goyal 1989). These methods utilize idealized cross-sections and make various assumptions concerning the structure's response to ground motions and its interaction with the foundation and reservoir. The validity of these assumptions must be carefully examined for each project prior to using any simplified analysis procedure; however, in most cases, these methods will be sufficient for use in feasibility level studies. The seismic coefficient method should not be used for final design of any structure where an earthquake loading condition is the controlling load case. Final designs in seismic zones 3 and 4 should use either response spectrum or time-history methods.

f. Input from ground motion studies. Site-specific ground motion studies required in accordance with paragraph $5 h(2)$ should provide magnitude, duration, and site-specific values for the peak ground acceleration (PGA), peak ground velocity (PGV), peak ground displacement (PGD), and design response spectra and time-histories in both the horizontal and vertical directions at the ground surface or a rock outcrop as a minimum. Site-specific studies should also consider soil-structure interaction effects which may reduce ground motions at the base of the structure.

g. Analysis progression. An important aspect of the design or evaluation process is to develop an analytical 
model of the structure and substructure which adequately represents the seismic behavior. The analysis process should be performed in phases, in order of increasing complexity, beginning with simplified empirical procedures. These procedures are based on satisfactory experience with similar types of structural materials and systems, and observations of failure due to strong ground motions. These general requirements are outlined in Appendix E. Performing the analysis in phases will ensure that the analytical model is providing realistic results and will provide a logical basis for decisions to revise the structural configuration and/or proceed to a more accurate analysis method. The structural analysis can range from simple two-dimensional (2D) beam models to sophisticated three-dimensional (3D) finite element models. All three components of ground motion may be required to capture the total system response. Dynamic analyses of most massive concrete structures usually require a model which includes interaction with the surrounding soil, rock, and water to produce meaningful results. Differences in structural shapes and variations in foundation materials or ground motion should be accounted for in evaluating the spatial variation in response between points on large structures. The structural significance of the mode shapes must be understood, especially when evaluating the stresses using a response spectrum analysis. The results of a finite element analysis of a reinforced concrete structure should be expressed in terms of moment, thrust, and shear, not just linear stresses at a point, in order to correctly evaluate the behavior of the reinforced crosssection. Areas where inelastic behavior is anticipated should be identified and concrete confinement requirements stated. In general, linear time-history methods applied to $2 \mathrm{D}$ or $3 \mathrm{D}$ models will provide the most complete understanding of structural performance during an earthquake. If a design is found to be inadequate using linear time-history methods of analysis, then nonlinear time-history methods should be considered. Such methods are beyond the scope of this policy, and shall be conducted in consultation with CECW-ED.

h. Seismic design principles. It is important to incorporate sound seismic engineering concepts in all aspects of the design or evaluation process. In all instances the design engineer should ensure that the structural configuration has minimum geometric irregularities, there are only gradual variations in structural stiffness, and any necessary structural discontinuities are properly detailed to account for the localized effects of stress concentrations. Continuous load paths, load path redundancy, and ductile behavior are important safe-guards to ensure that structures loaded past their elastic limit will continue to perform adequately and will function after extensive cracking. An example of load path redundancy is to lay out concrete gravity dams with a curved axis and keyed monolith joints. This will permit loads to be redistributed to the abutments even if the base foundation is weakened or displaced by an earthquake.

\section{Embankments, Slopes, and Soil Foundations}

a. General. The seismic evaluation and design of soil foundations, slopes, and embankments involves the interaction of geologists, seismologists, and geotechnical engineers. The activities for this effort can be grouped into four main areas: field investigations, site characterization, numerical analyses, and evaluation. It is essential that the investigations and site characterization adequately portray the nature, extent, and in-situ physical properties of the materials in the foundation, embankment, or slope being investigated.

b. Embankments. Appropriate methods should be used to analyze the liquefaction potential and/or to estimate deformations for embankment (dams, dikes, levees that retain permanent pools), slope, and foundation materials when subjected to ground motions corresponding to the MDE and the OBE.

c. Slopes and foundations. Slopes to be analyzed should include natural, reservoir rim, and other slopes, with or without structures, with the potential to affect the safety or function of the project. Foundation materials to be analyzed for liquefaction of the project include all foundation soils that support project features or the liquefaction of which would affect project features. The results of investigations and data review as described in paragraph 7 and the seismological evaluation will determine the appropriate methods, including dynamic analysis, to be performed on the project.

d. Evaluations. Evaluations of embankment, slope, and/or foundation susceptibility to liquefaction or excessive deformation will be performed for all projects located in seismic zones 3 and 4, and those projects in zone 2 where materials exist that are suspected to be susceptible to liquefaction or excessive deformation. Such evaluation and analysis should also be performed regardless of the seismic zone location of the project, where capable faults or recent earthquake 
epicenters are discovered within a distance that may result in damage to the structure.

e. Defensive design measures. Defensive design features should be incorporated in the foundation and embankment design regardless of the method of seismic analysis. These details of these features should be optimized based on the results of the analysis. Defensive features include:

(1) Additional dam height to accommodate the loss of crest elevation due to deformation, slumping, and fault displacement.

(2) Crest details that will minimize erosion in the event of overtopping.

(3) Wider transition and filter sections as a defense against cracking.

(4) Use of rounded or subrounded gravel and sand as filter material.

(5) Adequate permeability of the filter layers.

(6) Near vertical drainage zones in the central portion of the embankment.

(7) Zoning of the embankment to minimize saturation of materials.

(8) Wide impervious cores of plastic clay materials to accommodate deformation.

(9) Well-graded core and filter materials to ensure self healing in the event cracking should occur.

(10) Stabilization of reservoir rim slopes to provide safety against large slides into the reservoir.

(11) Removal and replacement of liquefaction susceptible material in the foundation.

(12) In-situ densification of foundation materials.

(13) Stabilization of slopes adjacent to operating facilities to prevent blockage from a slide associated with the earthquake.

(14) Flaring embankment sections at the abutment contacts.

\section{Actions for New Projects}

For new projects, the phases of study required for the seismic analysis and design shall be in accordance with ER 1110-2-1150 and shall progress as described in Appendix E. These requirements are summarized below.

a. Reconnaissance phase. This study phase shall include the initial assessment of the seismic ground motions at the project site for each of the design earthquakes, the potential impact of these motions on the project's design, and the engineering effort required for the seismic design during the feasibility study phase. If no site-specific ground motions are available for the design earthquakes, the ground motions can be estimated as described in paragraph $6 d$.

b. Feasibility phase. This study phase shall include the preliminary seismic analysis and design of the key features of the project in sufficient detail to prepare the baseline cost estimate and determine the contingencies appropriate for the level of sophistication of the analysis. The preliminary seismic analysis should also be of sufficient detail to develop a design and construction schedule, and allow detailed design on the selected plan to begin immediately following approval of the feasibility report. For projects for which seismic loads control the design, the feasibility study phase should include site-specific studies to determine the design ground motions and preliminary stability and response spectra analyses for design of the project.

c. Design memorandum phase. This study phase requires a seismic analysis and design in sufficient detail to serve as the basis for preparing plans and specifications (P\&S). Subsequent engineering for preparing the $P \& S$ should generally be limited to detailing and preparing specifications. The design memorandum study phase will also include detailed site-specific studies to determine the design ground motions $2 \mathrm{D}$ and $3 \mathrm{D}$ response spectrum analyses, and time-history analyses. When the project studies proceed directly to $P \& S$ from the feasibility phase, the design memorandum seismic studies should be conducted during the feasibility stage or as a separate study prior to the $P \& S$ phase.

\section{Actions for Existing Projects}

For existing projects, the phases of study required for seismic analysis shall be in accordance with ER 1110-21155 or the current major rehabilitation program 
guidance as provided by $\mathrm{CECW}-\mathrm{O}$. These requirements are summarized below and in Appendix F.

a. Preliminary evaluation. When an evaluation of existing project features must be initiated for reasons stated in paragraph $5 d$, the preliminary results should be presented in a Dam Safety Assurance or Major Rehabilitation Evaluation Report (DSAER or MRER, respectively) using the latest guidance. The report will adequately explain the seismic deficiency, and will outline additional investigations necessary to access the risk and to upgrade the project to meet current seismic criteria. This report will be submitted to HQUSACE, through the major subordinate command, for approval. b. Special studies. After approval of the DSAER or MRER, special studies may be required, and should proceed in three phases as defined in the current major rehabilitation program guidance as provided by CECW-O. Phase one studies can be reported as a letter report addendum to the evaluation report or as a supplement to an existing design memorandum. Phase two studies should be reported in a design memorandum.

\section{Funding}

General Investigation, Construction General, or Operation and Maintenance General funds should be used as appropriate to accomplish the investigations.

FOR THE COMMANDER:

6 Appendices

APP A - References

APP B - Hazard Potential Classification

for Civil Works Projects

APP C - Uniform Building Code Seismic

Zone Map

APP D - National Earthquake Hazard Reduction

Program Spectral Acceleration Maps

APP E - Progressive Seismic Analysis

Requirements for Concrete and Steel

Hydraulic Structures

APP F - Design and Analysis Requirements

for Seismic Evaluation Reports

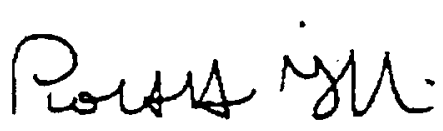

ROBERT H. GRIFFIN

Colonel, Corps of Engineers

Chief of Staff 


\section{APPENDIX A \\ REFERENCES}

\section{A-1. Required Publications}

ER 1110-2-1150

Engineering and Design for Civil Works Projects

ER 1110-2-1155

Dam Safety Assurance

TM 5-809-10/NAVFAC P-355/AFM 88-3, Chap. 13, Sec A

Seismic Design for Buildings

TM 5-809-10-1/NAVFAC P-355.1/AFM 88-3,

Chap. 13, Sec A

Seismic Design Guidelines for Essential Buildings

\section{Chopra 1987}

Chopra, A. K. 1987. "Simplified Earthquake Analysis of Concrete Gravity Dams," ASCE Journal of the Structural Division, 113 ST8.

\section{Chopra and Goyal 1989}

Chopra, A. K., and Goyal, A. 1989. "Earthquake Analysis and Response of Intake-Outlet Towers," Report No. UCB/EERC-89-04, Earthquake Engineering Research Center, University of California, Berkeley, CA.

\section{A-2. Related Publications}

\section{EM 1110-2-1902}

Stability of Earth and Rockfill Dams

EM 1110-2-2200

Gravity Dam Design

\section{EM 1110-2-2201}

Arch Dam Design

Algermissen 1983

Algermissen, S. T. 1983. "An Introduction to the Seismicity of the United States," Earthquake Engineering Research Institute, Berkeley, CA.

\section{Chopra 1981}

Chopra, A. K. 1981. Dynamics of Structures, A Primer, Earthquake Engineering Research Institute, Berkeley, CA.

\section{Clough and Penzien 1993}

Clough, R. W., and Penzien, J. 1993. Dynamics of Structures, McGraw-Hill, New York.

\section{Cornell 1968}

Comell, C. A. 1968. "Engineering Seismic Risk Analysis," Bulletin of the Seismological Society of America, Vol 58, pp 1583-1606.

Earthquake Engineering Research Institute Committee on Seismic Risk 1989. "The Basics of Seismic Risk Analysis," Earthquake Spectra, Vol 5, pp 675-702.

\section{Ebeling 1992}

Ebeling, R. M. 1992. "Introduction to the Computation of Response Spectrum for Earthquake Loading," Technical Report ITL-92-11, U.S. Army Engineer Waterways Experiment Station, Vicksburg, MS.

FEMA 1992

Federal Emergency Management Administration. 1992. "NEHRP Recommended Provisions for the Development of Seismic Regulations for New Buildings," 1991 Edition, FEMA 222 and 223, Washington DC.

Finn et al. 1986

Finn, W. D. L., Yogendrakumar, M., Yoshida, N., and Yoshida H. 1986. "TARA-3: A Program to Compute the Response of 2-D Embankments and Soil-Structure Interaction Systems to Seismic Loadings," Department of Civil Engineering, University of British Columbia, Vancouver, Canada.

\section{Housner and Jennings 1982}

Housner, G. W., and Jennings, P. C. 1982. "Earthquake Design Criteria," Earthquake Engineering Research Institute, Berkeley, CA.

\section{Hudson 1979}

Hudson, D. E. 1979. "Reading and Interpreting Strong Motion Accelograms; Engineering Monographs on Earthquake Criteria, Structural Design, and Strong Motion Records," Vol 1, Earthquake Engineering Research Institute, Berkeley, CA. 
Hynes-Griffin and Franklin 1984

Hynes-Griffin, M. E., and Franklin, A. G. 1984. "Rationalizing the Seismic Coefficient Method," Miscellaneous Paper GL-84-13, U.S. Army Engineer Waterways Experiment Station, Vicksburg, MS.

International Committee on Large Dams 1989 International Committee on Large Dams. 1989. "Selecting Seismic Parameters for Large Darns," Guidelines, Bulletin 72 .

\section{Krinitzsky and Chang 1987}

Krinitzsky, E. L., and Chang, F. K. 1987. "Parameters for Specifying Intensity-Related Earthquake Ground Motions," Report 25, "State-of-the-Art for Assessing Earthquake Hazards in the United States," Miscellaneous Paper S-73-1, U.S. Army Engineer Waterways Experiment Station, Vicksburg, MS.

\section{Makdisi and Seed 1978}

Makdisi, F. I., and Seed, H. B. 1978. "Simplified Procedure for Estimating Dam and Embankment Earthquake Induced Deformations," Journal of the Geotechnical Engineering Division, ASCE, Vol 104, No. GT7, pp 849-867.

Marcusen, Hynes, and Franklin 1990

Marcusen, W. F., III, Hynes, M. E., and Franklin, A. G. 1990. "Evaluation and Use of Residual Strength in Seismic Safety Analysis of Embankments," Earthquake Spectra, Vol 6, No. 3, pp 529-572.

\section{National Research Council 1988}

National Research Council. 1988. "Probabilistic Seismic Hazard Analysis," National Academy Press, Washington, $\mathrm{DC}$.

\section{Newmark and Hall 1982}

Newmark, N. M., and Hall, W. J. 1982. "Earthquake Spectra and Design; Engineering Monographs on Earthquake Criteria, Structural Design, and Strong Motion Records," Vol 3, Earthquake Engineering Research Institute, Berkeley, CA.
Newmark and Rosenbleuth 1971

Newmark, N. M., and Rosenbleuth, E. 1971. Fundamentals of Earthquake Engineering, Prentice-Hall, Englewood Cliffs, N.J.

\section{Poulos, Castro, and France 1985}

Poulos, S. J., Castro, G., and France, J. W. 1985. "Liquefaction Evaluation Procedure," Journal of Geotechnical Engineering Division, ASCE, Vol 111, No. 6, pp 772-792.

Poulos, 1988

Poulos, S. J. 1988. "Liquefaction and Related Phenomena," Advanced Dam Engineering for Design and Construction and Rehabilitation, Ch. 9, Robert B. Jansen, ed. Van Nostrand Reinhold, New York.

\section{Reiter 1990}

Reiter, L. 1990. Earthquake Hazard Analysis, Issues and Insights, Columbia University Press, New York.

Seed et al. 1975

Seed, H. B., Lee, K. L., Idriss, I. M., and Makdisi, F. I. 1975. "The Slides in the San Fernando Dams During the Earthquake of February 9, 1971," Journal of Geotechnical Engineering Division, ASCE, Vol 101, No. GT7, pp 651-688.

Seed 1979

Seed, H. B. 1979. "Soil Liquefaction and Cyclic Mobility Evaluation for Level Ground During Earthquake," Journal of Geotechnical Engineering Division, ASCE, Vol 105, No. GT2, pp 201-225.

Seed 1979

Seed, H. B. 1979. "19th Rankine Lecture: Considerations in the Earthquake Design of Earth and Rockfill Dams," Geotechnique, Vol 29, No. 3, pp 215-263.

Seed, Idriss, Arango 1983

Seed, H. B., Idriss, I. M. and Arango, I. 1983. "Evaluation of Liquefaction Potential Using Field Performance Data," Journal of Geotechnical Engineering Division, ASCE, Vol 1005, No. 3, pp 458-482. 


\section{APPENDIX B \\ HAZARD POTENTIAL CLASSIFICATION FOR CIVIL WORKS PROJECTS}

\begin{tabular}{|c|c|c|c|c|}
\hline \multicolumn{5}{|c|}{$\begin{array}{c}\text { Table B-1 } \\
\text { Hazard Potential Classification }\end{array}$} \\
\hline Category' & $\begin{array}{l}\text { Direct } \\
\text { Loss of Life }\end{array}$ & $\begin{array}{l}\text { Lifeline } \\
\text { Losses }^{3}\end{array}$ & $\begin{array}{l}\text { Property } \\
\text { Losses }^{4}\end{array}$ & $\begin{array}{l}\text { Environmental } \\
\text { Losses }^{5}\end{array}$ \\
\hline Low & $\begin{array}{l}\text { None (rural location, no } \\
\text { permanent structures } \\
\text { for human habitation) }\end{array}$ & $\begin{array}{l}\text { No disruption of services } \\
\text { (cosmetic or rapidly } \\
\text { repairable damage) }\end{array}$ & $\begin{array}{l}\text { Private agricultural } \\
\text { lands, equipment, and } \\
\text { isolated buildings }\end{array}$ & $\begin{array}{l}\text { Minimal incremental dam- } \\
\text { age }\end{array}$ \\
\hline Significant & $\begin{array}{l}\text { Rural location, only } \\
\text { transient or day-use } \\
\text { facilities }\end{array}$ & $\begin{array}{l}\text { Disruption of } \\
\text { essential facil- } \\
\text { ities and access }\end{array}$ & $\begin{array}{l}\text { Major public and pri- } \\
\text { vate facilities }\end{array}$ & $\begin{array}{l}\text { Major mitigation } \\
\text { required }\end{array}$ \\
\hline High & $\begin{array}{l}\text { Certain (one or more) exten- } \\
\text { sive residential, } \\
\text { commercial, or indus- } \\
\text { trial development }\end{array}$ & $\begin{array}{l}\text { Disnuption of } \\
\text { critical facil- } \\
\text { ities and access }\end{array}$ & $\begin{array}{l}\text { Extensive } \\
\text { public and pri- } \\
\text { vate facilities }\end{array}$ & $\begin{array}{l}\text { Extensive } \\
\text { mitigation cost } \\
\text { or impossible } \\
\text { to mitigate }\end{array}$ \\
\hline $\begin{array}{l}1 \text { Categorie } \\
2 \text { Loss of if } \\
\text { into acco } \\
\text { Indirect th } \\
\text { critical m } \\
\text { Direct ec } \\
\text { project se } \\
\text { water or } \\
5 \text { Environm } \\
\text { be expec }\end{array}$ & $\begin{array}{l}\text { ased upon project performance } \\
\text { tial based upon inundation ma } \\
\text { population at risk, time of flood } \\
\text { life caused by the interruption } \\
\text { lcilities. } \\
\text { impact of property damages to } \\
\text { i.e. impact on navigation indus } \\
\text { upply. } \\
\text { pact downstream caused by th } \\
\text { he magnitude flood event unde }\end{array}$ & $\begin{array}{l}\text { and do not apply to individ } \\
\text { oping of area downstream o } \\
\text { wave travel, and waming ti } \\
\text { of lifeline services due to p } \\
\text { project facilities and downs } \\
\text { ry of the loss of a dam and } \\
\text { e incremental flood wave p } \\
\text { which the failure occurs. }\end{array}$ & $\begin{array}{l}\text { uctures within a project. } \\
\text { project. Analyses of loss } \\
\text { failure, or operation, i.e } \\
\text { property and indirect ecc } \\
\text { lation pool, or impact upo } \\
\text { ed by the project failure, }\end{array}$ & $\begin{array}{l}\text { life potential should take } \\
\text { act loss of (or access to) } \\
\text { mic impact due to loss of } \\
\text { community of the loss of } \\
\text { ond which would normally }\end{array}$ \\
\hline
\end{tabular}

B-1 
APPENDIX C

UNIFORM BUILDING CODE SEISMIC ZONE MAP

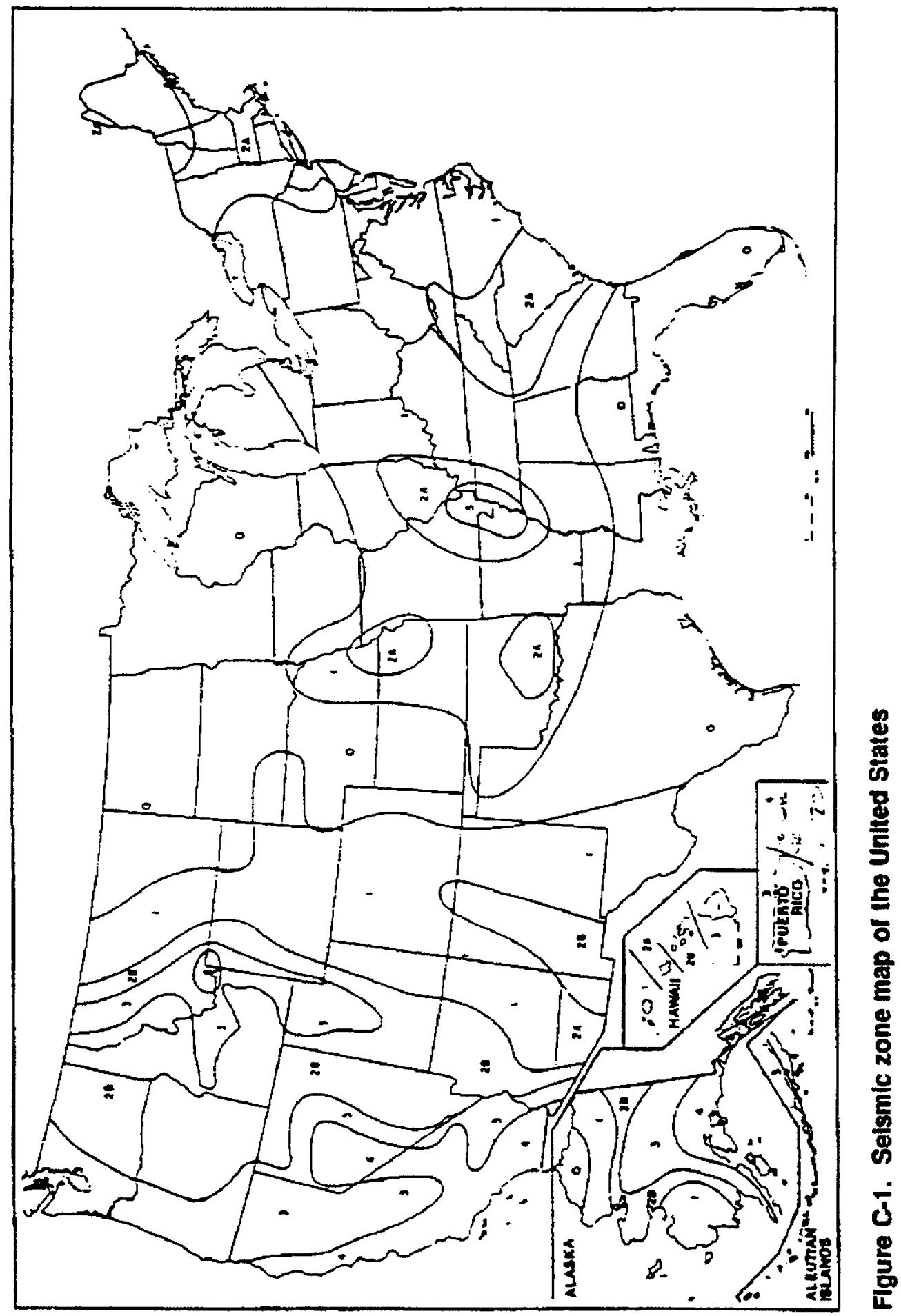

C-1 


\section{APPENDIX D \\ NATIONAL EARTHQUAKE HAZARD REDUCTION PROGRAM SPECTRAL ACCELERATION MAPS}

\section{NOTES}

1. Irregularly spaced contours are at intervals of $2,5,7.5,10,15,20,30,40,60,80,100,200$, and 300 percent g. In a few locations, supplemental contours are provided. Supplemental contours, if included, are always labeled. Spot values are included to supplement contours.

2. Contour variation with distance is rapid and complex in California, particularly near major faults and coastal regions. More detailed maps should be used when information is required in these areas.

3. The dashed curvilinear north-south line labeled "attenuation boundary" is the approximate division between western seismic source zones, modeled with Joyner and Boore's (1982) attenuation for soil, and eastern seismic source zones, modeled with Boore and Joyner's (1991) attenuation for soil. 


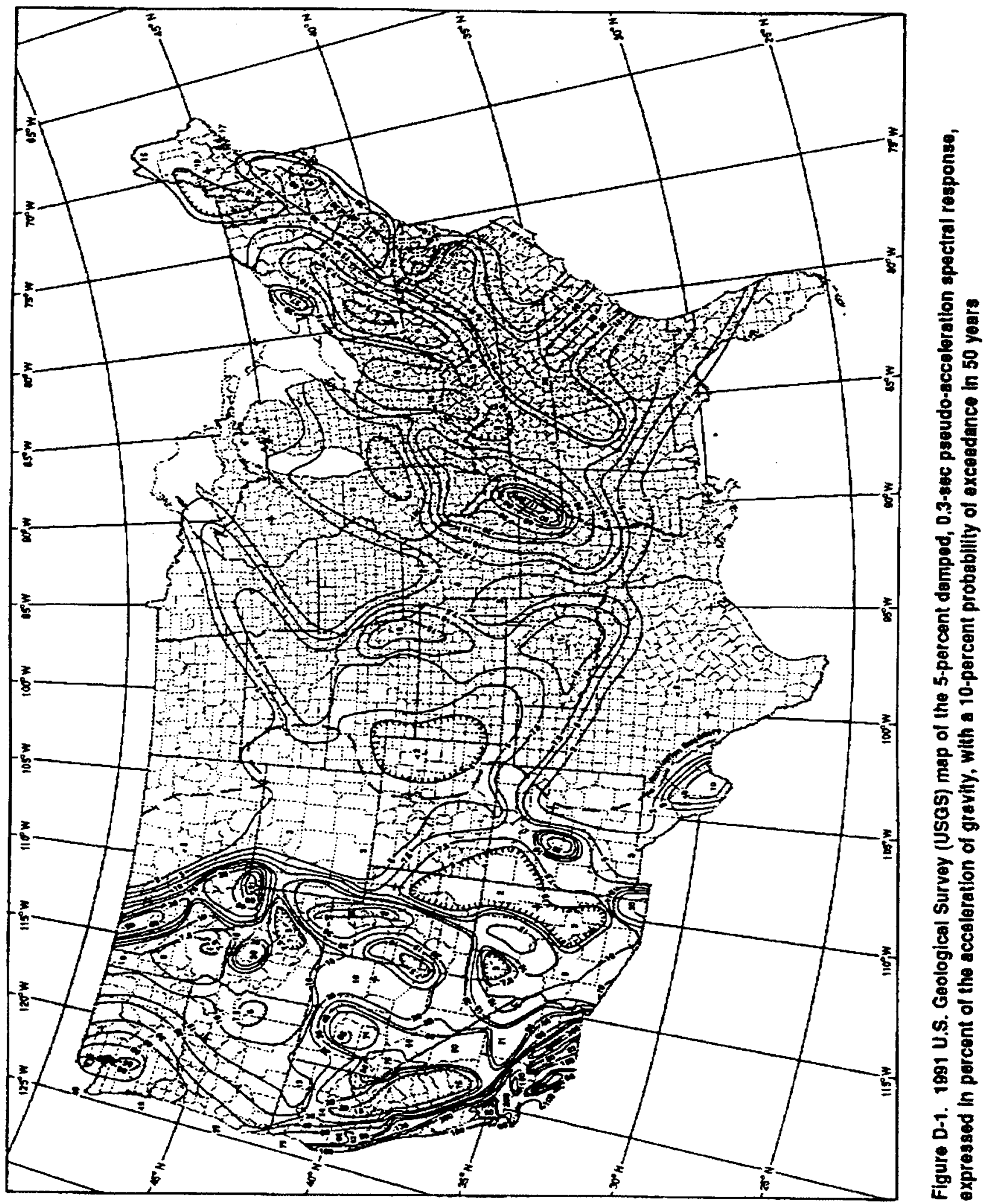




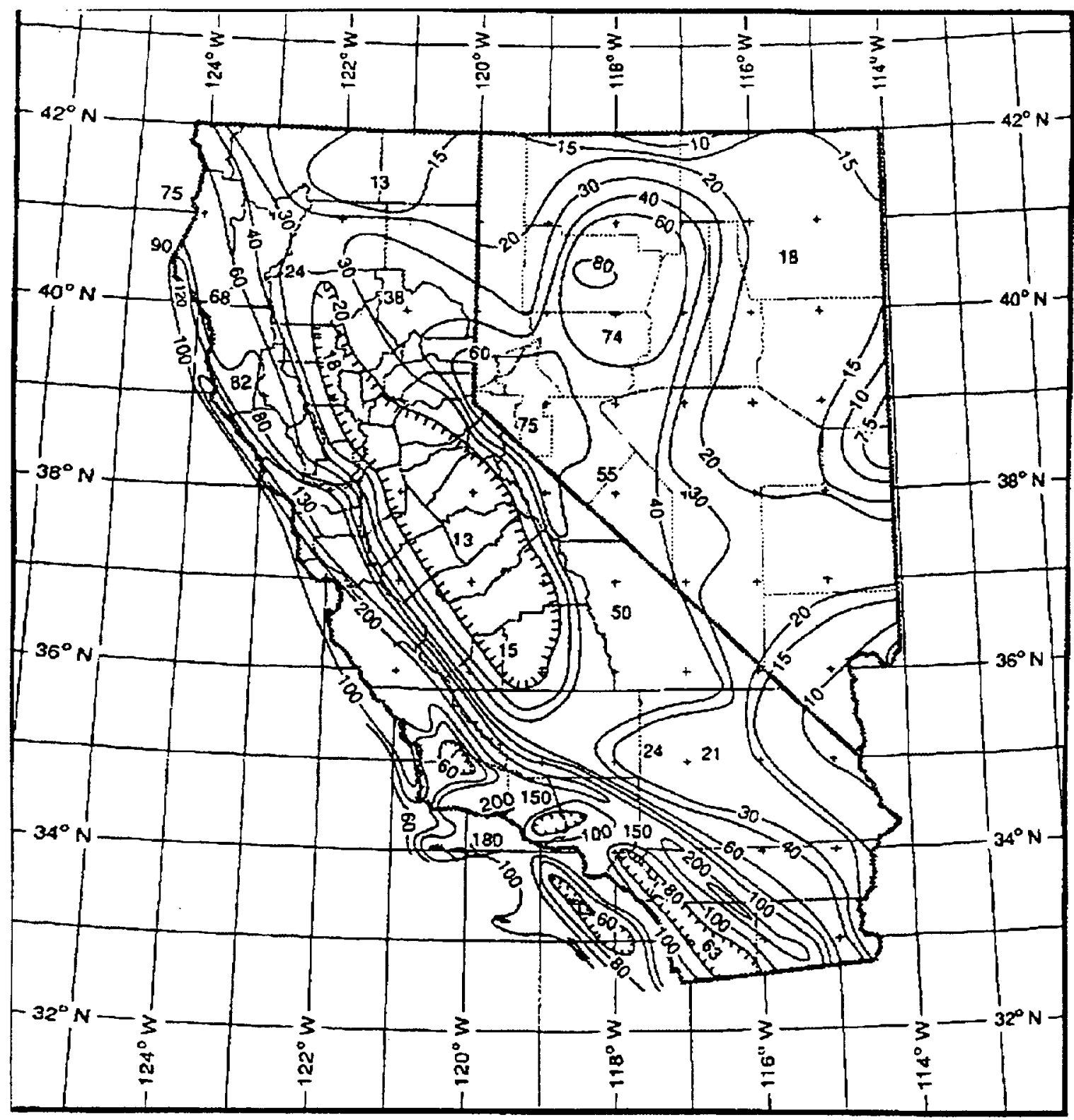

Figure D-2. 1991 USGS map of the 5-percent damped, 0.3-sec pseudo-acceleration spectral response, expressed in percent of the acceleration of gravity, with a 10-percent probability of exceedance in 50 years 


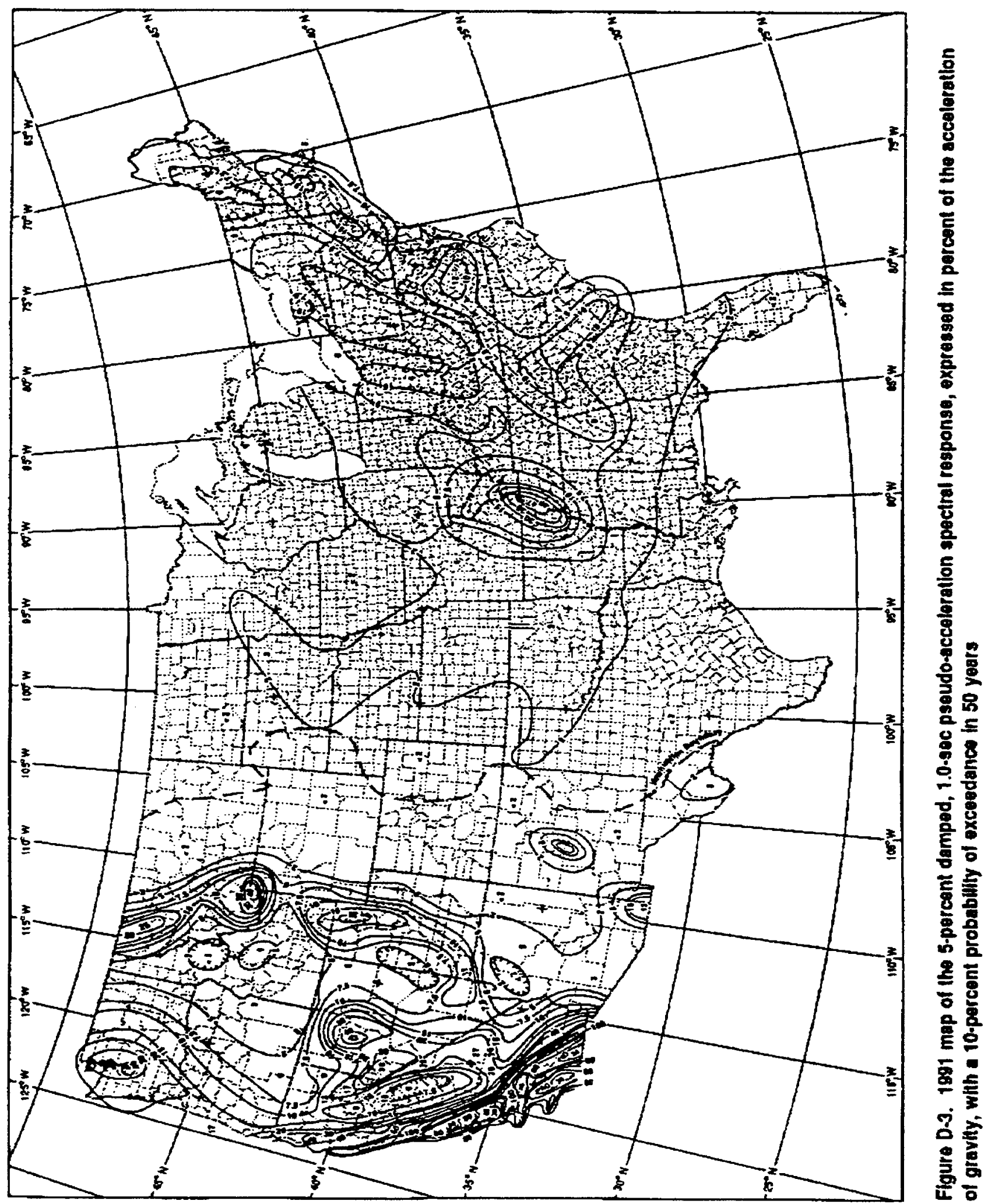


ER 1110-2-1806

31 Jul 95

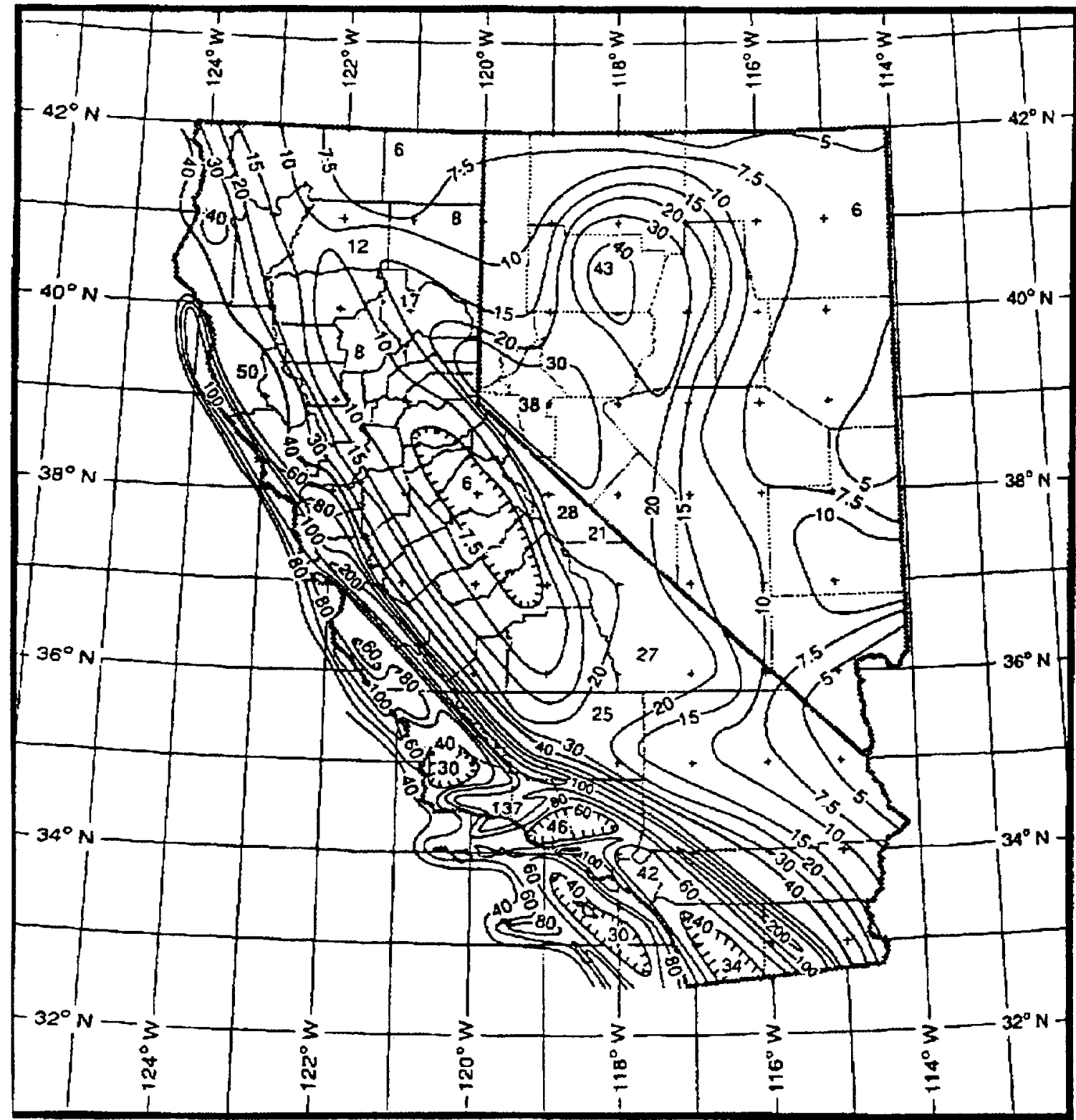

Figure D-4. 1991 USGS map of the 5-percent damped, 1.0-sec pseudo-acceleration spectral response, expressed in percent of the acceleration of gravity, with a 10-percent probability of exceedance in $\mathbf{5 0}$ years 
ER 1110-2-1806

31 Jul 95

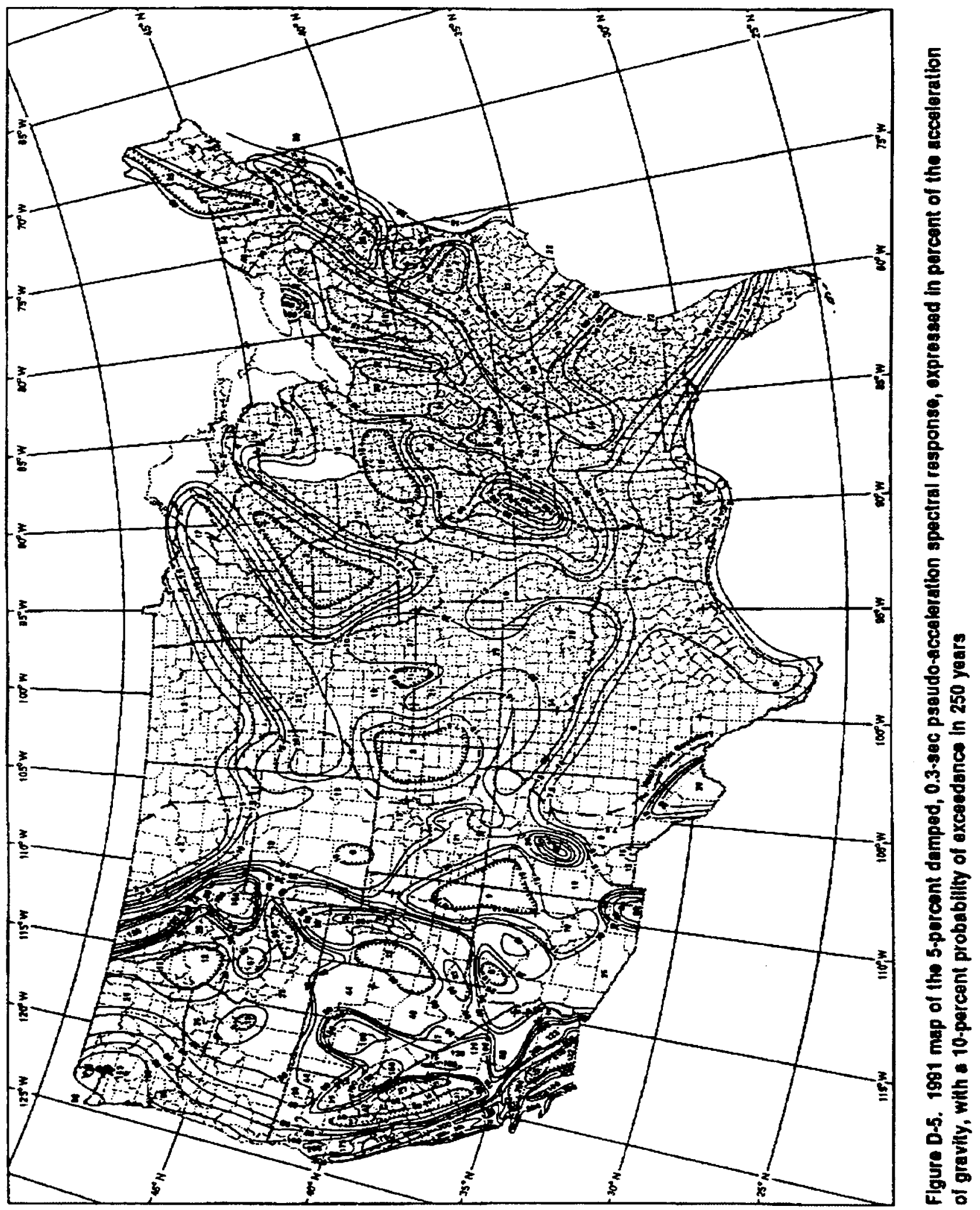

D-6 


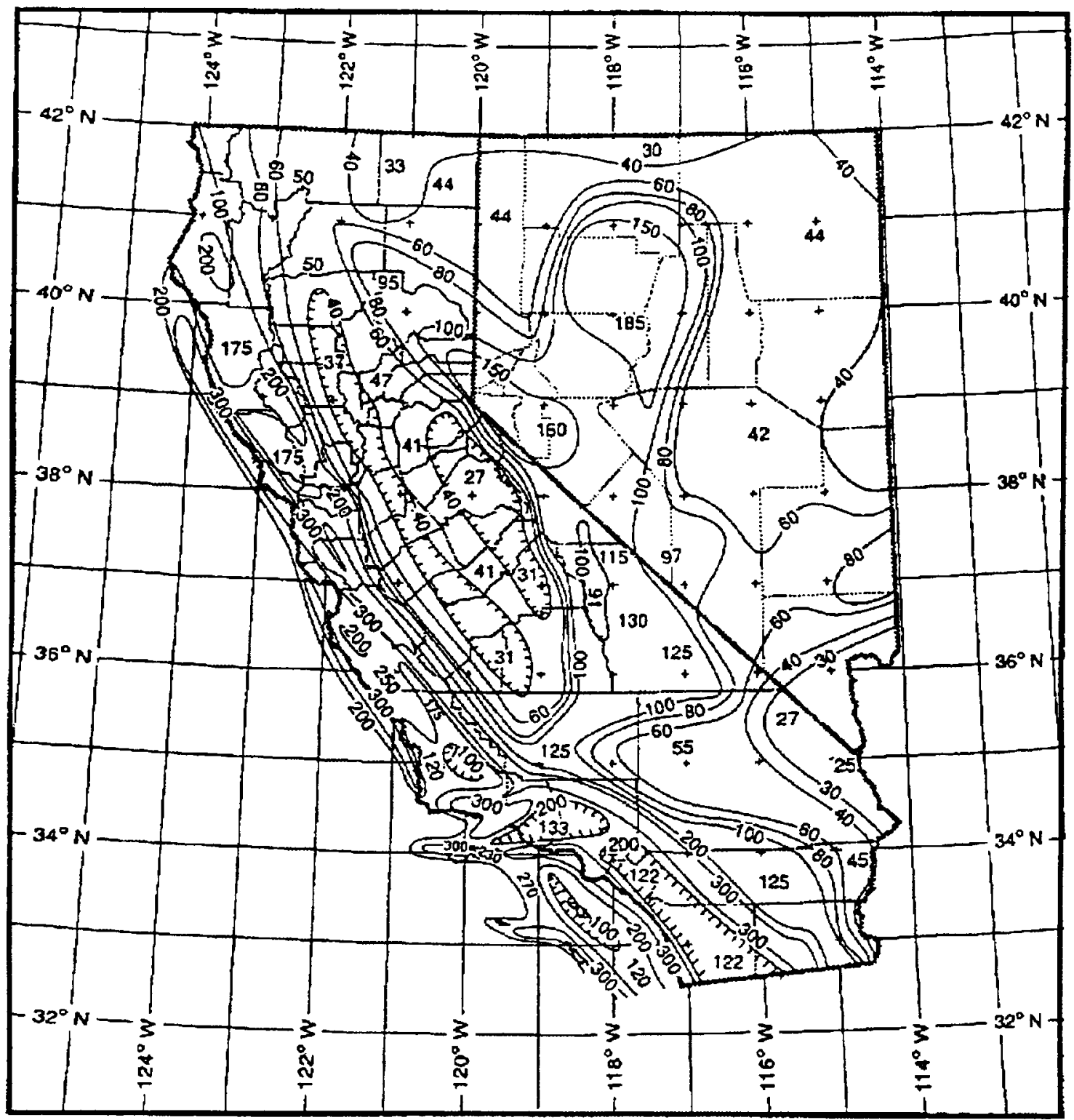

Figure D-6. 1991 USGS map of the 5-percent damped, 0.3-sec pseudo-acceleration spectral response, expressed in percent of the acceleration of gravity, with a 10-percent probability of exceedance in 250 years 


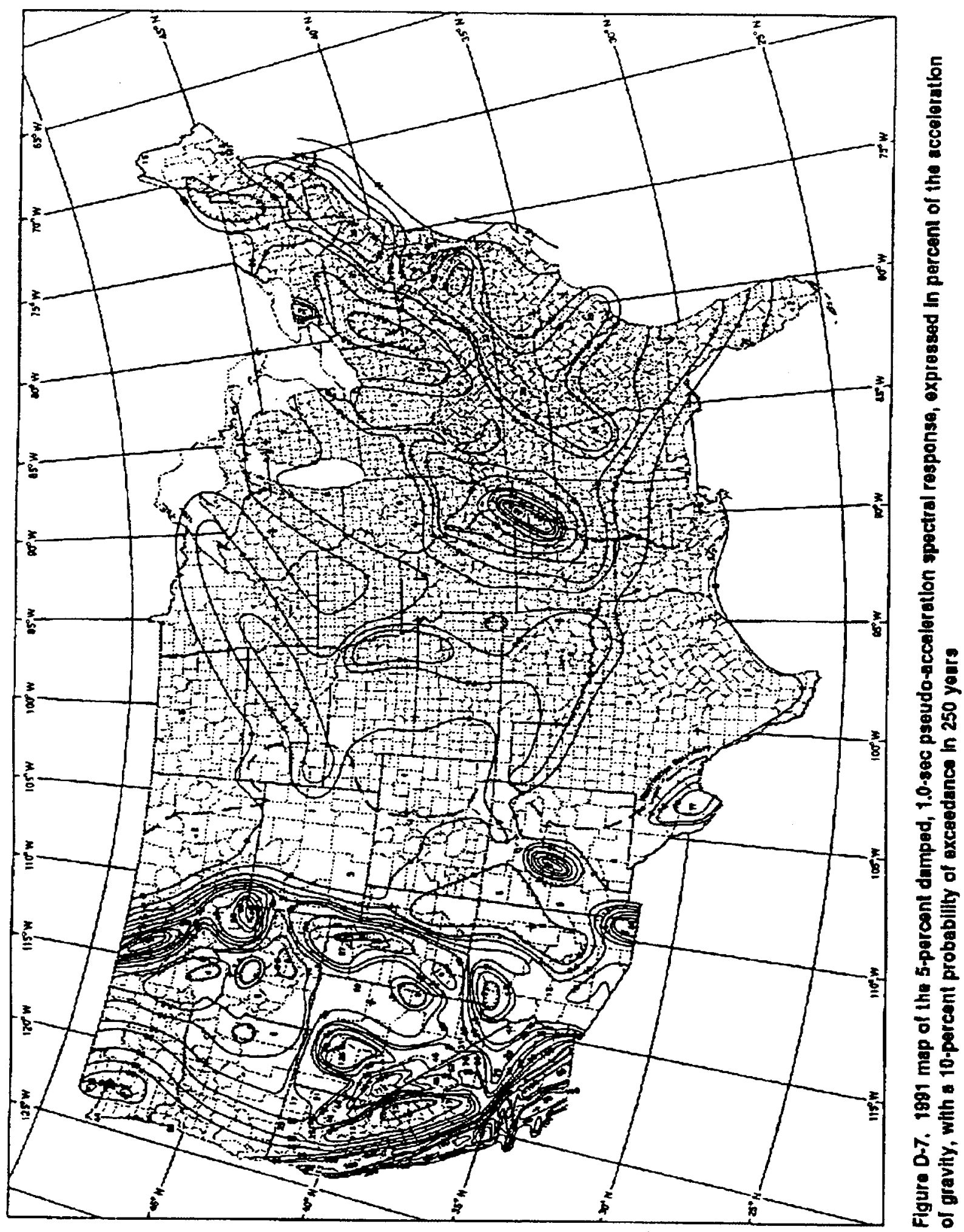

D-8 


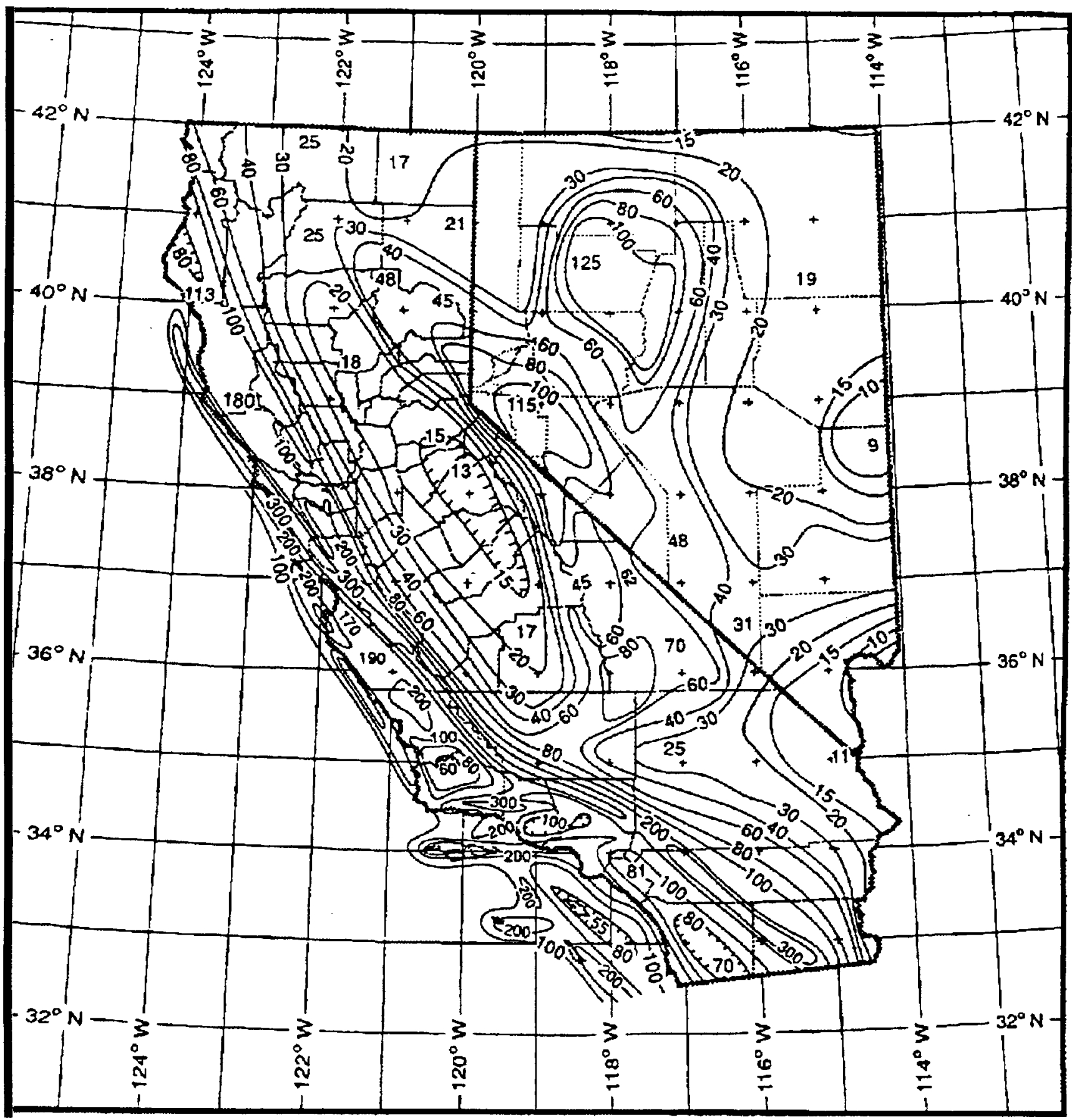

Figure D-8. 1991 USGS map of the 5-percent damped, 1.0-sec pseudo-acceleration spectral response, expressed in percent of the acceleration of gravity, with a 10-percent probability of exceedance in 250 years 


\section{APPENDIX E \\ PROGRESSIVE SEISMIC ANALYSIS REQUIREMENTS FOR CONCRETE AND STEEL HYDRAULIC STRUCTURES}

Table E-1 shows the progression of seismic analyses required for each phase of project design. Additional guidance concerning these methods of analysis is provided in paragraphs $8 e$ and $8 g$, and in the references in Appendix A. The types of project seismic studies are described in paragraphs $5 h$ and 10.

Table E-1

Seismic Analysis Progression

\begin{tabular}{l|lllll}
\hline \multirow{2}{*}{ Zone } & \multicolumn{5}{|c}{ Project Stage } \\
\cline { 2 - 6 } & Reconnaissance & \multicolumn{5}{c}{ Feasibility } & $\mathrm{DM}^{1}$ \\
\hline $\mathrm{O}$ and 1 & $\mathrm{E}$ & $\rightarrow$ & $\mathrm{SCM}$ & $\rightarrow$ & $\mathrm{RS}^{2}$ \\
\hline $2 \mathrm{~A}$ and 2B & $\mathrm{E}$ & $\rightarrow$ & $\mathrm{SCM}$ & $\rightarrow$ & $\mathrm{RS}$ \\
& $\mathrm{SCM}$ & $\rightarrow$ & $\mathrm{RS}^{2}$ & $\rightarrow$ & $\mathrm{TH}^{3}$ \\
\hline \multirow{3}{*}{3 and 4 } & $\mathrm{SCM}$ & $\rightarrow$ & $\mathrm{RS}$ & $\rightarrow$ & $\mathrm{TH}^{2}$ \\
& $\mathrm{SCM}$ & $\rightarrow$ & $\mathrm{RS}$ & $\rightarrow$ & $\mathrm{RS}^{4}$ \\
& $\mathrm{RS}^{2}$ & $\rightarrow$ & $\mathrm{TH}^{3}$ & $\rightarrow$ & $\mathrm{TH}^{3}$ \\
\hline
\end{tabular}

Note:

$E=$ Experience of the structural design engineer.

SCM = Seismic coefficient method of analysis.

RS $=$ Response spectrum analysis.

$T H=$ Time-history analysis.

1 If the project proceeds directly from feasibility to plans and specifications stage, a seismic design memorandum will be required for all projects in zones 3 and 4 , and projects for which a TH analysis is required.

2 Seismic loading condition controls design of an unprecedented structure, or unusual configuration or adverse foundation conditions.

3 Seismic loading controls the design requiring linear or nonlinear time-history analysis.

4 RS may be used in seismic zones 3 and 4 for the feasibility and design memorandum phases of project development only if it can be demonstrated that phenomena sensitive to frequency content (such as soilstructure interaction and structure-reservoir interaction) can be adequately modeled in an RS. 


\section{APPENDIX F \\ DESIGN AND ANALYSIS REQUIREMENTS FOR SEISMIC EVALUATION REPORTS}

The following outline summarizes the reporting requirements for seismic design and evaluation studies for both standard seismic studies and site-specific seismic studies as described in paragraph $5 h$. These are minimum requirements and should be supplemented as needed on a case-by-case basis.

\section{A. Summary of Applicable Seismic Criteria}

1. Hazard potential classification from Table B-1 (Include consequences of project failure)

2. Uniform Building Code seismic zone from map in Appendix $C$

3. Design earthquakes
a. MCE
b. MDE
c. $\mathrm{OBE}$
d. For each design earthquake provide:
(1) PGA, PGD, PGV
(2) Duration
(3) Response spectra

4. Critical project features (See paragraph $5 a$ )

5. Impact of seismic loads on project design (for new designs)

6. Impact of seismic loads on project safety (for existing projects)

\section{B. Description of Seismic Design or Evaluation Procedure}

1. Progressive seismic analysis process

2. Input motions used in the analysis

3. Loading combinations analyzed

4. Modeling techniques used for:
a. Structure
b. Substructure
c. Reservoir
d. Backfill or sediment

5. Material assumptions
a. Mass
b. Stiffness
c. Damping

6. Computer programs used in the analysis
a. Dynamic analysis programs
b. DSHA and PSHA ground motion programs
c. Soil column effects programs

C. Presentation of Results of Ground Motion Studies

1. Standard spectra used for preliminary studies and/or final designs

2. DSHA site-specific response spectra
a. Design response spectra
b. MCE (Mean)
c. MCE (84th percentile)

3. PSHA site-specific response spectra. Equal hazard mean spectra for return periods of:

72 years
144 years
475 years
950 years
, 000 years 


$$
\begin{array}{r}
5,000 \text { years } \\
10,000 \text { years }
\end{array}
$$

4. Time-history records

a. Natural time-history records used for final design

b. Synthetic time-history records used for final design (Natural time-histories modified to match target design response spectrum analysis)

c. Natural time-history scaling procedures

d. Synthetic time-history development procedures

e. Comparison of time-histories with design response spectra

\section{Results of Dynamic Analysis}

1. Periods of vibration

2. Mode shapes

3. Modal mass participation factors

4. Modal combination procedure (square root sum of squares, complete quadratic combination, etc.)

5. Governing loads and load combinations

6. Maximum forces (moments and shears)/or stresses where appropriate

7. Maximum displacements

8. For time-history analysis:

a. Plots of stress (or forces) with time for critical location

b. Plots of displacements with time

c. Procedure used to determine effective stresses (or forces) for design

d. Stress contour plots at points in time when stresses are maximum

9. Stability

a. Resultant locations (permanent rotations)

b. Sliding factors of safety (permanent translations)

\section{E. Design Measures Taken to Obtain:}

1. Ductility

2. Redundancy

3. Continuous and direct load paths

4. Prevent hammering of adjacent structures or components

5. Prevent loss of support at bridge bearings or other bearing locations

6. Smooth changes in mass or stiffness

\section{F. Results of Embankment Analyses}

1. Slope stability

2. Liquefaction potential

3. Settlement potential

4. Defensive design measures

\section{G. Results of Foundation Analyses}

1. Liquefaction potential

2. Bearing capacity

3. Settlement and deformation analyses

4. Defensive design measures

\section{H. Verification of Analysis Results}

1. Comparison of simplified procedure results with dynamic analysis results

2. Comparison of response spectra with time-history results

3. Comparison of results with those for similar type structures

4. Results of consultant review 
I. Presentation of Seismic Design or Evaluation Results

1. Assessment of the project and project features to resist the design earthquake results

2. Defensive design measures taken to protect project features from the damaging effects of earthquakes

3. Remedial measures required for existing projects 
CECW-E

CECW-O

CECW-P

Regulation

No. $1110-2-1156$

\section{Engineering and Design \\ DAM SAFETY - ORGANIZATION, RESPONSIBILITIES, AND ACTIVITIES}

\section{Purpose}

This regulation prescribes the policy, organization, responsibilities, and procedures for implementation of dam safety activities within the Corps of Engineers.

\section{Applicability}

This regulation applies to HQUSACE/OCE elements, major subordinate commands (MSC), districts, and field operating activities (FOA) having responsibility for planning, site selection, design, construction, operation, and maintenance of civil works projects.

\section{References} Army.

a. PL 92-367, Dams - Inspection - Secretary of the

b. ER 1110-2-100, Periodic Inspection and Continuing Evaluation of Completed Civil Works Structures.

c. ER 1110-2-101, Reporting of Evidence of Distress of Civil Works Projects.

d. ER 1110-2-110, Instrumentation for Safety Evaluations of Civil Works Projects.

e. ER 1110-2-112, Required Visits to Construction Sites by Design Personnel.

f. ER 1110-2-241, Use of Storage Allocated for Flood Control and Navigation at Non-Corps Projects.

g. ER 1110-2-1150, Engineering After Feasibility Studies. h. ER 1110-2-1942, Inspection, Monitoring and Maintenance of Relief Wells.

i. ER 1130-2-417, Major Rehabilitation Program and Dam Safety Assurance Program.

j. ER 1130-2-419, Dam Operations Management Policy.

k. Federal Guidelines for Dam Safety, June 1979.

\section{Background and Scope}

The safety of dams has been a major concern of the Corps of Engineers since it began building dams in the 1840 's. As part of the flood control development of the Muskingum River in the 1930's, the Corps started its multiple level of review requirement for dam design. For many years the Corps has made extensive use of expert consultants to advise on unusual and difficult designs. Advisory boards have been helpful in establishing design criteria and standards. Experience gained from the Fort Peck slide led the Corps to adhere to the highest design standards and comprehensive inspection and testing for construction. The Corps was one of the first agencies to initiate a periodic inspection and evaluation program.

a. As a result of several dam failures in the mid 1970 's, a Presidential Memorandum was issued on 23 April 1977 that required each Federal agency having responsibility for dams to review their practices and activities related to dam safety. This memorandum also directed the Federal Coordinating Council for Science, Engineering and Technology to prepare guidelines for management practices and procedures to ensure dam safety. "Federal Guidelines for Dam Safety" was published in June 1979, and with a memorandum dated 
4 October 1979, President Carter asked each Federal agency having responsibility for dams to adopt and implement these guidelines and report their progress to the Federal Emergency Management Agency (FEMA) on a biennial basis. Executive Order 12148 gives FEMA the responsibility to coordinate dam safety in the nation. The Interagency Committee on Dam Safety (ICODS) was established in 1979 to promote and monitor Federal and State dam safety programs. The Corps of Engineers is the Department of Defense representative on ICODS. The purpose of these guidelines is to enhance national dam safety and to encourage high safety standards in the management procedures and technical activities of Federal agencies. The guidelines require the head of each Federal agency having responsibility for design, construction, operation and regulation of dams to establish a dam safety office (officer) which reports directly to the head of the agency.

b. On 7 February 1980, the Chief of Engineers appointed the Chief of the Engineering Division, Directorate of Civil Works, as the HQUSACE Dam Safety Officer. This appointment also required that the Dam Safety Officer chair a standing committee composed of individuals having assigned responsibilities for dam safety to include programming and policy functions. The purpose of this committee is to provide surveillance, evaluation, and guidance for the administrative, technical, and regulatory practices within the Corps of Engineers. The Dam Safety Officer is advisory to the Chief of Engineers, through the Director of Civil Works.

c. The purpose and intent of this regulation is to ensure that the responsible officials at all levels within the decentralized organization of the Corps of Engineers implement and maintain a strong dam safety program that is in compliance with the Federal guidelines and ensures that all dams are designed, constructed, and operated safely and effectively under all conditions. Managers at all levels should ensure that they have sufficient organizational staffing of highly qualified personnel and that their programs related to dam safety are established and realistically funded.

\section{Organization and Responsibilities}

The Corps of Engineers maintains a decentralized organization of three levels. Each level will be staffed with qualified and experienced personnel in areas of design, construction, and operations of dams and appurtenant structures. Each level will have a Dam Safety Officer and organization as follows:

\section{a. HQUSACEJOCE.}

(1) Organization. The HQUSACE/OCE Dam Safety Officer is the Chief, Engineering Division, Directorate of Civil Works. The standing Dam Safety Committee members are as follows:

(a) Chief, Engineering Division, Directorate of Military Programs.

(b) Chief, Operations, Construction and Readiness Division, Directorate of Civil Works.

(c) Chief, Geotechnical and Materials Branch, Engineering Division, Directorate of Civil Works.

(d) Chief, Hydraulics and Hydrology Branch, Engineering Division, Directorate of Civil Works.

(e) Chief, Structural Branch, Engineering Division, Directorate of Civil Works.

(f) Chief, Electrical and Mechanical Branch, Engineering Division, Directorate of Civil Works.

(g) Chief, Construction Branch, Operations, Construction and Readiness Division, Directorate of Civil Works.

(h) Chief, Policy Development Branch, Policy and Planning Division, Directorate of Civil Works.

(2) Responsibilities.

(a) Dam Safety Officer. The HQUSACE/OCE Dam Safety Officer is responsible for ensuring that the Corps of Engineers maintains a proactive Dam Safety Program and is implementing all of the practices and procedures outlined in the "Federal Guidelines for Dam Safety." $\mathrm{He}$ is responsible for establishing technical criteria and the priority of work. He or his designated representative will represent the Corps of Engineers on ICODS. He will establish a program for implementing dam safety needs and monitor the activities of the MSCs. He will ensure that the HQUSACE/OCE committee periodically reviews and evaluates the existing policy, technical criteria and practices, administrative procedures, and regulatory functions to ensure their adequacy 
to support the agency dam safety program. Functions include oversight of design, construction, operation, maintenance, and rehabilitation programs to improve internal practices related to dam safety. He will perform an annual review of the status of emergency action plans and dam safety training. The Dam Safety Officer will monitor the activities of MSCs and periodically report to the Director of Civil Works and the Assistant Secretary of the Army for Civil Works.

(b) Dam Safety Committee. The committee will meet at least semiannually or as directed, make periodic inspections and field visits as necessary, and perform the following functions:

- Monitor and review the dam safety practices and procedures in the Corps of Engineers. Review and evaluate agency policy, directives, regulations, technical criteria, administrative procedures, and regulatory functions to ensure their consistency and adequacy to support the Corps' dam safety program.

- Review reservoir regulation, operation, emergency response plans and dam safety preparedness. Ensure that the inventory of dams is current and adequately maintained.

- Review the agency manpower to ensure that organizational staffing of highly qualified personnel is sufficient at all levels and that the MSC dam safety program is realistically funded.

- Review the research and development programs to ensure that the latest technologies related to dam safety receive consideration and evaluation.

- Review reports and make recommendations to the Assistant Secretary of the Army for Civil Works on dam safety matters.

b. Major Subordinate Commands (MSC).

(1) Organization. The MSC Dam Safety Officer will be the ChiefDirector of Engineering. The standing committee will contain the Chiefs of the same disciplines as those in paragraph 5a(1) (b) through (g).

(2) Responsibilities. The MSC Dam Safety Officer and Committee are responsible for coordination and implementation of the dam safety program. The committee will conduct a minimum of two meetings per year or as needed. Their responsibilities include:

(a) Ensure the organizational staffing of qualified personnel is sufficient and that their program is established and realistically funded.

(b) Establish dam safety related work priorities within the MSC.

(c) Ensure that at least two levels of review are conducted for all features of major civil works projects.

(d) Ensure adequate exploration and testing is accomplished in all stages of design and construction.

(e) Ensure adequate performance monitoring and evaluations of all dams is conducted and documented.

(f) Monitor the status of Emergency Action Plans.

(g) Monitor the public awareness program and coordinate with state agencies as required.

(h) Ensure adequate dam safety training is being conducted.

(i) Ensure that accurate data is submitted for the inventory of Corps dams.

(j) Plan, monitor, and conduct dam safety exercises.

\section{c. District Commands.}

(1) Organization. The District Dam Safety Officer will be the Chief, Engineering Division. The standing committee will comprise the same disciplines as that in the MSC.

(2) Responsibilities. The District Dam Safety Officer and Committee are responsible for the execution of the dam safety program. A minimum of two meetings will be held annually with the minutes forwarded to the Division. Responsibilities include but are not limited to:

(a) Ensuring that the organizational staff of qualified technical personnel is sufficient for program implementation. 
(b) Establishing a public awareness program with information at each project and coordination with downstream local interests.

(c) Monitoring and evaluating the performance of all dams and appurtenant structures and recommending remedial measures when necessary.

(d) Establishing the priority of dam safety related work.

(e) Conducting dam safety training for the technical staff and project operation and maintenance personnel.

(f) Ensuring that each dam has an adequate surveillance plan.

(g) Coordinating with local and State dam safety officials.

\section{Applicable Dams}

a. The Corps of Engineers' involvement in dams can be categorized as follows:

(1) Dams which the Corps has designed, constructed, operates, and maintains. Ownership remains with the Corps of Engineers.

(2) Dams which the Corps has designed and con others.

(3) Dams that are designed, constructed, operated, maintained, and owned by others in which flood control storage has been provided at Federal expense under the authority of the 1944 Flood Control Act.

(4) Dams for which the Corps has issued permits under its regulatory authority.

(5) Dams inspected and evaluated by the Corps under the authority of the National Program for the Inspection of Non-Federal Dams, PL 92-367.

b. In category 1, the Corps of Engineers has a definite responsibility for dam safety. For dams in category 2 , the primary responsibility for dam safety is with the agency or sponsor which accepts the project. The Corps' responsibility in this case is a supporting role with respect to the design and construction and to participate in periodic inspections conducted by the owner. In category 3 , the Corps should maintain pertinent data on the project and participate in inspections to ensure that the Federal flood control interest is being properly maintained. For categories 4 and 5 , the Corps has no legal liability or financial responsibility for dam safety.

\section{Emergency Preparedness}

Each MSC and district command is responsible for the planning, preparation, assignment of responsibilities, and coordination with local officials for each project's Emergency Action Plan. The Dam Safety Officer should conduct training, inspections, and exercises to ensure adequate preparedness for the full range of events that would affect dam operation.

\section{FOR THE COMMANDER:}

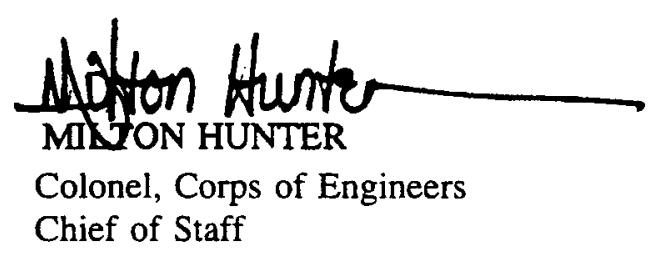


Regulation

No. $1110-2-103$

10 December 1981

\author{
Engineering and Design \\ STRONG-MOTION INSTRUMENTS FOR RECORDING \\ EARTHQUARE MOTIONS ON DAMS
}

1. Purpose. This regulation provides requirements and guidance for installation and servicing of strong-motion instruments for recording earthquake motions on Corps of Engineers (CE) dams.

2. Applicability. This regulation applies to all fleld operating activities having civil works responsibilities.

\title{
3. References.
}
a. EM 1110-2-1908 Chapter 3, Part 2 of 2.
b. EM 1110-2-4300, Chapter 7 .

4. General. All dams in seismic risk zones 2, 3, and 4 of the Seismic Risk Maps (Appendix A) should be instrumented for strong-motion earthquake measurements. Guldance on detalls of instrumentation location and selection is given in references $3 a$ and $3 b$. By interagency agreement, the Seismic Engineering Branch (SEB) of the US Geological Survey (USGS) is responsible for the installation and maintenance of approximately 200 accelerographs located at Corps dams in the western coast region and surrounding areas of the United States. Those Instruments located in the central and eastern United States areas will be Installed and serviced by the Waterways Experiment Station (WES). Sowe non-Corps instruments in custody of the USGS, located in the WES service region, will be serviced by WES on a one-for-one tradeoff basis with USGS. This arrangement is beneficlal because travel costs for malntenance of $C E$ instruments are minimized. In an effort to increase the rellabllity and overall effectiveness of the Strong-Motion Instrumentation Program (SMIP), it will be necessary, periodically, to modify and/or upgrade various instruments as malntenance records dictate and as technological advances are made. On an annual bas1s, WES will prepare an Engineer Circular which will serve as a stat us report for the CE SMIP. Included there in w1ll be current estimated costs for the installation and servicing of instruments and a tabulation of strong-motion instrumentation, both operational and planned. Charges for those services may be adjusted annually on the basis of actual cost experience. Transfer of funding authority to WES should be made on an annual basis via Intra-Army Order for Reimbursable Services (DA Form 2544), with expiration date no sooner than 31 January of the next calendar year.

This regulation supersedes ER $1110-2-103,9$ Aug 74 
ER $1110-2-103$

10 Dec 81

Presentiy, service visits will be made on a blannual basis, and billings to the districts against this authority will be made in the same manner. New instruments purchased by the fleld should be coordinated with uscs in the western region and WES in the central and eastern regions before procurement is made (See Appendix B for service agency.). WES and USGS may request that the instruments be shipped to their respective offices for calibration or modification before installation.

5. WES Responsib1lities. WES will be responsible for: (a) maintaining records of instrument servicing and location, (b) reviewing instrument locations and type to assure conformance with OCE policy, (c) processing and analyzing records that will be obtained, (d) furnishing coples of records obtained to the district concerned, (e) coordinating with USGS and the districts to establish schedules for inspection visits, ( $f$ ) billing districts for services provided, ( $g$ ) reimbursing USGS for expenses incurred, ( $h$ ) providing instrumentation services personnel for installation and maintenance of CE instruments not serviced by USGS, (1) providing (by letter) an annual cost estimate to each district served, and ( $j$ ) providing a draft of an annual Engineer C1rcular on the status of the program to CDR USACE (DAEN-CWE-SG) WASH DC 20314 for Corps wide distribution.

6. L1st of Se1smic Instrument Installations. A tabulation of strongmotion instrumentation now operational or planned at CE projects is attached as Appendix B (revised March 1981). This list will be revised annually and published in the Englneer Circular discussed in paragraph 4. Districts should review the list and notify the WES (through their division) of any necessary corrections or additions. Copies of correspondence should be sent to CDR USACE (DAEN-CWE-SG) WASH DC 20314 for information.

7. Review of Instrument Plans. When a structure is selected for installation, WES should be furn ished plans for reviews. These plans should include drawings showing instrument types, locations, and details of the instrument shelters and foundations. SEB, USGS, also should be furnished coples of the drawings showing instrument type and shelter details, for their review in those areas which they service. Information copies of correspondence should be furnished DAEN-CWE-SG.

8. Guldance for Destgn of Selsmograph Installations. Guidelines for design of se 1smograph installations are contalned in references $3 a$ and $3 b$ above, copies of which may be obtalned from WES. Other details may be clarified by contacting the Commander and Director, US Army Engineer Waterways Experiment Station, ATTN: WESGH, P.0. Box 631, Vicksburg, MS 39180.

FOR THE OOMMANDER:

2 Appendixes

APP A - Maps

APP B - Tabulation

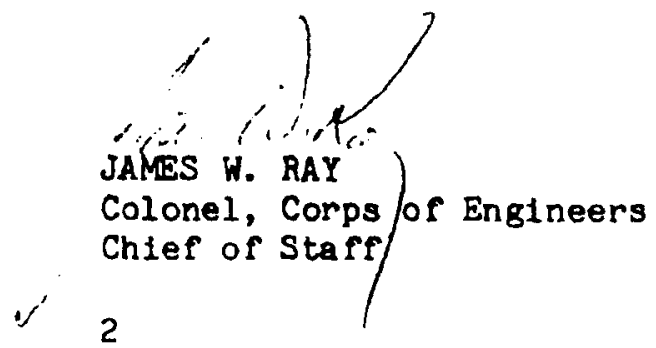




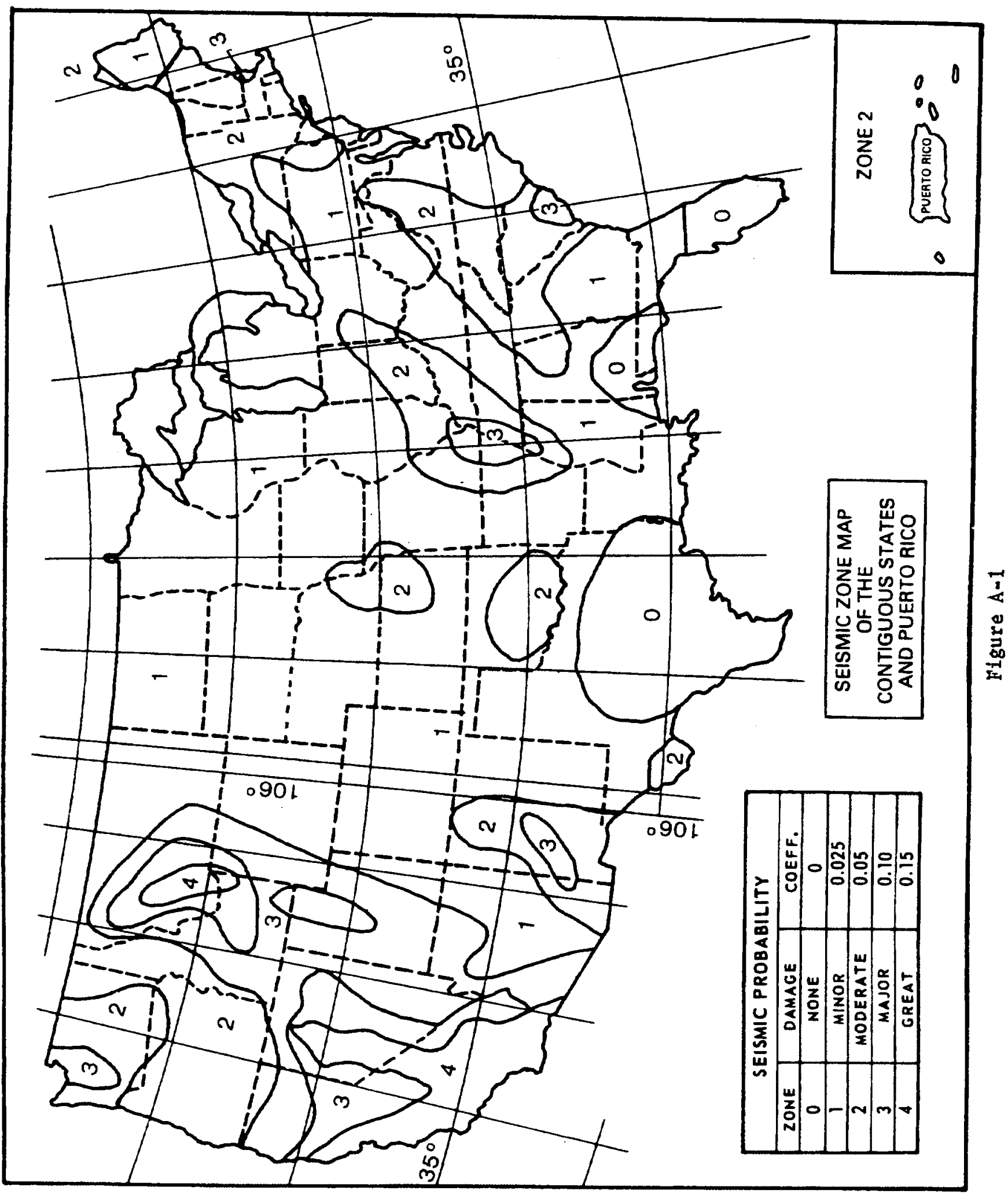

$A-1$ 
ER 1110-2-103

$10 \mathrm{Dec} 31$

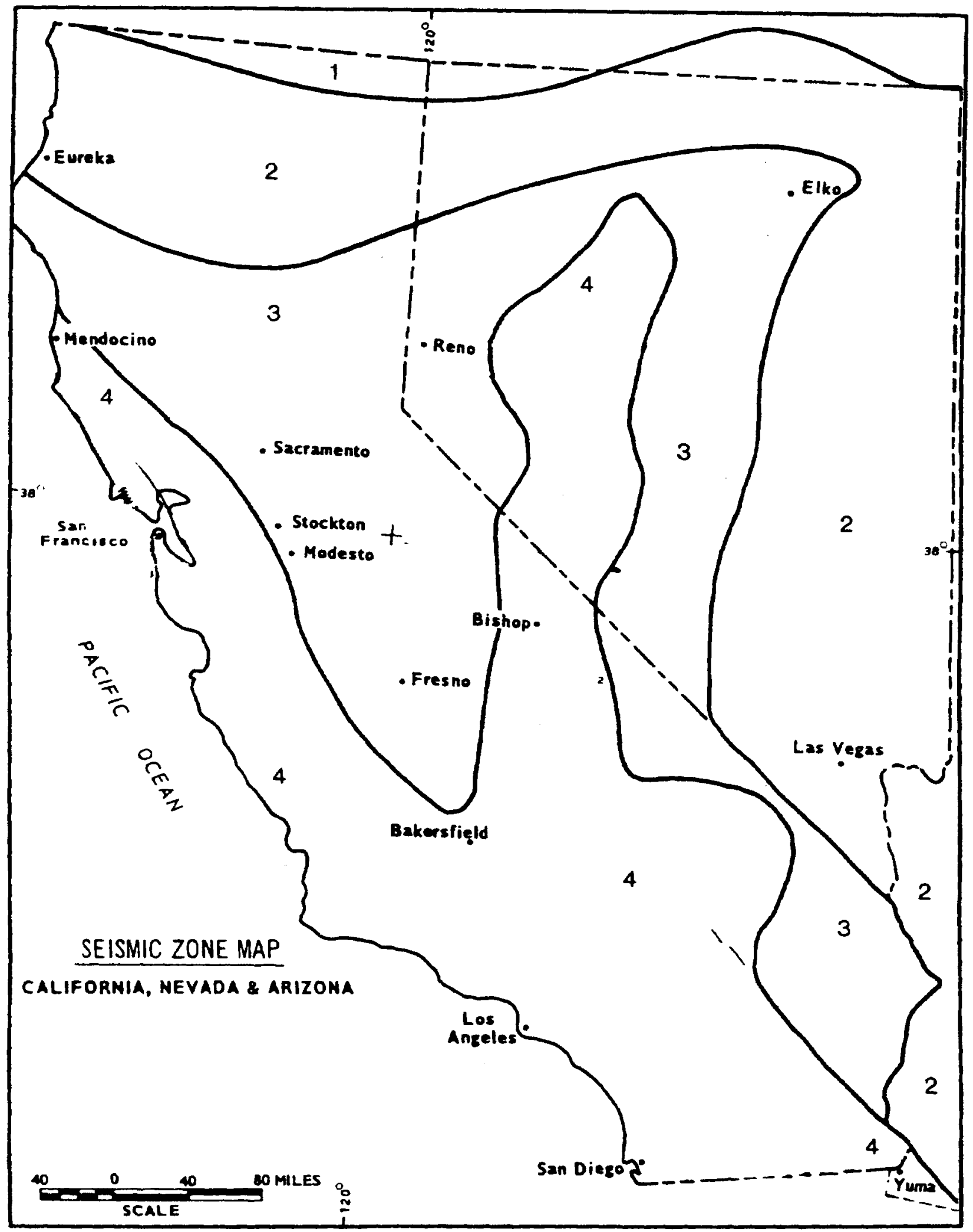

Figure $\mathrm{A}-2$

$$
\text { A-2 }
$$




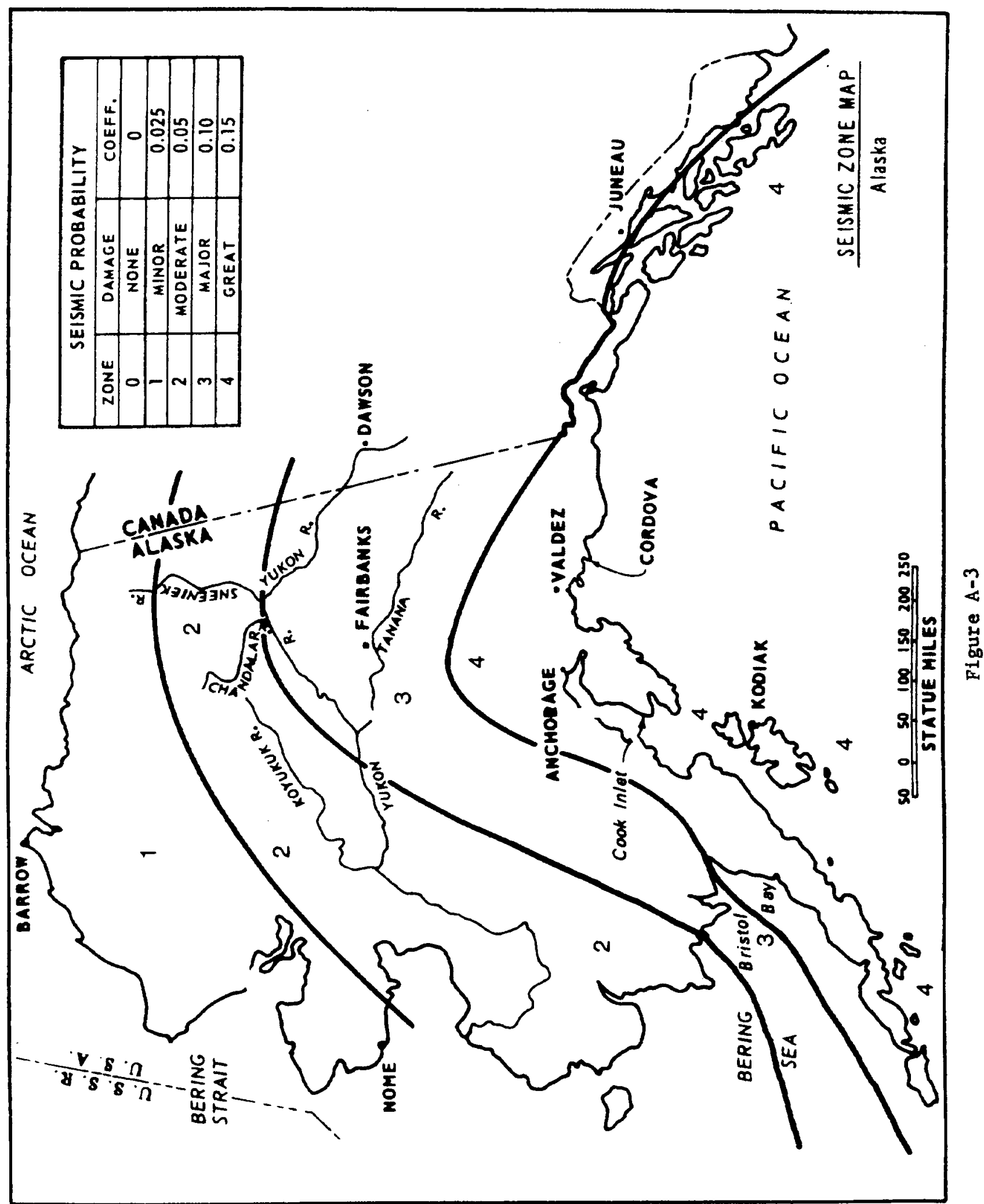

A-3 
ER 1110-2-103

10 Dec 81

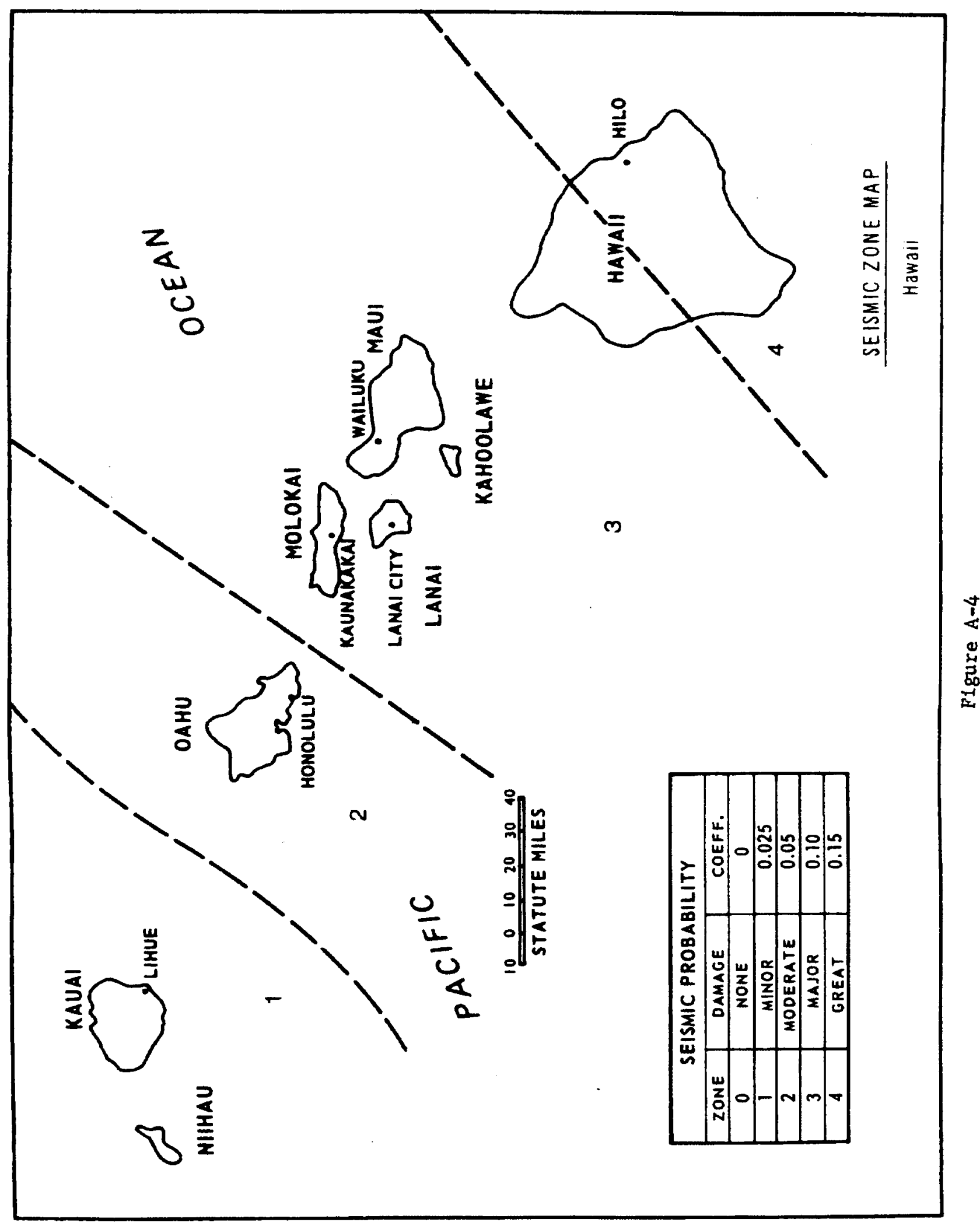

A-4 


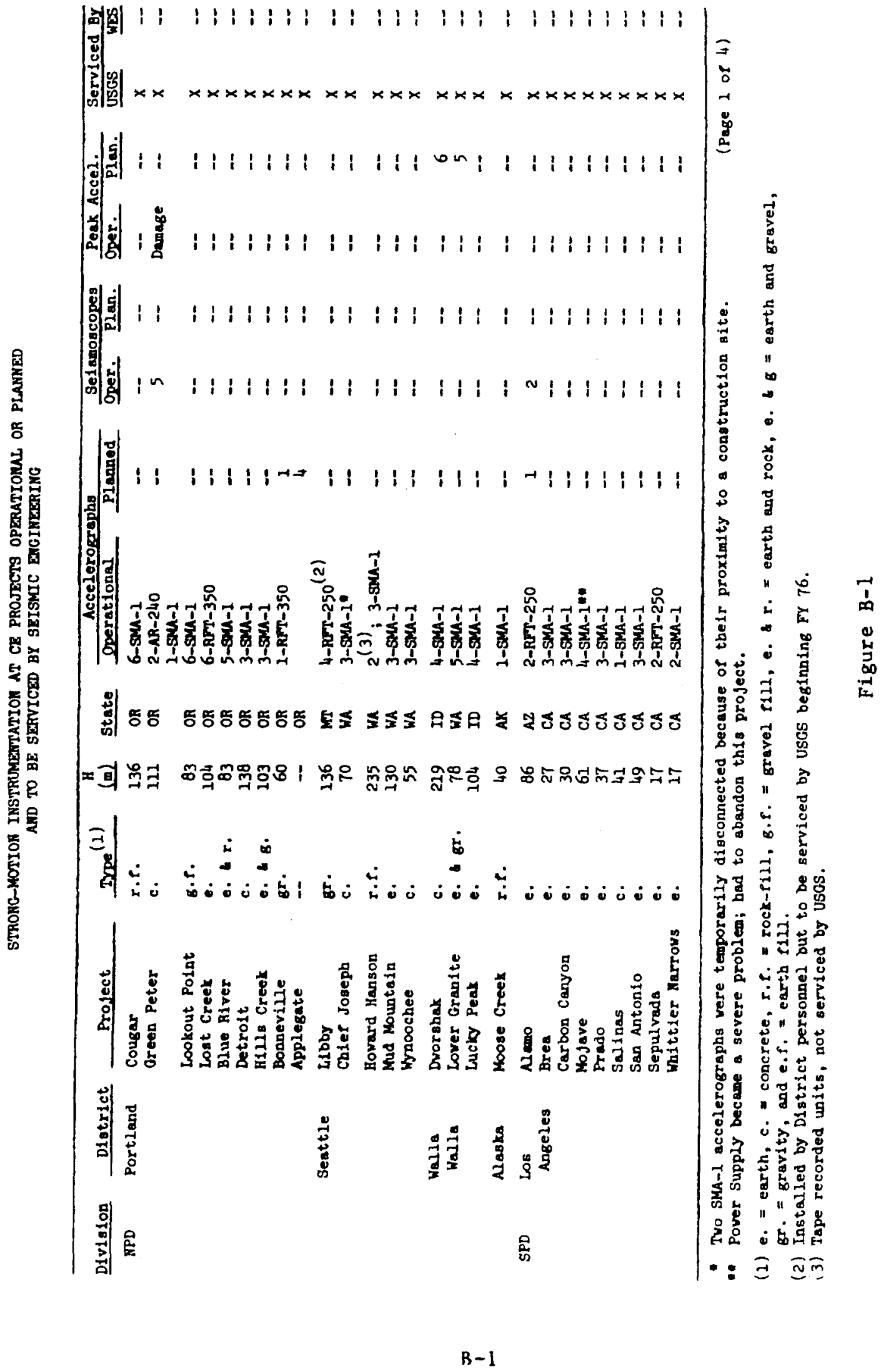


E.R $1110-2-103$

10 Dec 81

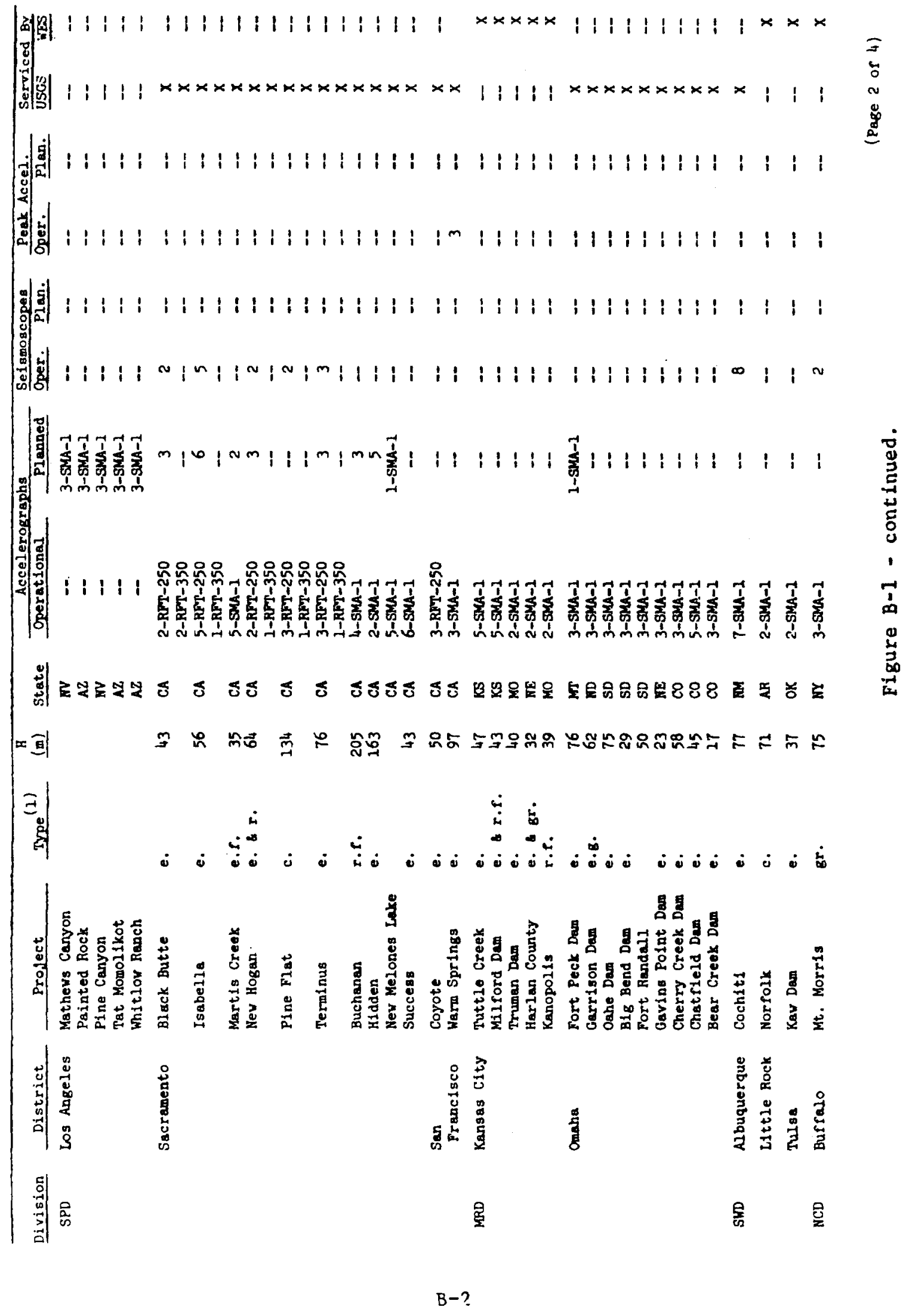


ER 1110-2-103

10 Dec 81

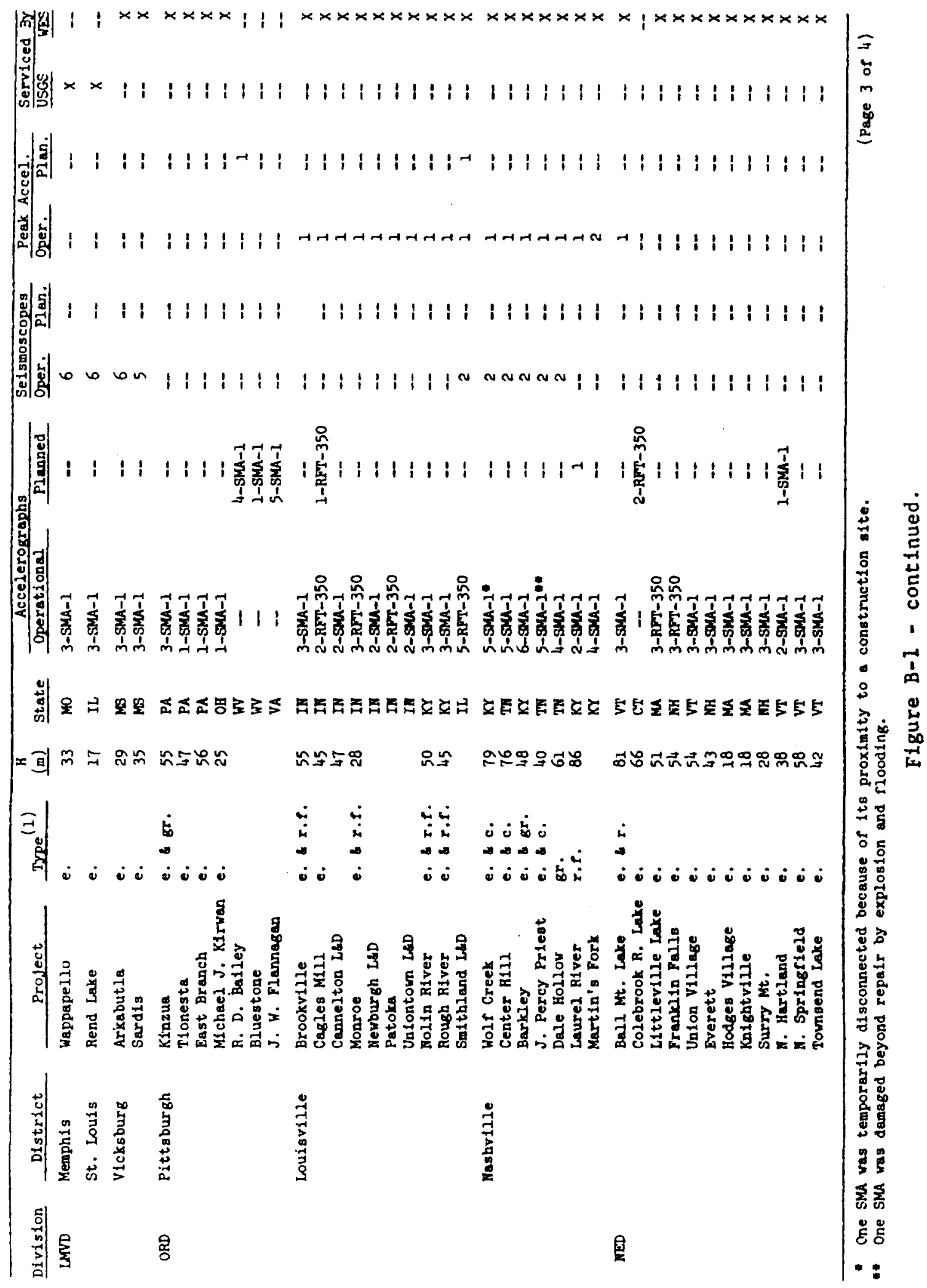

$B-3$ 
ER 1110-2-103

10 Dec 81

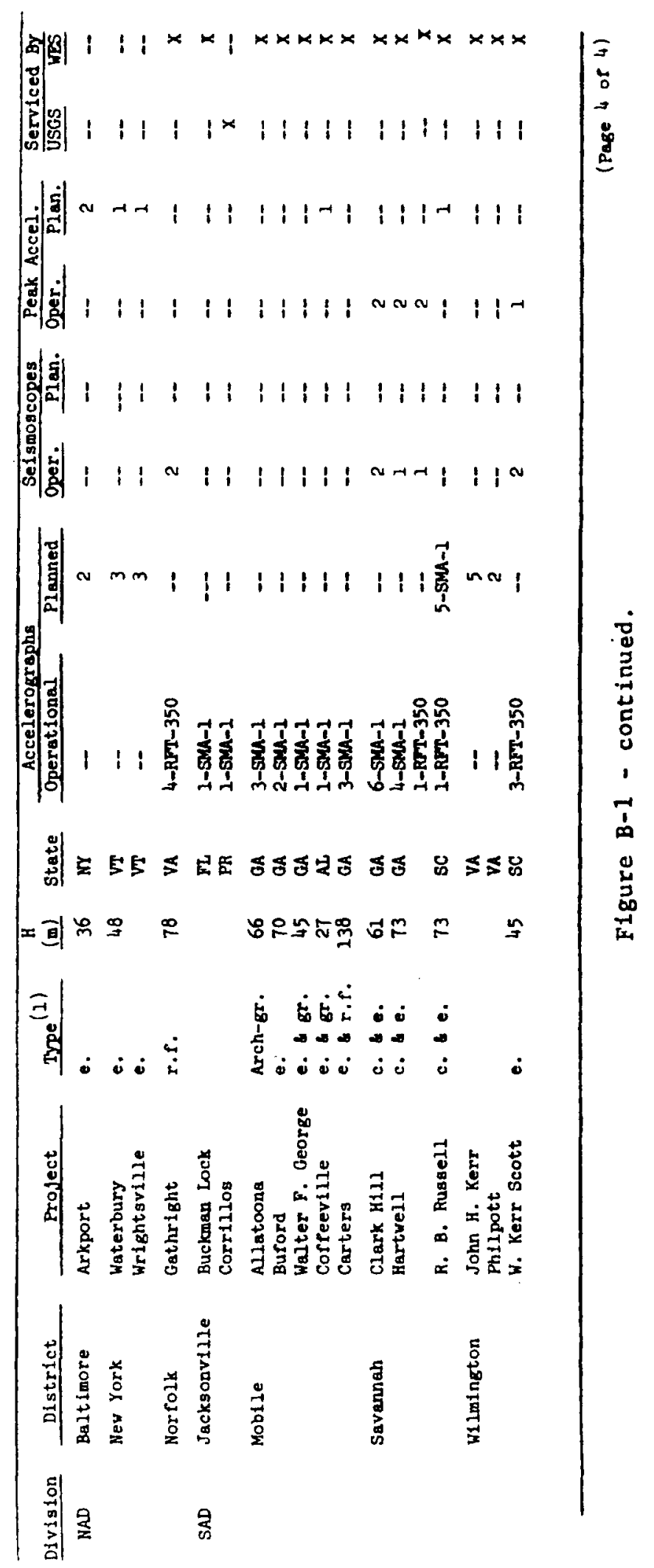

B-4 
DAEN-CWE-SG

Regul ation

No. $1110-2-1802$
DEPARTMENT OF THE ARMY

Office of the Chief of Engineers

Washington, D. C. 20314
ER 1110-2-1802

33 CFR Part 222

25 July 1979

Engineering and Design

REPORT ING EARTHQUARE EFFECTS

1. Purpose. This regulation states policy, defines objectives, assigns functions, and establishes procedures for assuring the structural integrity and operational adequacy of major $C i v i l$ Works structures following the occurrence of significant earthquakes. It primarily concerns damage surveys following the occurrences of earthquakes.

2. Applicability. This regulation is applicable to all field operating agencies having $C$ ivil Works responsibilities.

3. References.

a. ER 1110-2-100

b. ER $1110-2-1806$

c. ER 1110-2-8150

d. ER 1130-2-419

e. State-of-the-Art for Assessing Earthquake Hazards in the United States - WES Miscellaneous Papers S-73-1 - Reports 1 thru 14. Available from U.S. Anny Engi neer Waterways Experiment Station, P. O. Box 631, Vicksburg, Mississippi 39180 .

4. Policy. Civil Works structures, which could be caused to fail or partially fail by an earthquake and whose failure or partial failure would endanger the lives of the public and/or cause substantial property damage, will be evaluated following potentially damaging earthquakes to insure their conti nued structural stability, safety and operational adequacy. These structures include dams, navigation locks, powerhouses, and appurtenant structures, (intakes, outlet works, buildings, tunnels, paved spillways) which are operated by the Corps of Engineers and for which the Corps is fully responsible. Also included are major levees, floodwalls, and similar facilities designed and constructed by the Corps of Engineers and for whose structural safety and stability the Corps has a public obligation to be aware of although not responsible for their maintenance and operation. The evaluation of these structures will be based upon post-earthquake inspections which will be conducted to detect conditions

This regulation supersedes ER 1110-2-1802, 14 February 1979 
ER $1110-2-1802$

25 Jul 79

of significant structural distress and to provide a basis for timely initiation of restorative and remedial measures.

5. Post-Earthquake Inspections and Evaluation Surveys.

a. Limitations of Present Rnowledge. The design of structures for earthquake loading is limited by the infrequent opportunity to compare actual performance with the design. Damage which would affect the function of the project is unlikely if peak accelerations are below $0.1 \mathrm{~g}$.; but it cannot be assumed that a structure will not be damaged from earthquake loadings below that for which it was designed. Furthermore, earthquakes have occurred in several parts of the country where significant seismic activity had not been predicted by some seismic zoning maps. This indicates the possibility that earthquake induced loads may not have been adequately considered in the design of older structures.

b. Types of Reportable Damage. Many types of structural damage can be induced by ground motion from earthquakes or from large nuclear blasts (which also tend to induce ground vibrations in the more damaging lower frequency ranges). Any post-earthquake change in appearance or functional capability of a major Civil Works atructure should be evaluated and reported. Examples are symptoms of induced stresses in buildings made evident by cracked plaster, windows or tile, or in binding of doors or windows; cracked or shifted bridge pier footings or other concrete structures; turbidity or changed static level of water wells; cracks in concrete dams or earth embankments; and wisalignment of hydraulic control structures or gates. Induced dynamic loading on earth dams may result in loss of freeboard by settlement, or cause localized quick conditions within the embankment sections or earth foundations. Also, new seepage paths may be opened up within the foundation or through the embankment section. Ground motion induced 1 andslides may occur in susceptible areas of the reservoir rim, causing embankment overtopping by waves and serious damege. All such unusual conditions should be evaluated and reported.

6. Inspection and Evaluation Programs.

a. If the project is located in an area where the earthquake causes significant damage (Modified Mercal1i Intensity VII or greater) to structures in the vicinity, the Chief, Engineering Divioion, should be immediately notified and an engineering evalustion and inspection team should be sent to the project.

b. If the project is located in an area where the earthquake is felt but causes no or insignificant damage (Modified Mercalli Intensity VI or 1ess) to structures in the vicinity of the project, project operations personnel should make an immediate inspection. This inspection should determine (1) whether there is evidence of earthquake damage or disturbance, and (2) whether seismic instrumentation, where present, has 
been triggered. The Chief, Engineering Division, should be notified by phone of the results of the inspection. If damage is observed, which is considered to threaten the immediate safety or operational capability of the project, immediate action should be taken as covered in paragraph 6a. For other situations, the Chief of Engineering Division will determine the need for and urgency for an engineering inspection.

c. When an engineering inspection of structures is deemed necessary following a significant earthquake, HQDA (DAEN-CWE) WASH DC 20314 will be notified of the inspection program as soon as it is established.

d. As general rule, the structures which would be of concern following an earthquake are also the structures which are involved in the inspection program under ER 1110-2-100. Thenever feasible, instrumentation and prototype testing programs undertaken under ER 1110-2-100 to monitor structural performance and under ER 1110-2-8150 to develop design criteria will be utilized in the post-earthquake safety evaluation programe. Additional special types of instrumentation will be incorporated in selected structures in which it may be desirable to measure forces, pressures, loads, stresses, strains, displacements, deflections, or other conditions relating to damage and atructural safety and stability in case of an earthquake.

e. Where determined necessary, a detailed, systematic engineering inspection will be made of the post-earthquake condition of each structure, taking into account its distinctive features. For structures which have incurred earthquake damage a formal technical report will be prepared in a format similar to inspection reports required under $E R$ 1110-2-100. (Exempt from requirements control under paragraph 7-2b, AR 335-15). The report will include sumaries of the instrumentation and other observation data for each inspection, for permanent record and reference purposes. This report will be used to form a basis for major remedial work when required. Where accelerometers or other types of strong notion instruments have been installed, readings and interpretations from these instruments should also be included in the report. The report will contain recommendations for remedial work when appropriate, and will be transmitted through the Division Engineer for review and to DAEN-CWE for review and approval. For structures iacurring no damage a simple statement to this effect will be all that is required in the report, unless seismic instrumentation at the project is activated. (See paragraph $8 \mathrm{~d}$.)

7. Training. The dam safety training program covered by paragraph 6 of ER 1130-2-419 should include post earthquake inspections and the types of damage operations personnel should look for. 
BR 1110-2-1802

25 Ju1 79

\section{Responsibilities.}

a. The Engineering Divisions of the District offices will formulate the inspection program, conduct the post-earthquake inspections, process and analyze the data obtained from instrumentation and other observations, evaluate the resulting condition of the structures, and prepare the inspection reports. The Engineering Division is also responsible for plaming special instrumentation felt necessary in selected structures under this program. The Engineering Division is responsible for providing the training discussed in paragraph 7.

b. The Construction Divisions of the District offices will be responsible for the installation of the earthquake instrumentation devices and for data collection if an earthquake occura during the construction period.

c. The Operations Division of the District offices will be responsible for the imediate assesment of earthquake damage and notifying the Chief, Engineering Division as discussed in paragraphs 6a and $b$. The Operations Divisions will also be responsible for earthquake data collection after the construction period in accordance with the instrmental obeervation programs, and will assist and participate in the post-earthquake inspections.

d. The U.s. Geological Survey has the responsibility for servicing and collecting all data from strong motion instrumentation at Corps of Engineers dam projects following an earthquake occurrence. However, the U.S. Army Waterways Bxperiment Station (WES) is assigned the responsibility for analyzing and interpreting these earthquake data. Whenever a recordable earthquake record is obtained from seimic instrumentation at a Corps project, the Division will send a report of all pertinent instrumentation data to the Waterwaya Experiment station, ATTN: WESGH, P.0. Box 631, Vickeburg, Mississippi 39180. The report on each project should include a complete description of the locations and types of instruments and a copy of the instrumental records from each of the strong motion machines activated. (Exempt from requirements control under paragraph 7-2v, AR 335-15).

e. The Engineering Divisions of the Division offices will select structures for special instrumentation for earthquake effects, and will review and monitor the data collection, processing, evaluating, and inspecting activities. They will also be specifically responsible for promptly informing BQDA (DAEN-CWE) WASH DC 20314, when evaluation of the condition of the structure or analyses of the instrumentation data indicates the stability of a structure is questionable. (Exempt from requirements control under paragraph 7-20, AR 335-15). 
f. Division Engineers are responsible for issuing any supplementary regulations necessary to adapt the policies and instructions herein to the specific conditions within their Division.

9. Funding. Funding for the evaluation and inspection program will be under the Appropriation 96×3123, Operations and Maintenance, General. Funds required for the inspections, including Travel and Per Diem costs incurred by personnel of the Division office or the office, Chief of Engineers, will be from allocations made to the various projects for the fiscal year in which the inspection occurs.

FOR THE CHIEF OF ENGINEERS:

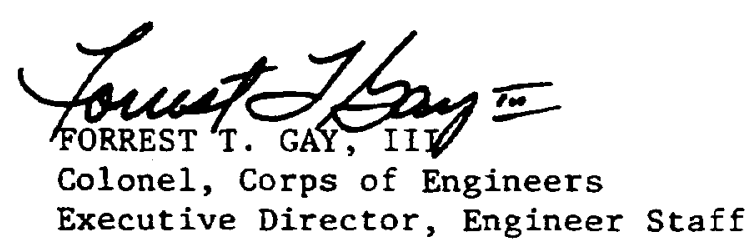




\section{Appendix B \\ WES Seismic Acceleration \\ Alarm Device, Model SAD Technical Specifications}

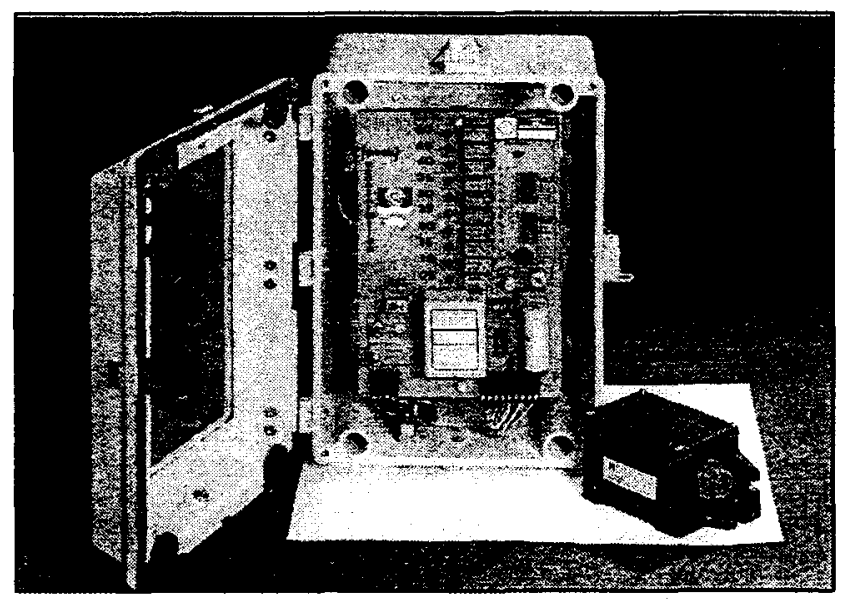

\section{Introduction}

The Seismic Acceleration Alarm Device, Model SAD, is designed and fabricated by personnel of the Instrumentation Services Division (ISD), US Army Corps of Engineers Waterways Experiment Station (WES). The purpose of the device is to provide project personnel with an immediate readout of the peak vertical acceleration level experienced on a structure following an earthquake. 


\section{General Description}

The Model SAD is an electronic peak acceleration recorder comprised of a vertical accelerometer unit and a control/display unit. The accelerometer unit senses and amplifies the acceleration level which is routed to the display unit by means of a 10-ft shielded cable. The control/display unit supplies the DC power and calibration commands to the accelerometer and processes the incoming acceleration signal. Acceleration that exceeds a preset level is stored in a latching relay bank and the peak level is retained and displayed by an array of light emitting diodes (LEDs) located on the control/display board. If a preset alarm threshold is exceeded, an audible alarm or a optional relay contact closure is activated. The optional relay contact can activate a telephone dialer, GOES satellite transmission, control circuit, computer interface, etc.

The glass windowed door of the control/display unit is locked to prevent unauthorized access to critical controls and calibration switches. Acceleration level LEDs, DC power indicator, battery charger light, as well as alarm level and calibration switches, can clearly be seen through the door window. The audible alarm reset button is the only external control.

The device is typically calibrated to display ten (10) peak acceleration levels from 0.05 to $0.50 \mathrm{~g}$. Acceleration of or greater than $0.50 \mathrm{~g}$ will cause the 0.50 $\mathrm{g}$ LED to remain illuminated. The output alarm level is switch selective to trigger from any one of ten levels, $0.05 \mathrm{~g}$ to $0.50 \mathrm{~g}$.

The power system consisting of a 12-volt, 6.5 amp-hour battery, an 8 amp-hour battery charger and a DC/DC converter provides an uninterruptible power supply. Battery charger power is normally drawn from the conventional 120 -volt commercial AC line. This arrangement provides a 48-hour continuous back up capability.

\section{Operation}

The device is designed to operate unattended for long periods. Routine periodic inspections consist of viewing the display board through the observation window to ensure that the DC power LED light is on and the battery charger light and data LEDs are off.

When an acceleration level greater than $0.05 \mathrm{~g}$ occurs, the device will indicate the peak level by latching "on" the appropriate $0.05 \mathrm{~g}$ resolution LED. An alarm is sounded indicating the instrument has triggered and should be read. The alarm is silenced by pushing the ALARM RESET button located on the outside of the control/display unit. The acceleration level from the display, the approximate time and date of the event are normally recorded in the project log book. 


\section{Special Operational Features}

$a$. After the device has been triggered, it remains active ready to record levels which exceed previously recorded peaks.

b. Only the maximum peak vertical level is stored.

c. The alarm is sounded each time the alarm threshold is exceeded.

d. Data stored in the latching relays is recoverable, even if the power is lost. Simply reapply power.

$e$. The only way to clear the level display LED is to reset the storage relays with the SYSTEM RESET push button on the main control/display board. Typically, the panel door is locked.

$f$. The $0.50 \mathrm{~g}$ LED indicates that the device has experienced acceleration at or above the $0.50 \mathrm{~g}$ level.

g. It is designed to operate in a bipolar fashion. Either positive or negative acceleration peaks will drive the data display. The system can be made to operate in unipolar manner by removing the appropriate operational amplifier and/or dot bar driver.

h. The ALARM RESET push button is the only external operator control. Operating this switch will reset the audible alarm; it will not reset the data display.

\section{Example}

A hypothetical example will help illustrate SAD operation. Consider the device operating with no LED illuminated when a $0.22 \mathrm{~g}$ acceleration occurs. Data is latched into the storage relays, the $0.20 \mathrm{~g} \mathrm{LED} \mathrm{data}$ array is updated to display the acceleration level, and the audible alarm is turned "on" to alert the project operators that the $0.10 \mathrm{~g}$ alarm threshold has been exceeded. Project personnel should then reset the alarm and record the $0.20 \mathrm{~g}$ reading, time, date, etc.

The device is now operating with the $0.20 \mathrm{~g}$ LED illuminated when another earthquake occurs. This second earthquake has a peak acceleration amplitude of $0.36 \mathrm{~g}$. The $0.20 \mathrm{~g}$ LED light will be turned "off" and the $0.35 \mathrm{~g}$ LED turned "on" since the new acceleration is greater. The alarm will again be sounded to alert the operators that an earthquake has occurred. They should then reset the alarm and record the new reading, time, date, etc.

Another aftershock occurs later with a peak acceleration of only $0.16 \mathrm{~g}$. The alarm will be sounded indicating the alarm threshold has been exceeded. 
However, the $0.35 \mathrm{~g}$ LED light will remain "on" since it represents the largest of the two acceleration levels.

The data LEDs could be reset after each alarm if a qualified person unlocks the control/display panel and depresses the display reset button. A policy should be established as to when, why and by whom the device is reset.

Cost

The 1998 cost of a Model SAD in quantities of 5 or more is $\$ 3250$ each. Installation cost (1998) is the same as an electronic accelerograph and is $\$ 700$ each.

\section{Options}

The Model SAD can be modified to accept a horizontal accelerometer if that mode is desired. The distance between the accelerometer and control/display panel can be increased up to $100 \mathrm{ft}$ at a cost for cable of $\$ 1.50$ per $\mathrm{ft}$. It is recommended that the panel and accelerometer be located inside a weatherproof building; however, at additional cost the system can be made weatherproof. Contact WES about other needs or options not listed.

\section{WES Points of Contact}

Lewis Smithhart, Electronics Technician

601-634-2578 or 601-634-3300

EMAIL: smithhl3@ex1.wes.army.mil

Joe Savage, Electronics Engineer

601-634-3414

FAX: 601-634-2747

EMAIL: savagem@ex1.wes.army.mil

USAE Waterways Experiment Station

ATTN: CEWES-IJ-O

3909 Halls Ferry Road

Vicksburg, MS 39180-6199 


\section{Appendix C \\ Seismic Alarm Device, Model SAD Operation Manual}

Mod 3: 15 June 1992

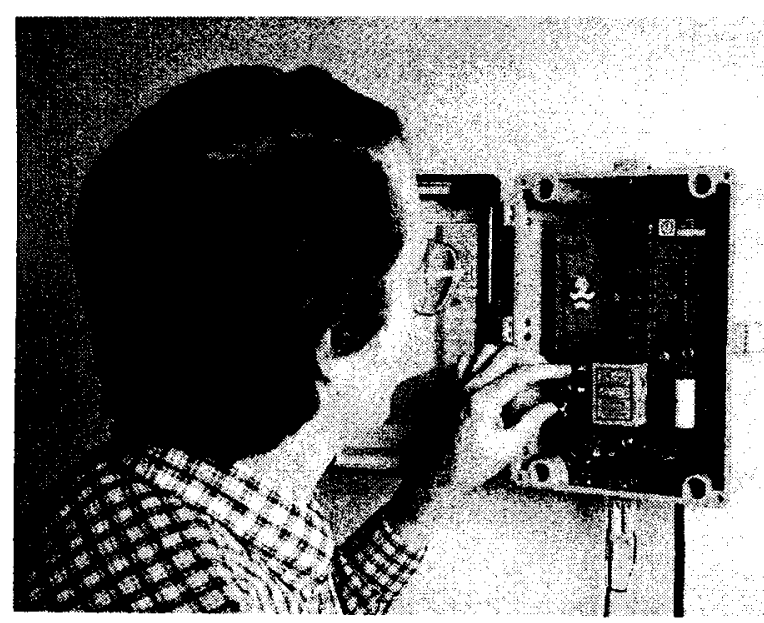

USACE WATERWAYS EXPERIMENT STATION CEWES-IJ-O

601-634-2578 


\subsection{INTRODUCTION}

This manual describes the Seismic Acceleration alarm Device, SAD mod 3. The following upgrades were incorporated into the standard SAD design to produce the mod 3:

1. An eleven position rotary switch has been added to the alarm set point circuit. This switch allows any one ten acceleration levels to trigger the alarm.

2. $\mathrm{PC}$ board plug $\mathrm{P} 2$ has been increased from 9 to 10 pins to accommodate an easy interface for a remote alarm switch closure connection.

3. An external battery charger has been added to replace the internal charger.

4. Minor changes have been made to the PC board layout.

\subsection{GENERAL DESCRIPTION}

The SAD consist of a low frequency accelerometer and a signal processor unit. The processor contains the electronics necessary to process and display the acceleration input. It also contains the power supply, alarm and control circuits of the SAD.

The SAD monitors and displays the maximum peak acceleration output from its Kinemetric's model FBA-11 accelerometer. Ten LEDs on the display panel are used to indicate the peak acceleration level recorded.

Any one of ten acceleration levels can be selected to generate both a local audible alarm and a relay switch closure for a remote alarm indication.

\subsection{INITIAL SYSTEM CHECK}

The steps for the pre-installation check out are as follows:

1. Inspect the SAD for any damage that may have occurred in shipping. Make sure that all of the electrical terminal connections are tight.

2. Verify that the SAD controls are set as follows:
a. Power switch is OFF
b. Cal rotary switch is in position $\mathbf{0}$
c. Dip switches are all $\mathbf{O N}$
d. Alarm Set Point rotary switch is set to position 1
e. AC/DC jumper is in DC 
3. Install the 12 volt battery in the space provided behind the plexiglass back plate. Connect the positive terminal to the red wire; the negative terminal to the black wire.

4. Replace the plexiglass back plate and PC board. Plug the charger into a $120 \mathrm{AC}$ volt outlet. Measure +12 VDC between pin 1 (HI) and pin 3 (LOW) of P1 on the PC board. Verify that the charger is operational.

5. Turn the Power switch to ON. Momentarily depress the Data Reset and Alarm Reset push buttons and verify that the audio alarm and the red Data LEDs are off. The green Power On LED should be illuminated.

6. Check the converter power output at connector P2:

Pin 1

Pin 2

$+12 \mathrm{VDC}$

Pin 3 COMMON

-12 VDC

7. The SAD processor converts the voltage output from the FBA-11 into an acceleration display. In order to insure that this conversion is accurate, the SAD comparator reference voltage must be set to match the FBA11 's calibration. This procedure must be repeated any time an accelerometer or processor board is replaced.

Monitor the voltage between the Range Test Point (HI) and common (pin 2 of P2). Adjust the Range Adjust potentiometer for a DC voltage that is equal $(+/-10 \mathrm{mv})$ to the absolute value (disregard sign) of the $0.50 \mathrm{~g}$ calibrated voltage output as indicated on the FBA Acceleration Calibration Data sheet. This voltage is approximately equal to 1.25 volts for a $1 \mathrm{~g}$ full scale FBA. The accelerometer output is now calibrated to the SAD display. A copy of the calibration should be left on site for further reference.

8. The following instructions explain how setup the FBA accelerometer:

a. Turn the Power switch to OFF.

b. Turn the Alarm (dip switch no.4) to OFF.

c. Place the FBA on a level surface. Its input arrow must be aligned to the axis of installation. For the normal VERTICAL measurement installation the arrow will point UP. Connect the FBA to the Processor input cable.

d. Connect a meter to monitor the DC voltage input to the comparator circuit (R4 to COMMON).

e. Turn the Power switch to $\mathbf{O N}$. 


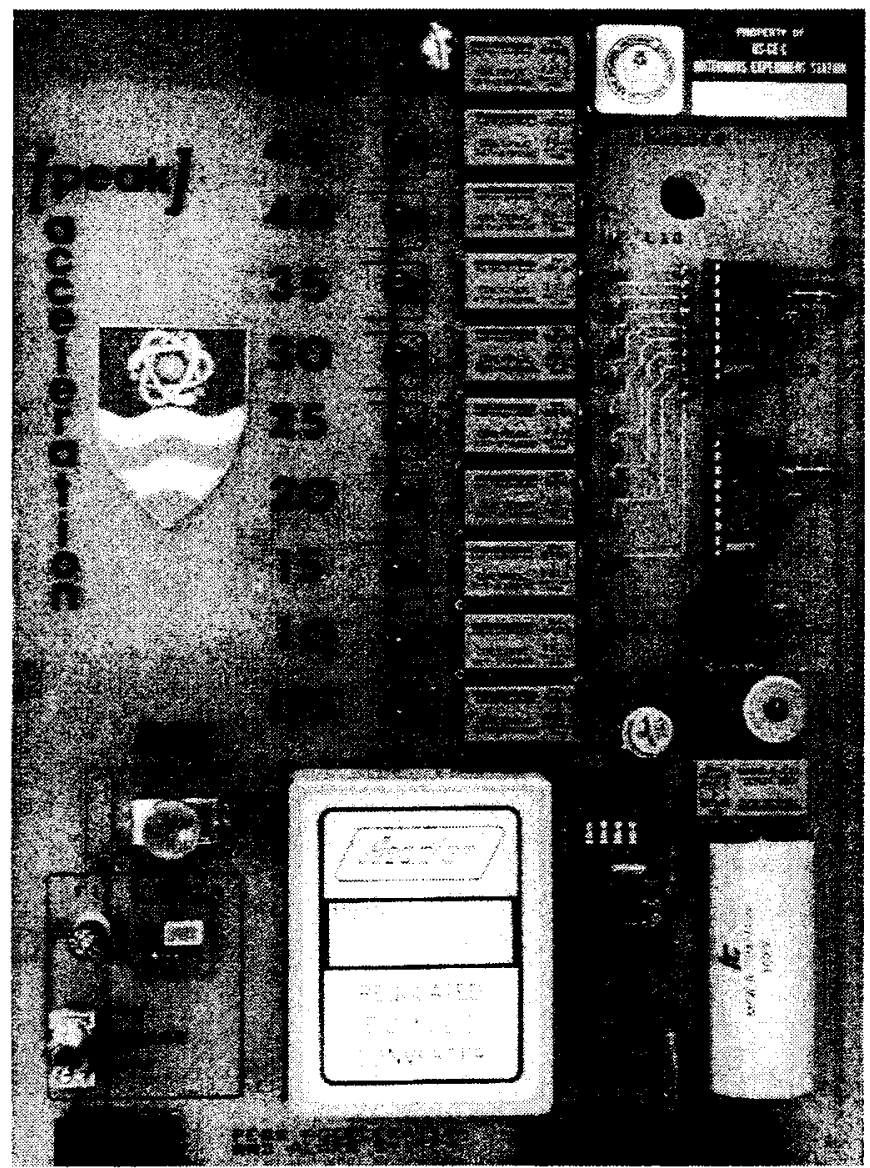

Figure C-1. SAD control panel

$f$. Follow the accelerometer adjustment instructions as outlined in paragraph 5.0 of the FBA-11 operations manual to balance the meter reading to less than $+/-10 \mathrm{mv} \mathrm{DC}$.

g. Momentarily depress the Data Reset push button to clear the data display.

$h$. Tilt the accelerometer and note that the data display LEDs update properly.

9. Check the alarm circuit operation. Turn the Alarm (dip switch no.4) to ON and select a minimum alarm set point with the Alarm Set Point rotary switch. Tilt the FBA and note that the alarm is sounded when the set point is reached. A switch closure will appear between pins 9 and 10 of $P 2$ when the SAD is in an alarm condition. 


\subsection{INSTALLATION GUIDE}

Use the following steps as a guide for permanent installation of the SAD.

1. Select a permanent location for the SAD on the structure that is free from high background vibrations and strong RF fields that might effect the instrument.

2. Readjust the balance after the FBA has been secured in place. $A$ large offset will cause the display to be in error by the amount of the offset!

3. Check the Cal Step voltage.

a. Record the offset voltage at R4.(note sign $+/$-)

b. Turn the CAL rotary switch to position $\mathbf{1}$.

c. Record the FBA output voltage at R4.

d. Subtract the voltage measured in step 1 from the reading taken in step 3. Record this calculated value in the local file as the Cal Step Voltage.

e. Return the Cal switch to the $\mathbf{0}$ position and reset the display.

4. Make the following checks before securing the instrument:

Select desired alarm threshold with the Alarm Set Point switch.

Make sure that dip switches are all $\mathbf{O N}$.

Push the Data Reset and Alarm Reset push buttons and verify that the data display and alarm are off.

Verify that battery and charger are connected and working properly.

\subsection{ELECTRICAL CONNECTIONS}

$\mathrm{P} 1$ is the 3 pin PC board connector.

Pin

\section{Function}

1

2

+12 Volt Battery

3

Audio Alarm Trigger

Common Battery

$\mathrm{P} 2$ is the 10 pin PC board connector. 
Pin

1

2

3

4

5

6

7

8

$9 / 10$

\section{Function}

+12 Volt Converter Output

Common

- 12 Volt Converter Output

Signal Common

Undamp Command to the FBA

Step Command to the FBA

Accelerometer Signal Output

Alarm Reset

Switch Closure For Remote Alarm

\subsection{CONTROLS}

\section{CONTROL}

Power Switch

Dip Switch

Data Reset PB

Alarm Reset PB

Alarm Set Point

CONTROL

Cal

Jumper

Range Adjust

\section{FUNCTION}

Applies battery and charger power to SAD

1. + Accelerometer signal to comparator

2. - Accelerometer signal to comparator

3. Not used

4. Audio alarm on/off

Resets the red data display LEDS

Resets the audio and remote alarm

Used to select acceleration level that will activate the alarm circuit

\section{FUNCTION}

Used to test FBA accelerometer

0 . Normal operation position

1. Cal step command to FBA

2. Undamp command to FBA

Caution: Never set $\mathrm{Cal}$ switch to any position other than 0,1 , OR 2 .

Selects AC or DC input coupling

Single turn potentiometer that is used to calibrate the SAD output 


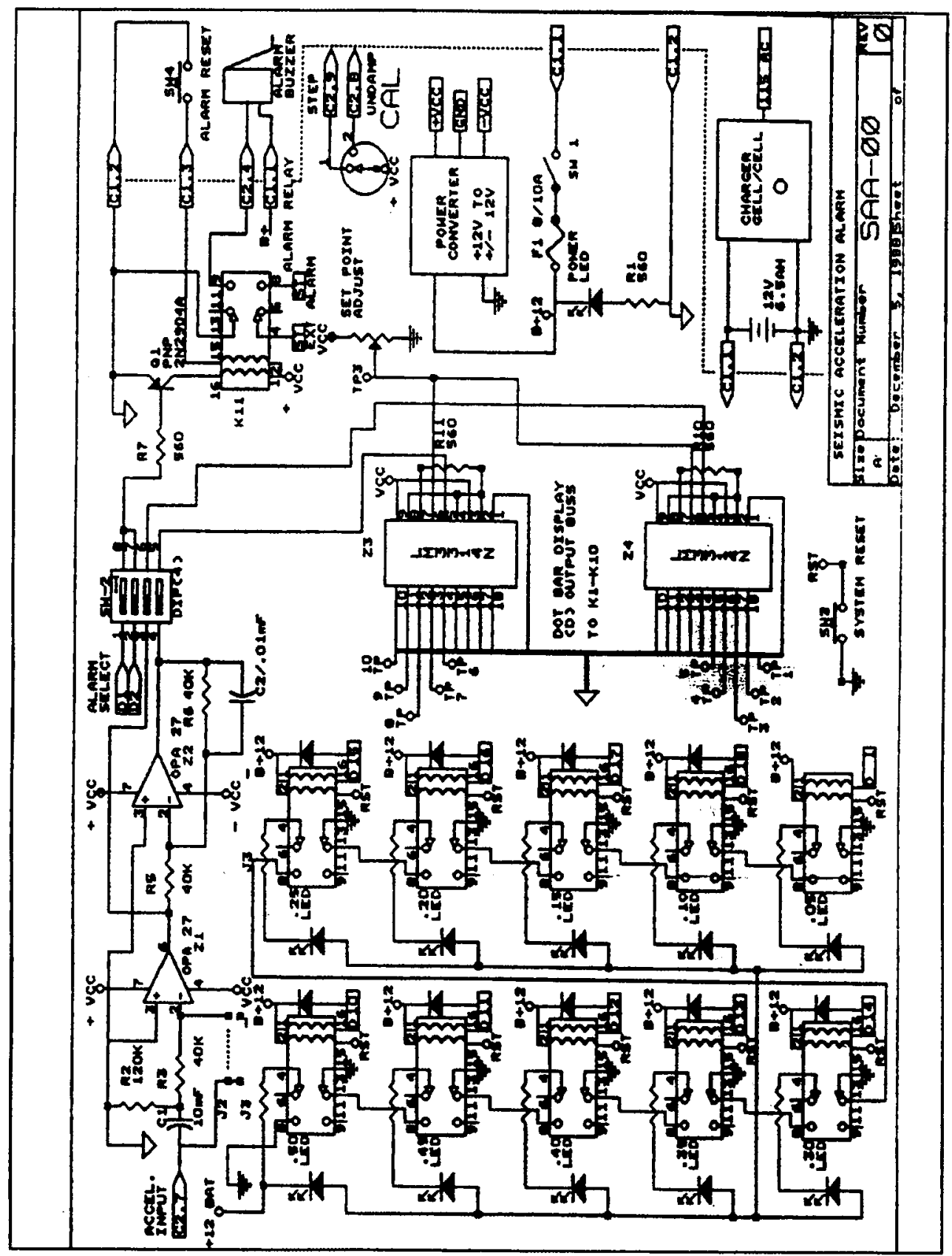

Figure C-2. Diagram of SAD circuitry. 


\subsection{INDICATORS}

INDICATOR

Data Display

Power LED

\section{FUNCTION}

10 Red LEDS that indicate peak acceleration

Green LED that indicates that power is applied

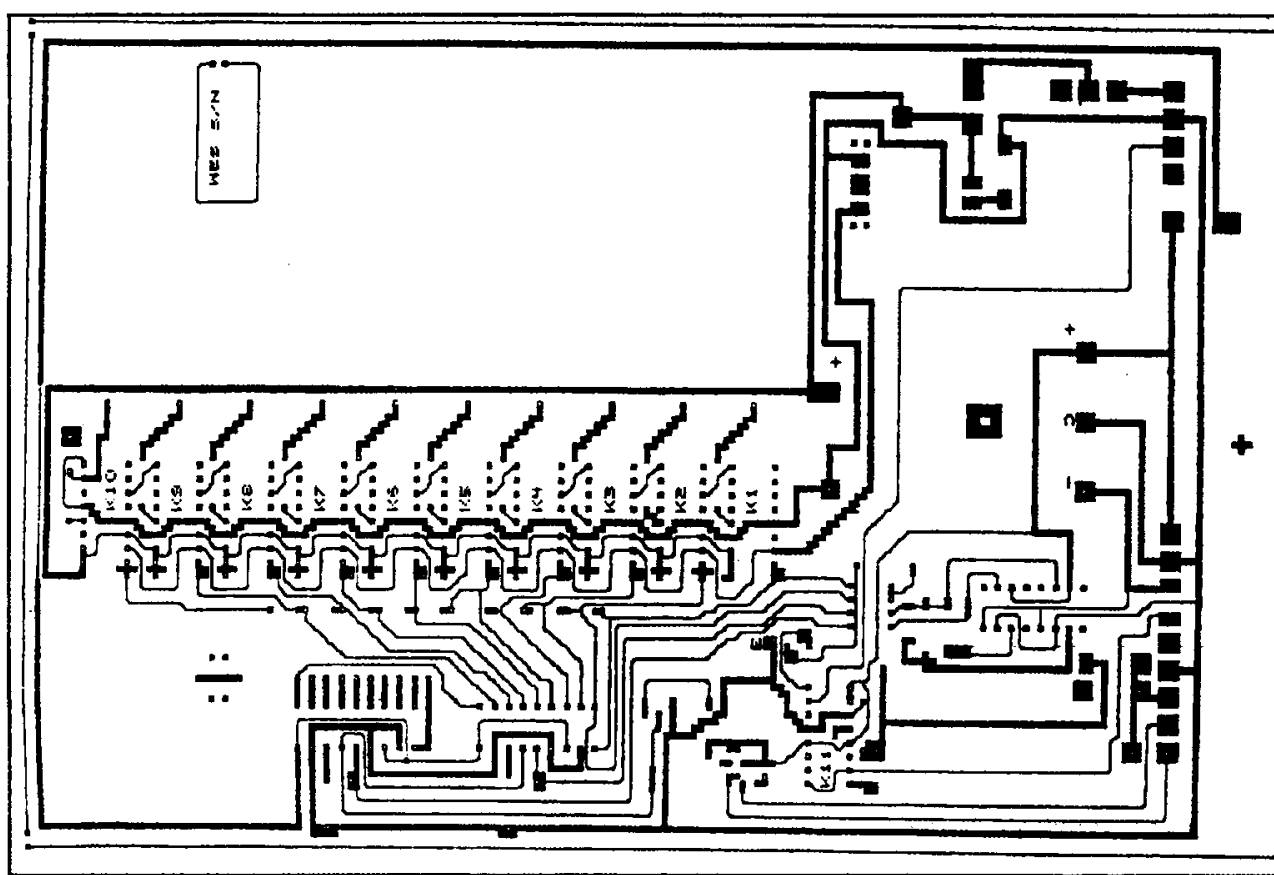

Figure C-3. SAD circuitry diagram (solder side) 


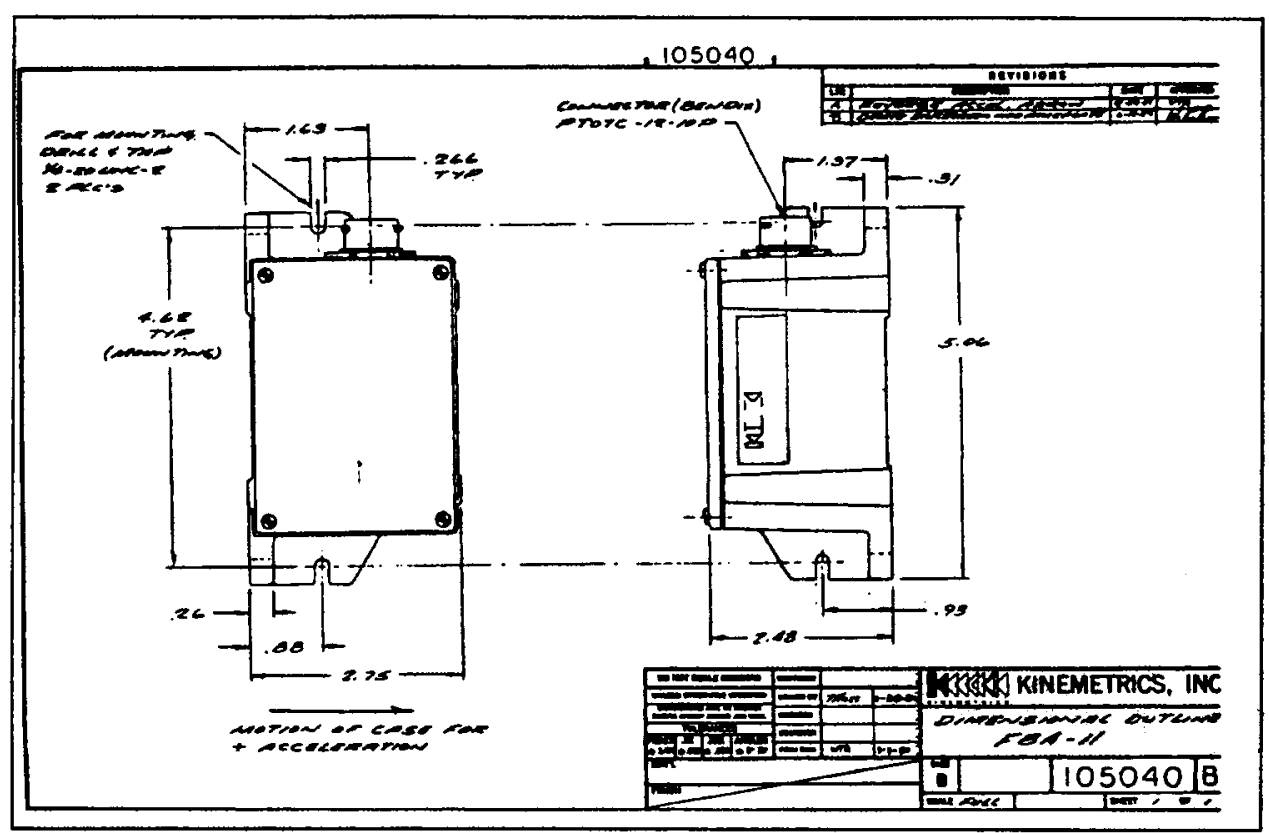

Figure C-4. Dimensional outline of accelerometer case

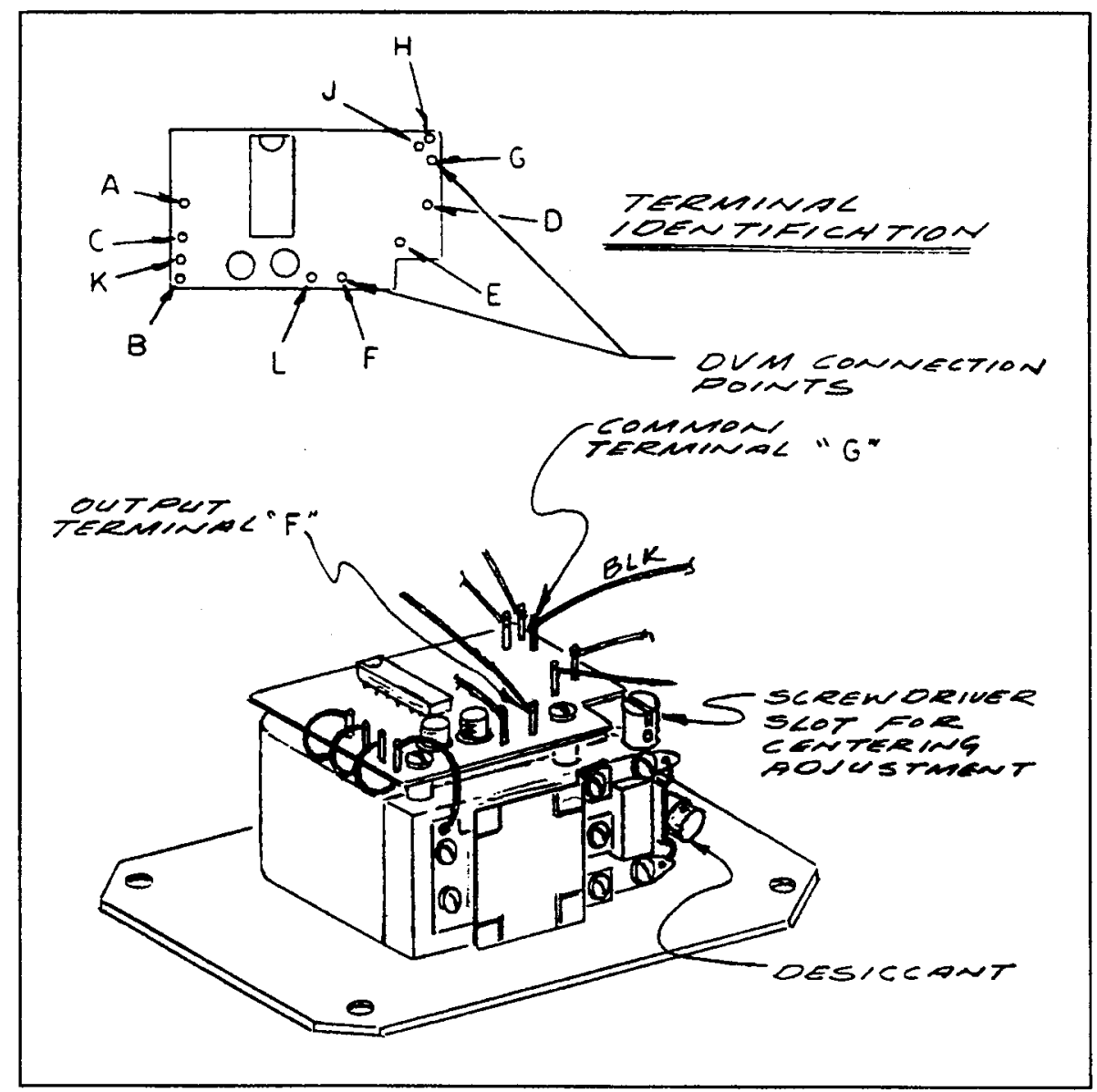

Figure C-5. Balancing accelerometer output 


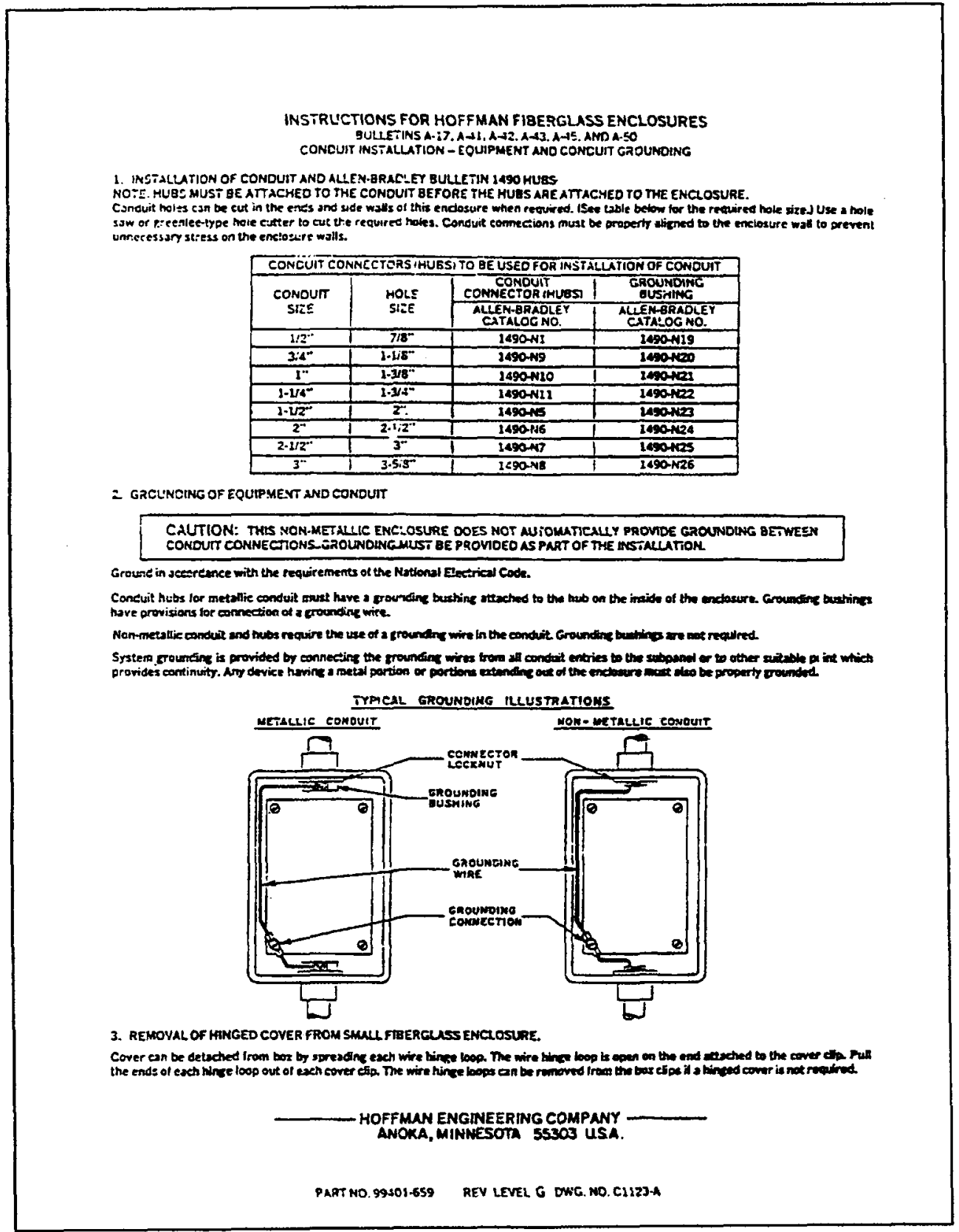

Figure C-6. Conduit installation - equipment and conduit grounding 


\section{Appendix D USGS NEIC On-Line Information Program}

The On-Line Information Program program is available to individuals and groups having access to a 1200 - or 2400 -baud terminal with dial-up capabilities to a commercial telephone number at the USGS National Earthquake Information Center in Golden, Colorado. Available on a 24-hour basis, 7 days a week, this program has three options: Quick Epicenter Determinations (QED), Earthquake Lists, and Geomagnetic Field Values. More information may be obtained by contacting:

The On-Line Information Program /QED/

USGS/NEIC

Box 25046, Federal Center, MS 967

Denver, CO 80225

Phone: 303-273-8500

\section{Information Via Computer}

\section{On-Line Information System.}

800-358-2663

Within Colorado: 303-273-8672

qed@neis.cr.usgs.gov

Access to earthquake and geomagnetic information within the last 3 weeks. (300 to 1200 baud, 7 data bits, 1 stop bit, zero parity)

\section{Current Seismicity}

finger quake@gldfs.cr.usgs.gov

The time period of data available in the QED is approximately 3 weeks -from about 2 days behind real time to the current Preliminary Determination of Epicenters (PDE) in production. Events within 7 days of real time are still being revised and republished for the QED as new data are received from contributing observatories. Events older than 7 days are no longer revised for the QED, but are retained in the database (and are available to QED users) until they are reworked for publication on the PDE. 
The following are printouts of actual data collected via QED.

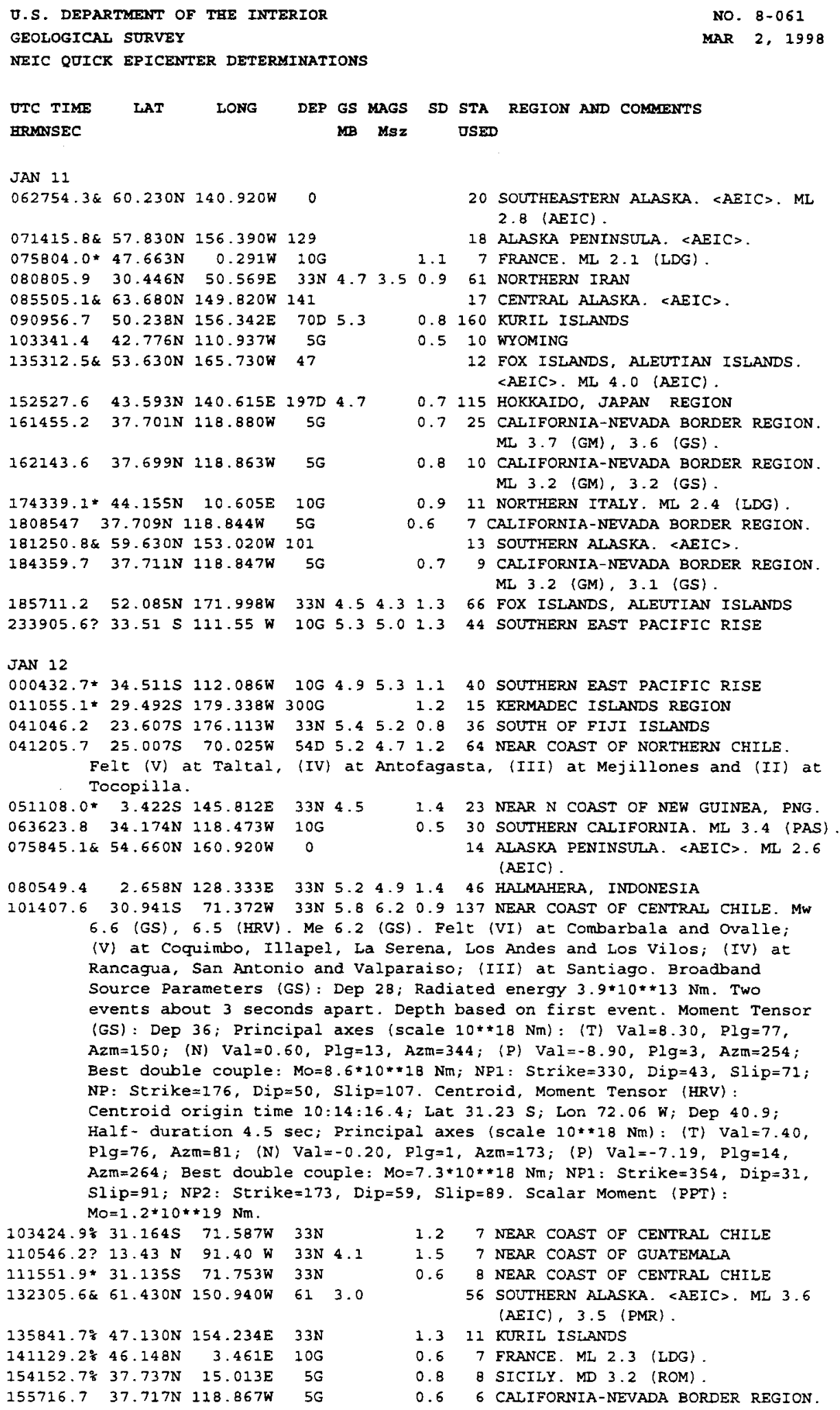


Symbols Following origin Iime:

$\& \quad$ Indicates that parameters of the hypocenter were supplied or determined by a computational procedure not normally used by NEIS. The source or nature of the determination is indicated by a 2 to 5 letter code enclosed by angle brackets and appearing in the first line of comments. A "-P" appended to the code indicates that the computation is preliminary. These codes are included in the list of abbreviations below.

: Indicates a single network solution. A non-furnished hypocenter has been computed using data reported by a single network of stations for which the date and/or origin time cannot be confirmed from seismograms available to a NEIS analyst. The geometric mean of the semi-major and semi-minor axes of the horizontal $90 \%$ confidence ellipse is less than or equal to $16.0 \mathrm{~km}$.

* Indicates a less reliable solution. In general, the geometric mean of the semi-major and semi-minor axes of the horizontal $90 \%$ confidence ellipse is greater than $8.5 \mathrm{~km}$ and less than or equal to 16.0 $\mathrm{km}$.

? Indiates a poor solution, published for completeness of the catalogue. In general, the geometric mean of the semi-major and semiminor axes of the horizontal $90 \%$ confidence ellipse is greater than $16.0 \mathrm{~km}$. This includes a poor solution computed using data reported by a single network.

Q Indicates a preliminary solution obtained from the NEIC Earthquake Early Alerting Service program "Quick-quake."

The lack of any symbol indicates that the geometric mean of the semi-major and semi-minor axes of the horizontal $90 \%$ confidence ellipse is less than or equal to $8.5 \mathrm{~km}$.

\section{Symbols Following Depth:}

N Indicates depth was restrained at $33 \mathrm{~km}$ for earthquakes whose character on seismograms indicate a shallow focus but whose depth is not satisfactorily determined by the data.

D Indicates depth was restrained by the computer program based on 2 or more compatible PP phases and/or unidentified secondary arrivals used as pP.

$G$ Indicates the depth was restrained by a geophysicist.

* Indicates a less well-constrained free depth. The $90 \%$ marginal confidence interval on depth is greater than $8.5 \mathrm{~km}$ and less than or equal to $16.0 \mathrm{~km}$.

? Indicates a poorly-constrained free depth. The $90 \%$ marginal confidence interval on depth is greater than $16.0 \mathrm{~km}$.

The lack of any symbol indicates that the $90 \%$ marginal confidence interval on depth is less than or equal to $8.5 \mathrm{~km}$, or that a contributed hypocenter was computed with a free depth, regardless of the size of the confidence interval.

Symbols and Abbreviations Used in Comments:

BLA Virginia Polytechnic Institute and State University, Blacksburg.

BRK University of California, Berkeley.

CL Coda length magnitude.

DOE U.S. Department of Energy.

ERDA U.S. Energy Research and Development Administration.

EXPLO Some or all parameters of explosion (controlled or accidental) supplied by any group or individual other than ERDA or its successor organizations.

GLD U.S. Geological Survey, Golden, Colorado (other than NEIS). 


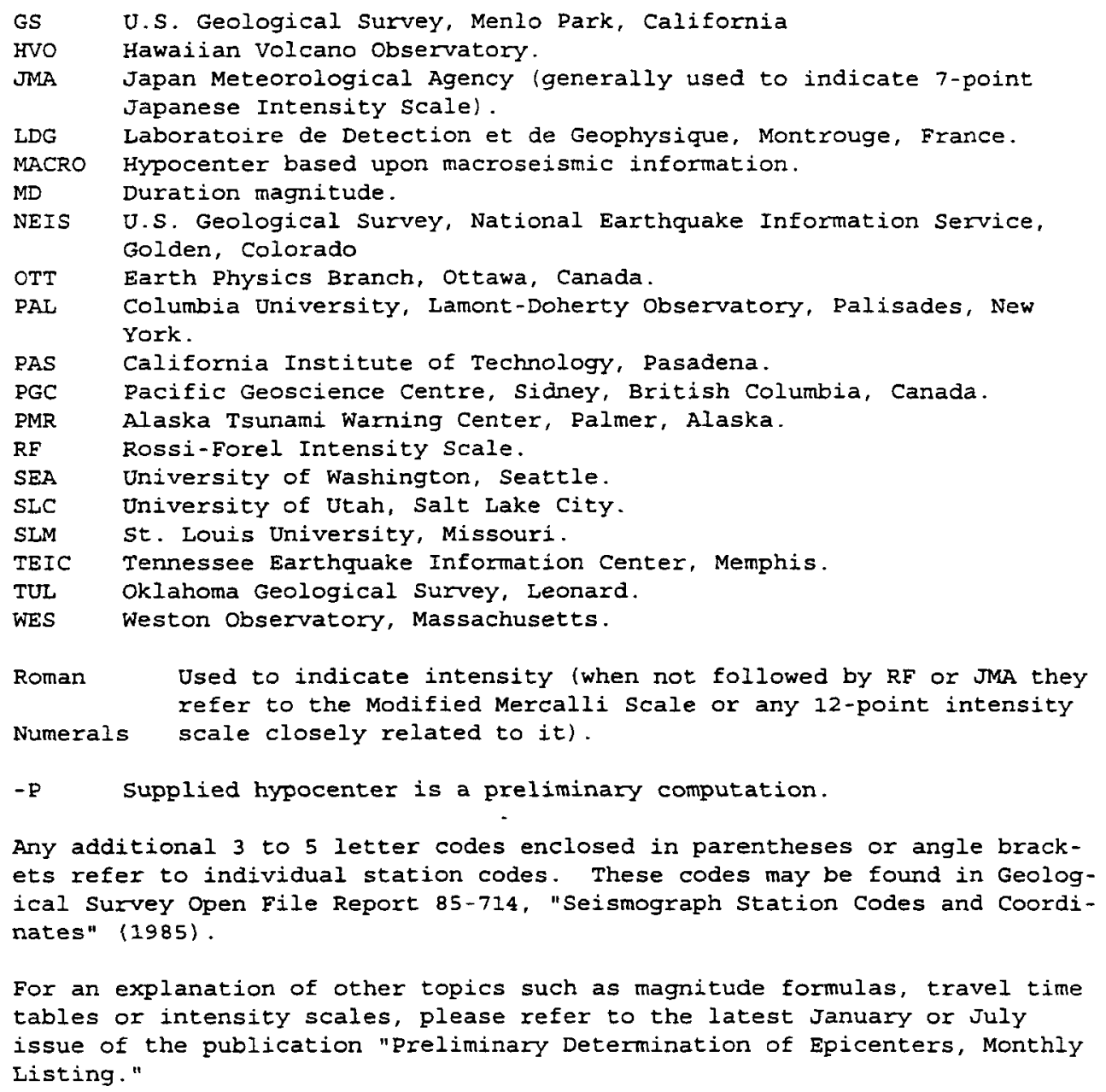

Near real-time earthquake information bulletins as well as current earthquake maps, and lists of significant earthquakes are available from the USGS NEIC via the internet at http://wwwneic.cr.usgs.gov/current_seismicity.shtml. Examples of information available from this site are shown on the following pages. 


\section{ख्याSTS}

\section{2) National Earthquake Infonnation $C_{\text {enter }}$ \\ - World Dara Center $A_{\text {for }}$ Seismology}

Gomain $\underline{H}_{\operatorname{mads}}$

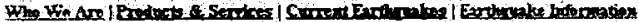

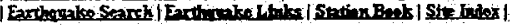

\section{- CURRENT EARTHOUAKE INFORMATION}

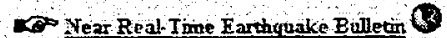

Updated as of Thu Jul 23 09:04:48 MDT 1998 .

Lists the lest 2 I earthounakes wordd wide.

Co Explanation of eathquake parmerem

The arralability of add dicanel informalion, and our publicasion enteri

Current Earthquake Maps.

Earthquakes showe on these seisomicty maps are taken fom the

NEIC Near-Real Twe Er hquake Bulletin (above)

- Iatest Fast Mameat Solutions

- Prenous Mones Solutions

Corrent Hypocenter and Fhas $\mathrm{D}_{\text {ata }}$

Recent Earthquake Iists

Updated once a day, ar 6:30-7:00 ANG Mouman Tine

Contains approsenately 3 weeks of iniormation

\section{- 1998 Lange Earthquakes}

- List of Significant Earthquakes of the World for 1998

Fast USGS Moment Tensor Snlutions

- Enst Mfomen Nolificaion Service

\section{[GW GW Hecord Section of Recent Earthquake}

Broatband record section of recent signficant earthquake recorded by the United States Natonal Stisnograph Network (DSNSN) and contributog starions

- Earthquake Natification Serviens

Data Araitable Through FIP

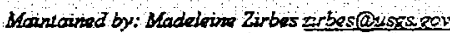

5 m

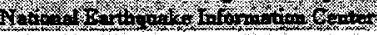

Jpdated Friday, 10-Jul-98 13:46:35 MDT

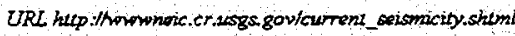


EISGS

INational Earthquake Information Center
$W_{\text {orld }} D_{\text {ara }} C_{\text {enter }} \mathrm{A}_{\text {for }} S_{\text {eismology }}$

Geologic Howands

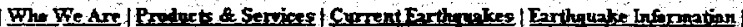

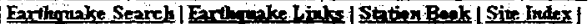

U.S. Geological Survey's National Earthquake Information Center.

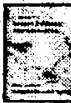

\section{Guide to Products and Services}

Following is a description of the products and services offered by the United Sutes Geological Surver's Wational Earthouake Infor Prices are subject to change without notice. Addresses and telephone numbers are listed for the distribution office of each of the prc the products and services, plicase contact the USGSAEIC at the address below.

U.S. Geological Survey

National Earthquake Information Center

P. 0. Box 25046

Denver Federal Center, MS 967

Denver, Co 80225

(303)2 33-8500

\section{Contents}

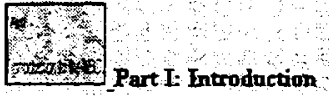

-The USGS National Earthouake Irformation Center

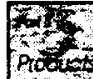

Prodots

Product

CD-ROM Products

- Esthquale Diqta Dat CD-ROMI

- Map and Poster Prodiucts

- Foll-Color Global and State Seismictr Maros

- Additona State Seisiniciry Maps

- Other NEIC Products

- Earthouake Data Report

US Eartholakes

Seismicty of the United States, $1568-1989$

Despotses to Tben Brownen's Prediction of a 1990 New Madrid. Mussoun Eamouake

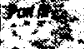

Serves Part III Services

- Data Base Services

The On-Line Infomation Frogtam

Other NETC Services

The Earhouake Information Line

(Contact NETC for curront product pricing.)

Mantaniod by Madeleine Zirbes zimbesaunsgs gov

H

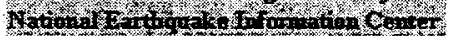

Updated Thursday, 26-Feb-98, 13:29:46 NSST

URL hetp:/fwowneic.cr.tsgs gov/netspaADsttitle.hem 


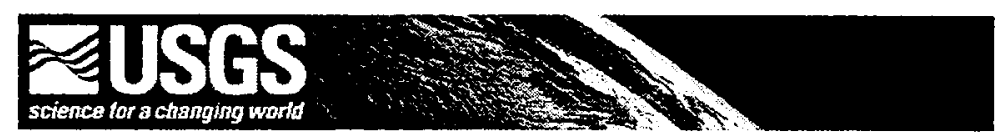

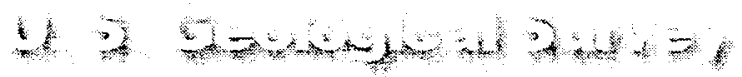

NATIONAL STRONG-MOTEN PROGRAM

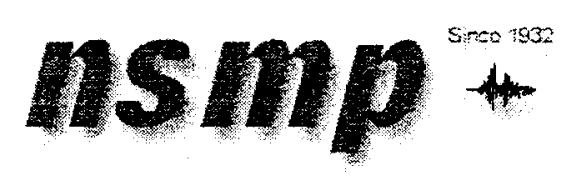

Seismic Engineening and Ground Response Studies

The National Strong-Hotion Program (NSMP) comprises three principal sections:

- Network Development and Operations section, responsible for overall management of the Mational Strong-Motion Network

- Data Management section, responsible for anahses and dissemination of processed data from the National Strong-Motion Netwark

- Engineering Research section, with specific responsibilities for the investigation of structure response and site effects.

Progam News. Recent Events Station List Station Maps Recent Studies Catabgues

Date Sets : NoD : BAP Aska Geologist

Surfing the Internet for Strong-Motion Data

The USGS Home Page is at httpithmun. usas.gov

The USGS Geologic Division Home Page is at http://geologu.usqs.qov

The URL of this page is http:/agram.wr.usgs.gov

Contacts:

Network Development and Operations: Ron Porcella

Data Analysis and Dissemination: Chris Stephens

Engineering Research: Mehmet Celebi

Webmaster: Kent Fogleman

This site was last updated on May 14, 1998 (KF) 


\section{Appendix $\mathrm{E}$ Tabulation of USACE Strong- Motion Data, 1971-1997}




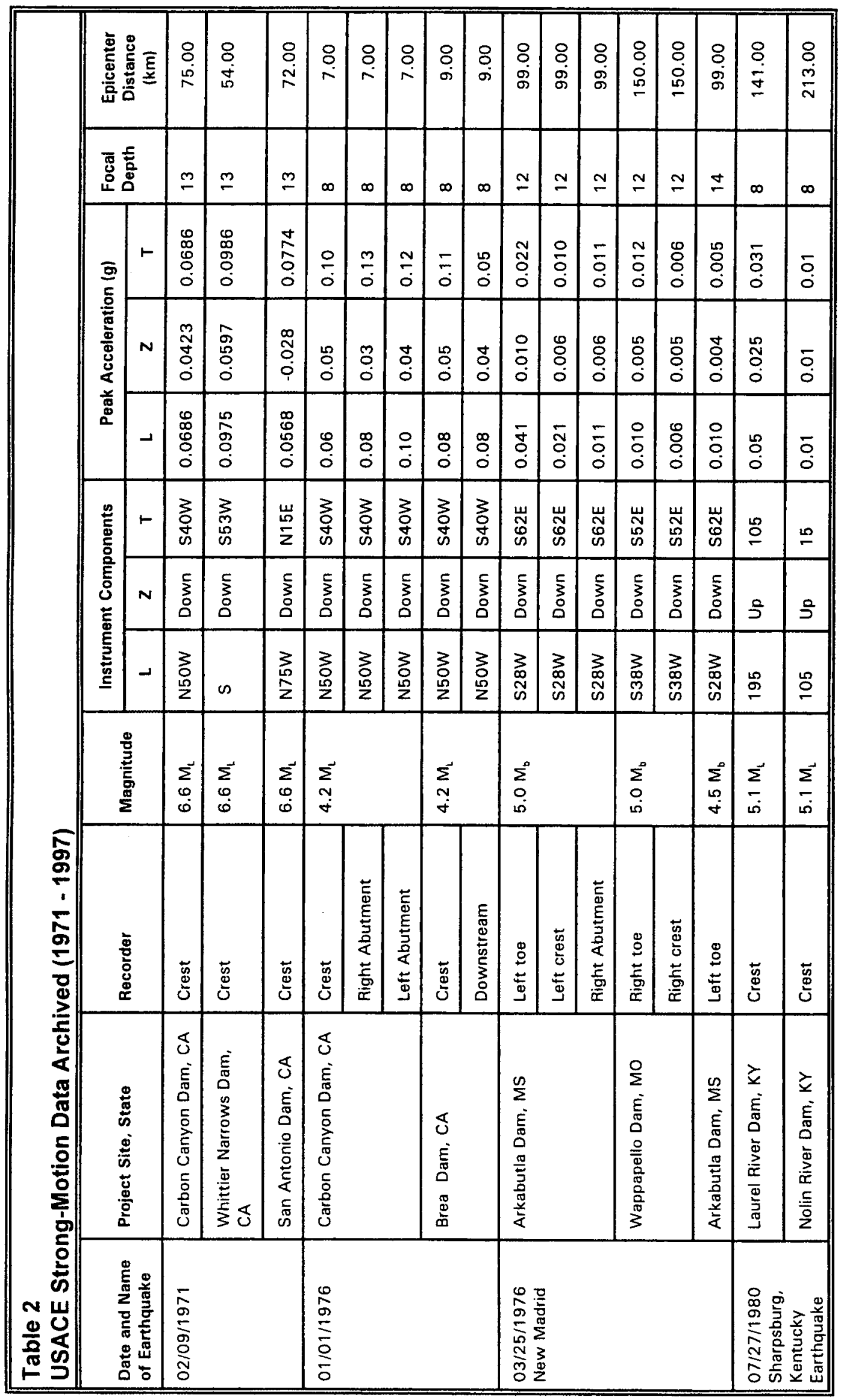




\begin{tabular}{|c|c|c|c|c|c|c|c|c|c|c|c|c|c|c|c|c|c|c|c|c|c|c|c|c|}
\hline & 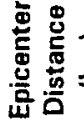 & & $\begin{array}{l}8 \\
\infty \\
\infty\end{array}$ & $\begin{array}{l}8 \\
\infty \\
\infty\end{array}$ & $\begin{array}{l}8 \\
\infty \\
\infty\end{array}$ & $\begin{array}{l}8 \\
\dot{0} \\
8\end{array}$ & $\begin{array}{l}8 \\
\dot{0} \\
\dot{0}\end{array}$ & $\begin{array}{l}8 \\
\dot{8} \\
\dot{0}\end{array}$ & $\frac{8}{6}$ & $\frac{8}{5}$ & $\begin{array}{l}8 \\
\dot{0} \\
i\end{array}$ & $\begin{array}{l}\stackrel{8}{0} \\
\stackrel{+}{+}\end{array}$ & $\begin{array}{l}\stackrel{8}{0} \\
\dot{+}\end{array}$ & $\begin{array}{l}8 \\
\dot{j} \\
-\end{array}$ & $\begin{array}{l}8 \\
\dot{+} \\
\end{array}$ & $\begin{array}{l}\text { ঃ } \\
\dot{0} \\
\text { j }\end{array}$ & $\begin{array}{l}8 \\
\dot{g} \\
=\end{array}$ & $\begin{array}{l}8 \\
\dot{g} \\
\end{array}$ & $\begin{array}{l}8 \\
\dot{0} \\
\stackrel{2}{=}\end{array}$ & $\begin{array}{l}8 \\
\stackrel{0}{0} \\
\stackrel{\infty}{0} \\
-\end{array}$ & $\begin{array}{l}8 \\
\dot{8} \\
\infty \\
-\end{array}$ & $\begin{array}{l}8 \\
\stackrel{0}{0} \\
\square\end{array}$ & $\begin{array}{l}8 \\
8 \\
8 \\
\infty \\
-\end{array}$ & $\begin{array}{l}\circ \\
8 \\
\circ \\
\infty \\
-\end{array}$ \\
\hline & 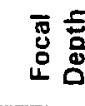 & & $\begin{array}{l}\infty \\
\dot{\sigma} \\
\dot{q}\end{array}$ & $\begin{array}{l}\infty \\
\dot{+}\end{array}$ & $\begin{array}{l}\infty \\
\dot{v}\end{array}$ & $\stackrel{\infty}{\dot{q}}$ & $\stackrel{\infty}{+}$ & $\stackrel{\infty}{\dot{q}}$ & $\stackrel{\infty}{+}$ & $\begin{array}{l}\infty \\
\dot{q}\end{array}$ & $\begin{array}{l}\infty \\
\dot{q}\end{array}$ & ما & 0 & o & م & 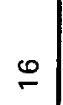 & $\stackrel{6}{-}$ & $\stackrel{\oplus}{\circ}$ & $\stackrel{\oplus}{\stackrel{1}{2}}$ & $\stackrel{\oplus}{-}$ & $\stackrel{\bullet}{\circ}$ & $\stackrel{0}{-}$ & $\stackrel{\circ}{\circ}$ & 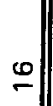 \\
\hline & 可 & $\vdash$ & $\begin{array}{l}0 \\
0 \\
0 \\
0 \\
0\end{array}$ & $\begin{array}{l}0 \\
\text { 号 } \\
0 \\
0 \\
0\end{array}$ & $\begin{array}{l}N \\
\tilde{m} \\
0\end{array}$ & $\begin{array}{l}\stackrel{L}{\sim} \\
0 \\
\dot{0} \\
\end{array}$ & $\begin{array}{l}\hat{8} \\
\dot{0} \\
\end{array}$ & 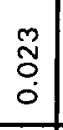 & $\begin{array}{l}8 \\
: \\
0 \\
0\end{array}$ & $\begin{array}{l}\mathscr{8} \\
\dot{8} \\
\dot{0} \\
\end{array}$ & $\begin{array}{l}\text { N. } \\
0 \\
0\end{array}$ & $\stackrel{\stackrel{\mathscr{N}}{\sim}}{\circ}$ & 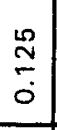 & $\begin{array}{l}3 \\
\stackrel{9}{0} \\
\dot{0} \\
\end{array}$ & $\begin{array}{l}10 \\
0 \\
0 \\
0 \\
0\end{array}$ & $\begin{array}{l}0 \\
\stackrel{0}{0} \\
0 \\
0 \\
\end{array}$ & $\begin{array}{l}0 \\
0 \\
0 \\
0\end{array}$ & 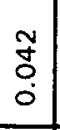 & $\begin{array}{l}8 \\
8 \\
0 \\
0 \\
0\end{array}$ & $\begin{array}{l}\sim \\
\overline{0} \\
0 \\
\end{array}$ & $\begin{array}{l}\bar{g} \\
0 \\
0 \\
\end{array}$ & مo & $\frac{m}{0}$ & $\begin{array}{l}\bar{t} \\
0 \\
0 \\
\end{array}$ \\
\hline & 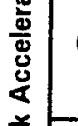 & $N$ & 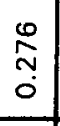 & $\stackrel{0}{\stackrel{0}{0}}$ & $\frac{0}{\circ}$ & \begin{tabular}{l}
\multirow{N}{*}{} \\
$\dot{0}$ \\
\end{tabular} & $\begin{array}{l}\mathscr{0} \\
8 \\
0 \\
\end{array}$ & $\begin{array}{l}\stackrel{9}{0} \\
\stackrel{0}{0}\end{array}$ & $\begin{array}{l}\infty \\
0 \\
0 \\
0 \\
0 \\
\end{array}$ & $\begin{array}{l}n \\
\overline{0} \\
0\end{array}$ & $\frac{ \pm}{0}$ & $\begin{array}{l}\stackrel{\infty}{\sim} \\
\stackrel{0}{\circ}\end{array}$ & $\begin{array}{c}\stackrel{\infty}{\sim} \\
\stackrel{0}{0}\end{array}$ & $\frac{9}{\circ}$ & $\begin{array}{l}\stackrel{J}{ల} \\
\stackrel{0}{0} \\
0\end{array}$ & $\begin{array}{l}0 \\
0 \\
0\end{array}$ & $\begin{array}{l}\infty \\
8 \\
0 \\
0\end{array}$ & $\begin{array}{l}\sim \\
0 \\
0\end{array}$ & $\begin{array}{l}m \\
\ddot{g} \\
0 \\
0\end{array}$ & \begin{tabular}{l}
$\infty$ \\
\hdashline \\
0
\end{tabular} & $\begin{array}{l}\infty \\
8 \\
0 \\
0\end{array}$ & $\begin{array}{l}0 \\
0 \\
0\end{array}$ & $\begin{array}{l}\circ \\
0 \\
0\end{array}$ & $\begin{array}{l}\text { Na } \\
0 \\
0 \\
0\end{array}$ \\
\hline & $a^{\infty}$ & لـ & $\frac{9}{\stackrel{9}{9}}$ & 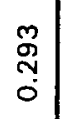 & 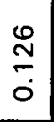 & $\begin{array}{l}\stackrel{M}{2} \\
0 \\
\dot{0}\end{array}$ & $\begin{array}{l}8 \\
: \\
0\end{array}$ & \begin{tabular}{l}
$\infty$ \\
\hdashline \\
0 \\
0
\end{tabular} & $\begin{array}{l}\frac{m}{5} \\
0 \\
0\end{array}$ & $\begin{array}{l}\infty \\
0 \\
0 \\
0\end{array}$ & $\begin{array}{l}\tilde{N} \\
\text { ơ } \\
0\end{array}$ & $\begin{array}{l}\tilde{O} \\
\stackrel{0}{0}\end{array}$ & $\begin{array}{l}\tilde{N} \\
0 \\
0 \\
0\end{array}$ & $\begin{array}{l}\mathscr{8} \\
\stackrel{0}{0} \\
0 \\
0\end{array}$ & $\frac{2}{\frac{2}{0}}$ & $\begin{array}{l}n \\
\vdots \\
0 \\
0\end{array}$ & $\frac{m}{0}$ & $\begin{array}{l}\mathscr{P} \\
0 \\
0 \\
0\end{array}$ & $\begin{array}{l}\overline{0} \\
0 \\
0\end{array}$ & $\begin{array}{l}N \\
\overline{0} \\
0\end{array}$ & $\begin{array}{l}\tilde{y} \\
\tilde{0} \\
0\end{array}$ & $\begin{array}{l}\frac{10}{0} \\
0\end{array}$ & $\frac{0}{0}$ & \begin{tabular}{l||}
$\bar{g}$ \\
0 \\
0
\end{tabular} \\
\hline & 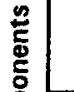 & $\vdash$ & $\stackrel{\mathscr{m}}{=}$ & $\frac{12}{m}$ & $\frac{\omega}{m}$ & $\begin{array}{l}\stackrel{5}{\circ} \\
\stackrel{5}{\circ}\end{array}$ & $\stackrel{\text { 吕 }}{=}$ & $\stackrel{\llcorner}{\Omega}$ & $\begin{array}{l}\stackrel{D}{\infty} \\
\text { 品 }\end{array}$ & $\stackrel{L}{\stackrel{D}{N}}$ & $\stackrel{\mathscr{\infty}}{\square}$ & : & $\stackrel{\infty}{-}$ & $\mathscr{\mathscr { \sigma }}$ & $\stackrel{\mathscr{m}}{\sim}$ & $\overline{5}$ & $\stackrel{g}{\mathrm{~g}}$ & $\stackrel{\oplus}{-}$ & $\stackrel{\mathscr{m}}{=}$ & $\stackrel{\stackrel{D}{\sim}}{\mathrm{N}}$ & $\stackrel{\mathscr{D}}{\mathrm{N}}$ & $\stackrel{\text { 号 }}{\text { N }}$ & f & 号 \\
\hline & 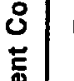 & $\mathbf{N}$ & 5 & $\frac{0}{5}$ & 5 & $\stackrel{0}{5}$ & $\stackrel{2}{5}$ & $\stackrel{2}{5}$ & 5 & s) & 5 & 옹 & $5^{2}$ & 5 & 윽 & $\stackrel{2}{5}$ & $\stackrel{2}{3}$ & 5 & 5 & s & $\frac{2}{51}$ & 5 & $\stackrel{2}{5}$ & 에 잉 \\
\hline & . & ــ & $\stackrel{\sim}{N}$ & 8 & 号 & $\stackrel{\text { L }}{\underset{N}{2}}$ & 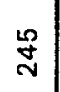 & $\stackrel{L}{\stackrel{D}{N}}$ & $\stackrel{2}{2}$ & 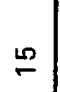 & $\stackrel{+\infty}{\sim}$ & ஜ & $\hat{\Sigma}$ & $\stackrel{\mathscr{D}}{-}$ & $\frac{m}{N}$ & $\bar{\Xi}$ & $\stackrel{\text { N }}{\text { D }}$ & $\stackrel{乛}{N}$ & 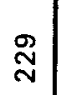 & $\stackrel{\stackrel{\sim}{\tilde{O}}}{ }$ & $\stackrel{\mathscr{N}}{0}$ & $\hat{\sigma}$ & 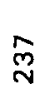 & 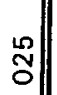 \\
\hline & 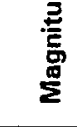 & & $\begin{array}{l}\sum_{0}^{0} \\
\dot{+} \\
\dot{d}\end{array}$ & & & $\begin{array}{l}\sum_{+}^{\infty} \\
+ \\
+\end{array}$ & & & $\begin{array}{l}\sum_{+}^{\infty} \\
\dot{+}\end{array}$ & & $\begin{array}{l}\sum^{0} \\
\dot{\sigma} \\
\dot{\sigma}\end{array}$ & $\begin{array}{l}\sum_{j}^{0} \\
\dot{+} \\
\dot{+}\end{array}$ & $\begin{array}{l}\vec{\Sigma} \\
\dot{J} \\
\dot{\sigma}\end{array}$ & & & $\begin{array}{l}\sum^{-} \\
\sigma \\
\dot{\omega}\end{array}$ & $\stackrel{\sum_{m}^{\infty}}{\stackrel{m}{r}}$ & & & 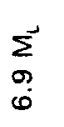 & & & & \\
\hline & 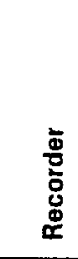 & & 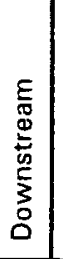 & 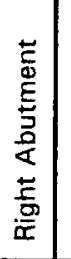 & $\begin{array}{l}\text { 苟 } \\
\stackrel{\Xi}{0}\end{array}$ & $\begin{array}{l}\tilde{g} \\
\stackrel{0}{0} \\
\stackrel{0}{0}\end{array}$ & 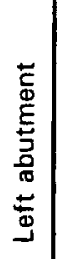 & 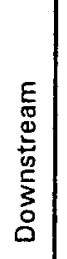 & $\begin{array}{l}\overrightarrow{\mathrm{E}} \\
\stackrel{\mathrm{d}}{\mathrm{E}} \\
\overrightarrow{\mathrm{J}} \\
\mathrm{Q}\end{array}$ & 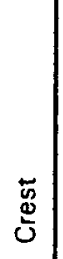 & $\begin{array}{l}\text { 总 } \\
\text { 岕 }\end{array}$ & $\begin{array}{l}\bar{\Phi} \\
\stackrel{d}{\dot{d}}\end{array}$ & 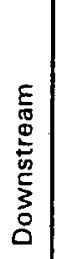 & $\begin{array}{l}\bar{\Phi} \\
\stackrel{0}{0}\end{array}$ & $\begin{array}{l}\frac{\pi}{3} \\
\frac{3}{\bar{n}} \\
\frac{\bar{n}}{n}\end{array}$ & 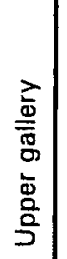 & 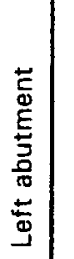 & 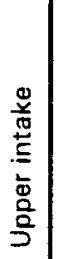 & 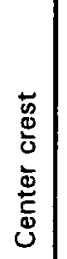 & 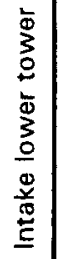 & 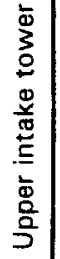 & 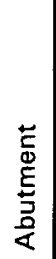 & 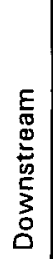 & 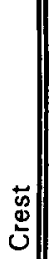 \\
\hline$\stackrel{\underline{\Xi}}{\Xi}$ & 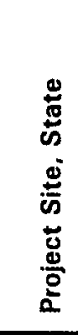 & & 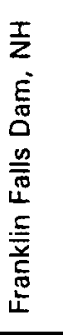 & & & 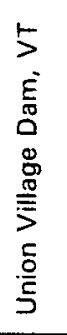 & & & 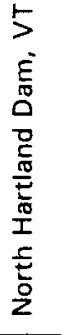 & & 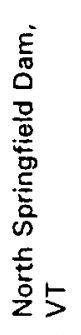 & 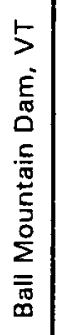 & 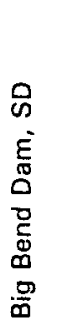 & & & 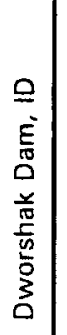 & 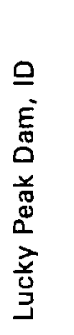 & & & 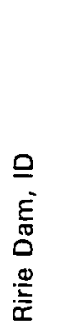 & & & & \\
\hline $\begin{array}{l}0 \\
N \\
\frac{0}{0} \\
\frac{0}{0} \\
上\end{array}$ & 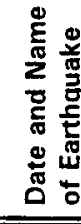 & & 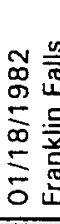 & تِّ & & & & & & & & & 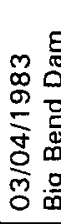 & & & 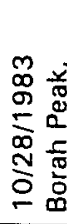 & 总 & & & & & & & \\
\hline
\end{tabular}




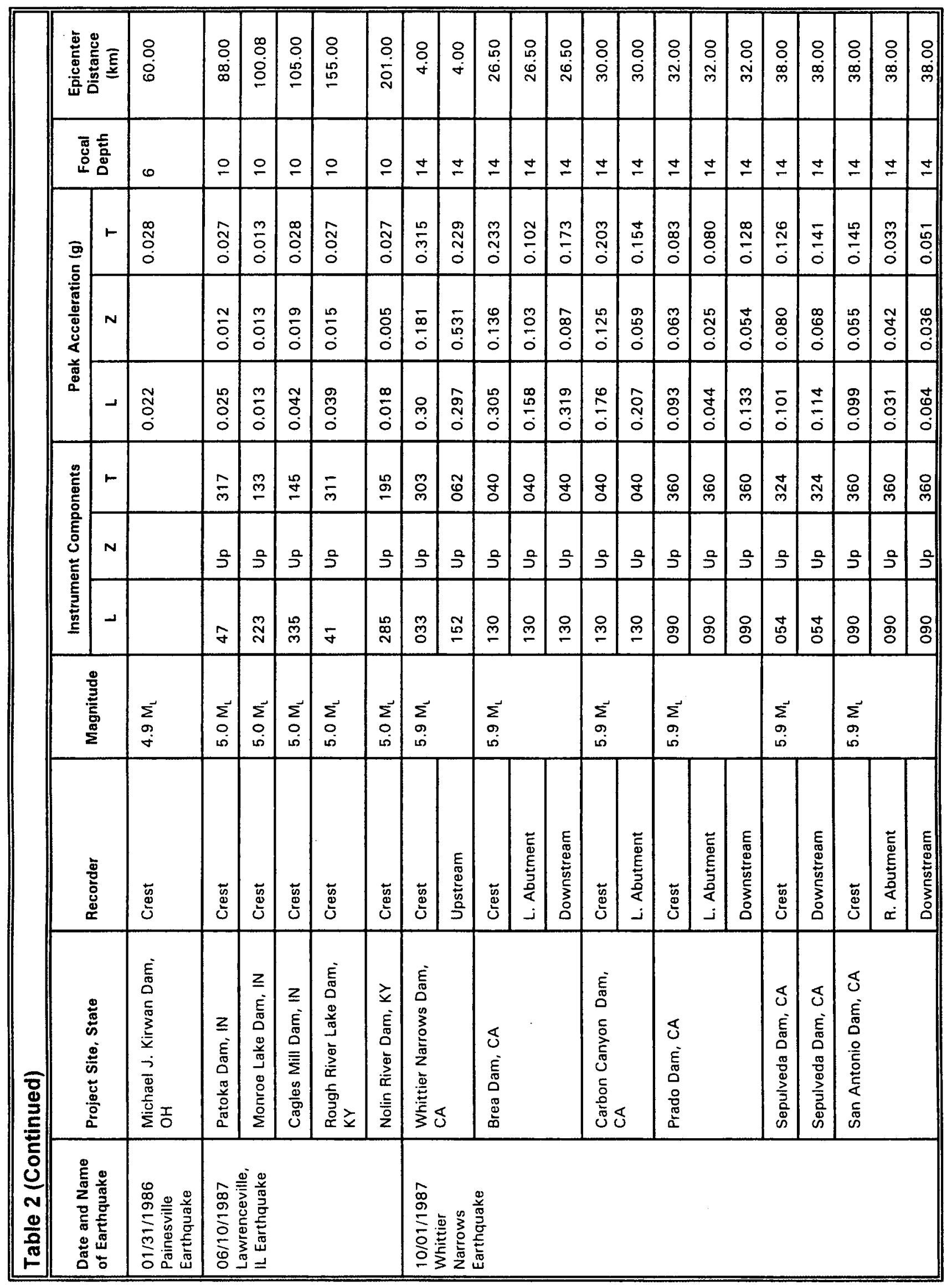




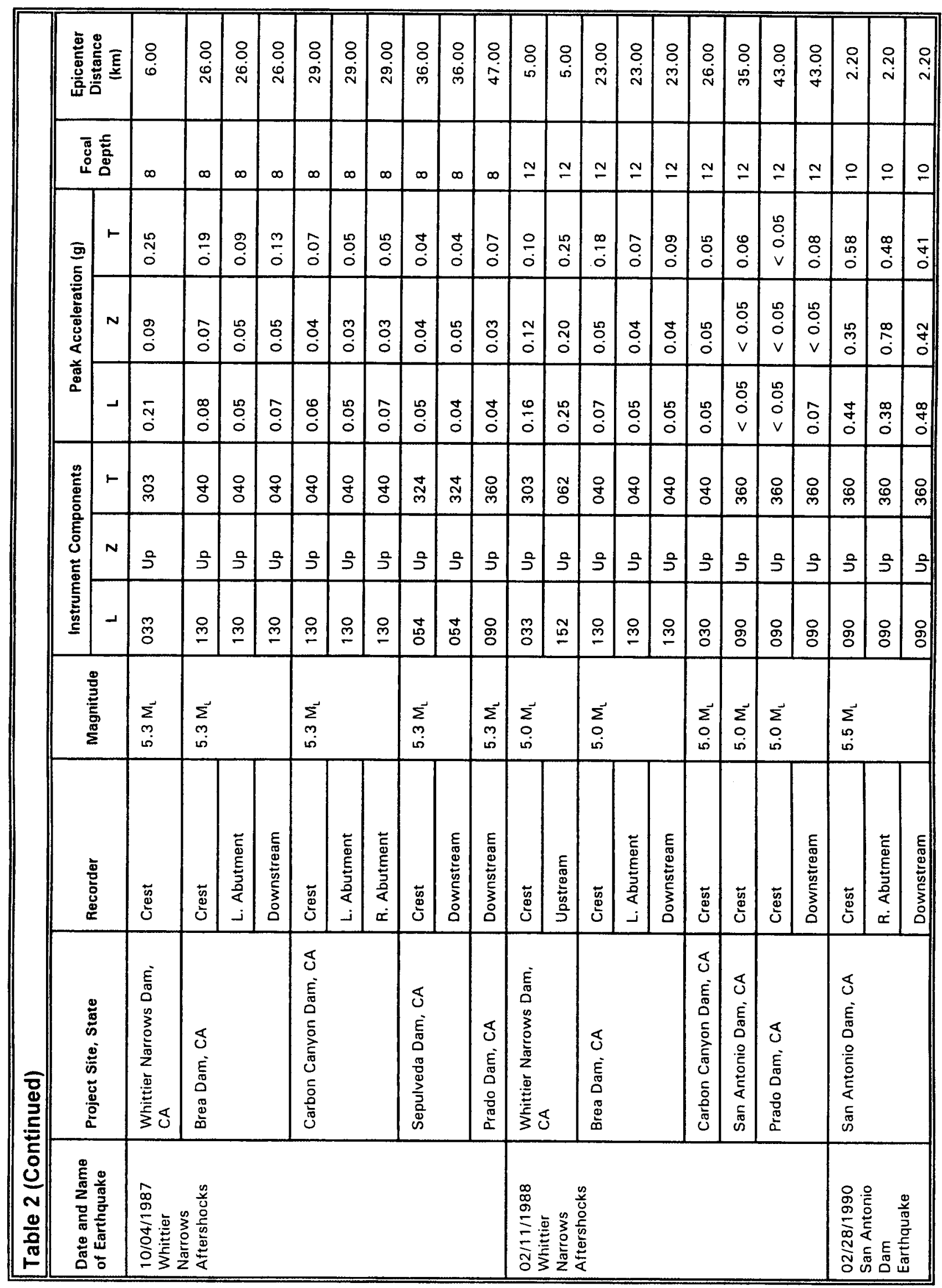




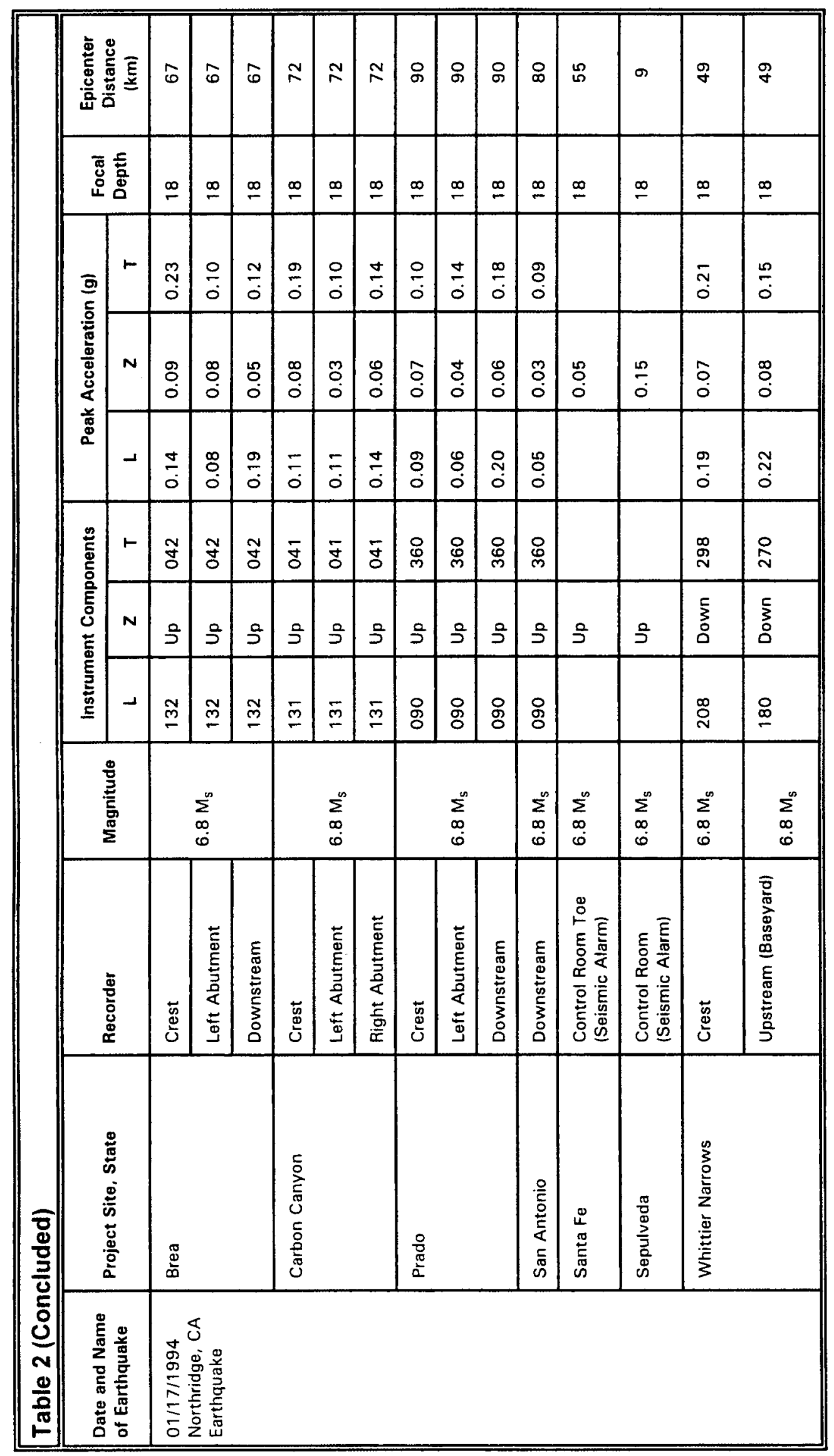


Public reporting burden for this collection of information is estimated to average 1 hour per response, including the time for reviewing instructions, searching existing data sources, gathering and maintaining the data needed, and completing and reviewing the collection of information. Send comments regarding this burden estimate or any other aspect of this collection of information, including suggestions for reducing this burden, to Washington Headquarters Services, Directorate for Information Operations and Reports, 1215 Jefferson Davis Highway, Suite 1204. Arlington, VA 22202-4302, and to the Office of Management and Budget, Paperwork Reduction Project 107040188), Washington, DC 20503.

\begin{tabular}{|l|l|l|}
\hline 1. AGENCY USE ONLY (Leave blank) & $\begin{array}{l}\text { 2. REPORT DATE } \\
\text { September } 1998\end{array}$ & $\begin{array}{l}\text { 3. REPORT TYPE AND DATES COVERED } \\
\text { Final report }\end{array}$ \\
\hline
\end{tabular}

\begin{tabular}{|l|l|l|}
\hline 4. TITLE AND SUBTITLE & 5. FUNDING NUMBERS
\end{tabular}

U.S. Army Corps of Engineers Seismic Strong-Motion Instrumentation Program 6. AUTHOR(S)

Robert F. Ballard, Jr., Tina H. Grau

7. PERFORMING ORGANIZATION NAME(S) AND ADDRESS(ES)

8. PERFORMING ORGANIZATION REPORT NUMBER

U.S. Army Engineer Waterways Experiment Station 3909 Halls Ferry Road Technical Report GL-98-25

Vicksburg, MS 39180-6199

9. SPONSORING/MONITORING AGENCY NAMEIS) AND ADDRESS(ES)

10. SPONSORING/MONITOAING AGENCY REPORT NUMBER

U.S. Army Corps of Engineers

Washington, DC 20314-1000

\section{SUPPLEMENTARY NOTES}

Available from National Technical Information Service, 5285 Port Royal Road, Springfield, VA 22161.

12a. DISTRIBUTION/AVAILABILITY STATEMENT

12b. DISTRIBUTION COOE

Approved for public release; distribution is unlimited.

13. ABSTRACT (Maximum 200 words)

This report is an expanded, updated version of a paper presented and published in the proceedings of the 1993 National Earthquake Conference held May 3-5, 1993 in Memphis, TN. The U.S. Army Corps of Engineers (USACE) currently operates a seismic Strong-Motion Instrumentation Program (SMIP) throughout the United States to provide a measure of project performance, provide insight into the safety of USACE projects, and establish a database for earthquake research. Strong-motion instruments used for SMIP consist of digital and analog accelerographs, peak acceleration recorders, and seismic alarm devices. These instruments have been placed at earth, rock, earth and rock, arch, and gravity dams owned and operated by the USACE. At present, 123 projects located in 32 states and Puerto Rico are monitored with more than 500 strong-motion instruments. The USACE network is second in size to that operated by the California Division of Mines and Geology.

The purpose of this report is to present various aspects of the USACE SMIP including criteria for design of installations, recording equipment, operation, maintenance, performance to date, upgrades, future goals, and the importance of interagency cooperation. Particular attention is focused on economics and advantages associated with ultimate conversion to remotely accessed digital instrumentation.

14. SUBJECT TERMS

Accelerograph, Dam safety, Earthquake instrumentation, Earthquake measurement and analysis, Earthquake research, Seismic safety criteria

\begin{tabular}{|l|l|}
\hline 17. SECURITY CLASSIFICATION & $\begin{array}{l}\text { 18. SECURITY CLASSIFICATION } \\
\text { OF REPORT } \\
\text { OF THIS PAGE } \\
\text { UNCLASSIFIED }\end{array}$ \\
UNCLASSIFIED
\end{tabular}

NSN 7540-01-280-5500

U

19. SECURITY CLASSIFICATION
OF ABSTRACT
UNCLASSIFIED

115

16. PRICE CODE 
Destroy this report when no longer needed. Do not return it to the originator. 